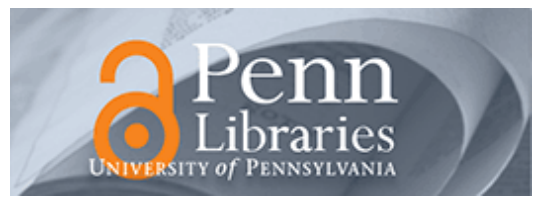

University of Pennsylvania ScholarlyCommons

\title{
Pharmaceutical Strategy and the Evolving Role of Merger and Acquisition
}

Lawton R. Burns

University of Pennsylvania

Sean Nicholson

Cornell University

Joanna P. Wolkowski

Boston Consulting Group

Follow this and additional works at: https://repository.upenn.edu/hcmg_papers

Part of the Health and Medical Administration Commons, Pharmacoeconomics and Pharmaceutical Economics Commons, and the Pharmacy Administration, Policy and Regulation Commons

\section{Recommended Citation (OVERRIDE)}

Burns, L.R., Nicholson, S., \& Wolkowski, J.P. (2012). Pharmaceutical Strategy and the Evolving Role of Merger and Acquisition. In Burns, L.R. (Ed.), The Business of Healthcare Innovation, 2nd Edition (pp. 116-193). New York: Cambridge University Press.

This paper is posted at ScholarlyCommons. https://repository.upenn.edu/hcmg_papers/2

For more information, please contact repository@pobox.upenn.edu. 


\title{
Pharmaceutical Strategy and the Evolving Role of Merger and Acquisition
}

\author{
Abstract \\ It is not the strongest of the species that survives, nor the most intelligent that survives. It is the one that \\ is the most adaptable to change. \\ Introduction \\ The sections in this chapter deal with a common set of topics: horizontal consolidation, merger and \\ acquisition (M\&A), advantages of size, economies of scale and scope, diversification, and industry \\ concentration. These topics all interrelate around the fundamental issue in industrial organization: how \\ best to organize firms and markets in order to achieve optimal economic performance? \\ Consolidation has been rampant in most sectors of the healthcare industry since the 1980 s and 1990s. \\ Indeed, the industry was the second most active in terms of M\&A activity (behind finance) between 2008 \\ and 2009. In the pharmaceutical sector, the prior decades had been a time of growth and consolidation, \\ as companies leveraged both size and scale in bringing drugs to market. The current landscape, however, \\ is one of new challenges requiring new approaches to their solution. Companies are faced with internal \\ pressures of declining pipeline productivity and compressed timelines, external pressures of patent expiry \\ and pricing, and the uncertain implications of healthcare reform. Accompanying this evolution of \\ challenges has been an evolution in the strategic approaches taken by pharmaceutical companies to best \\ position themselves for success in the upcoming years. \\ Disciplines \\ Health and Medical Administration | Pharmacoeconomics and Pharmaceutical Economics | Pharmacy \\ Administration, Policy and Regulation
}




\section{Pharmaceutical strategy and the evolving role of merger and acquisition}

Lawton Robert Burns*, Sean Nicholson, and Joanna P. Wolkowski

Introduction

Drivers of pharmaceutical strategy (including M\&A)

M\&A trends among pharmaceutical and biotechnology firms

M\&A rationales in industrial organization theory and research

M\&A rationales among pharmaceutical firms

The impact of M\&A on the performance of pharmaceutical firms

It is not the strongest of the species that survives, nor the most intelligent that survives. It is the one that is the most adaptable to change.

\section{Introduction}

The sections in this chapter deal with a common set of topics: horizontal consolidation, merger and acquisition (M\&A), advantages of size, economies of scale and scope, diversification, and industry concentration. These topics all interrelate around the fundamental issue in industrial organization: how best to organize firms and markets in order to achieve optimal economic performance?

Consolidation has been rampant in most sectors of the healthcare industry since the 1980s and 1990s. Indeed, the industry was the second most

\footnotetext{
* The authors wish to thank David Cassak, Deanna Kamienski, and Amanda Micklus from Windhover Publications for making available the data presented in Figure 3.2, Figure 3.3, and Figure 3.5. We thank Martin Reeves from the Boston Consulting Group for permission to use Figure 3.1 and Figure 3.4. We also thank Brian McVeigh from GlaxoSmithKline for Figure 3.7 and Figure 3.8.
}

active in te In the phar and consol drugs to $\mathrm{m}$ : requiring $\mathrm{r}$ internal pre lines, exter implication: lenges has b ceutical con years.

A critical " approaches : as long-term operational positioning $\mathrm{v}$ are choosing taking differs monly focus approaches $h$ in diversifico research and ceutical M\&t current indus from being a realizing strat

In the first ] pharmaceutica challenges faci term solution turning to $M \&$ rather a tool fo and specific dir well as the res! opportunities $n$ The chapter 1 in establishing taken in an eff, greater firm size 


\section{$d \mathbf{t}$}

d Joanna P. Wolkowski

$\begin{array}{ll} & 116 \\ & 119 \\ \text { s } & 124 \\ \text { sh } & 130 \\ & 132 \\ \text { Grms } & 147 \\ & 156 \\ \text { egration } & 157 \\ \text { ture performance } & 159 \\ \text { pective on innovation } & 166\end{array}$

nor the most intelligent that nge.

in set of topics: horizontal vantages of size, economies wentration. These topics all dustrial organization: how achieve optimal economic

irs of the healthcare indussitry was the second most

d Amanda Micklus from Windhover Figure 3.3, and Figure 3.5. We thank to use Figure 3.1 and Figure 3.4. We ad Figure 3.8. active in terms of M\&A activity (behind finance) between 2008 and 2009. ${ }^{1}$ In the pharmaceutical sector, the prior decades had been a time of growth and consolidation, as companies leveraged both size and scale in bringing drugs to market. The current landscape, however, is one of new challenges requiring new approaches to their solution. Companies are faced with internal pressures of declining pipeline productivity and compressed timelines, external pressures of patent expiry and pricing, and the uncertain implications of healthcare reform. Accompanying this evolution of challenges has been an evolution in the strategic approaches taken by pharmaceutical companies to best position themselves for success in the upcoming
years.

A critical question confronting the pharmaceutical sector is whether these approaches are meant as short-term fixes to the current challenges or serve as long-term solutions that will challenge the productivity frontier. Whereas operational effectiveness may be improving, it is unclear what strategic positioning will come as a result of the directions pharmaceutical companies are choosing. The sector is currently at an exciting point, as companies are taking different strategic bets on the future. Whereas past strategies commonly focused on increasing scale and scope through M\&A, recent approaches have revealed more nuanced and differentiated strategies rooted in diversification, entry into developing markets, or strengthening of research and development (R\&D). It is important to understand pharmaceutical M\&A from a historical perspective not only to appreciate the current industry landscape, but also to recognize that M\&A has shifted from being a goal in itself to being a tool in creating opportunities for realizing strategic bets.

In the first part of this chapter, we examine some of the current drivers of pharmaceutical strategy (including M\&A). ${ }^{2}$ This section outlines the major challenges facing the sector and suggests how M\&A provides one shortterm solution to address them. Given the distinct ways companies are now turning to M\&A, it no longer can be itself considered a strategy for success, rather a tool for achieving it. We then highlight some of the strategic choices and specific directions companies have taken to address these challenges, as well as the resulting market positions that firms have established to create opportunities moving forward.

The chapter then turns to examine the historical role that M\&A has played in establishing the current industry landscape. M\&A has often been undertaken in an effort to achieve scale and scope economies, while leading to greater firm size and industry concentration. The chronicle of pharmaceutical 
M\&A involves horizontal integration of similar firms (1980s-2000s), vertical integration of firms into adjacent stages in the value chain such as pharmacy benefit management (1990s) and biotechnology (1990s-2000s), and/or diversification into related industries (2000s). All three types of integration can be considered M\&A, but with very different partners (other large pharmaceutical firms, pharmacy benefit managers, biotechnology firms, manufacturers of generic drugs and vaccines).

The remainder of the chapter examines the theory behind pharmaceutical $M \& A$ and the empirical reality. We first review the rationales for M\&A, and attempt to disentangle some of the different effects of scale (firm scale, project scale, critical mass). We next review the evidence on the performance effects of M\&A on R\&D intensity, $R \& D$ productivity, and firm economic performance, as well as the broader research evidence from the field of industrial organization on the value of size, concentration, and integration. The following section discusses other sources of value creation beyond the scale and structures created through M\&A, such as the processes of knowledge sharing and coordination, which serve as sources of potential advantage by means of building capabilities that can enhance future performance. The chapter concludes with a discussion of both the future of M\&A in the pharmaceutical sector and the relevance of a value chain perspective for innovation in the pharmaceutical sector. ${ }^{3}$

Our analysis addresses several related questions. What is the value of size, scale, and M\&A for pharmaceutical firms? Do such strategies help firms to develop new products? What are the challenges and opportunities created by M\&A? Next, does the lens of industrial organization and its focus on the boundaries of the firm and its structural configuration provide the best perspective for understanding innovation in these firms? A different, but parallel, perspective suggests that firm processes within these larger, merged structures are more important than their structures for fostering increased innovation and productivity. Such processes include: generation and sharing of knowledge, coordination of diverse specialists, integration of different partners (e.g., payers), and balancing of different strategies within the same firm. Can the merged firm leverage or exploit its increased size to improve these processes, or is the merger transaction and accompanying larger size a distraction from the important process work of the firm? Finally, how is the innovative activity of pharmaceutical firms tied to the larger value chain in the healthcare industry, and does a value chain view highlight important problems that pharmaceutical firms must address in their quest to improve the productivity of their R\&D arms? 
ms (1980s-2000s), vertical de chain such as pharmacy 990s-2000s), and/or divertypes of integration can be other large pharmaceutical $y$ firms, manufacturers of

ry behind pharmaceutical e rationales for $M \& A$, and fects of scale (firm scale, e evidence on the perforD productivity, and firm zsearch evidence from the E size, concentration, and $r$ sources of value creation $1 \& \mathrm{~A}$, such as the processes rrve as sources of potential zan enhance future perforof both the future of M\&A $f$ a value chain perspective

s. What is the value of size, ıch strategies help firms to and opportunities created zation and its focus on the guration provide the best ise firms? A different, but within these larger, merged ures for fostering increased lude: generation and sharists, integration of different strategies within the same ; increased size to improve accompanying larger size a he firm? Finally, how is the to the larger value chain in เ view highlight important is in their quest to improve

\section{Drivers of pharmaceutical strategy (including M\&A) ${ }^{4}$}

While pharmaceutical companies have their own specific approaches and rationales for undertaking $M \& A$, there are six main drivers of pharmaceutical strategy: decrease in $\mathrm{R} \& \mathrm{D}$ productivity, deconstruction of the pharmaceutical industry, diversification in business approach, diversification in capabilities, capture of synergies, and expansion within developing markets. These drivers underlie and motivate most of the strategic bets now being placed.

\section{Decrease in R\&D productivity}

There are various metrics of $R \& D$, each pegged to a different phase in the project lifecycle: new molecular entities (NMEs); investigational new drug (IND) applications; first-in-human (FIH) starts; proof-of-concept (PoC) declarations; phase III starts; and new drug applications (NDAs). ${ }^{5}$ There are also various metrics one can use to evaluate R\&D productivity - for example, absolute or relative number of NMEs approved, cost per NME approval, or total sector R\&D spend. Regardless of the calculation used, the analysis yields the same conclusion that productivity of the pharmaceutical industry has been decreasing, as is the case in other healthcare sectors. ${ }^{6}$ Over the past two decades, the number of NMEs approved peaked at fifty-five in 1997 and then fell to sixteen approvals in $2008 .^{7}$ At the same time that new drug approvals have fallen, the average value of the drugs introduced in the last six years dropped 35 percent below prior years. ${ }^{8}$ During this same time period, industry R\&D spending grew from less than $\$ 10$ billion to more than $\$ 60$ billion (see Figure 3.1). ${ }^{9}$ The cost of developing a single drug has escalated in the past decade alone from $\$ 100$ million to over $\$ 1$ billion. $^{10}$ An even longer-term analysis suggests that the rate of NME approval has been basically flat during most of the period from 1950 to 2008 (with a slight upward trend between 1980 and 1996), while NME cost has grown exponentially since the 1950s at an annual rate of 13.4 percent. ${ }^{11}$ Confronted by rising costs and falling approvals, the pharmaceutical sector now faces the "productivity cliff."

One explanation for declining $R \& D$ productivity is companies having concurrently prosecuted similar blockbuster ( $\$ 1+$ billion in revenue) drug targets with decreasing returns on that investment. Firms pursued blockbusters based on the belief that blockbuster revenues were necessary to cover the escalating costs of overall drug development, as well as to increase 


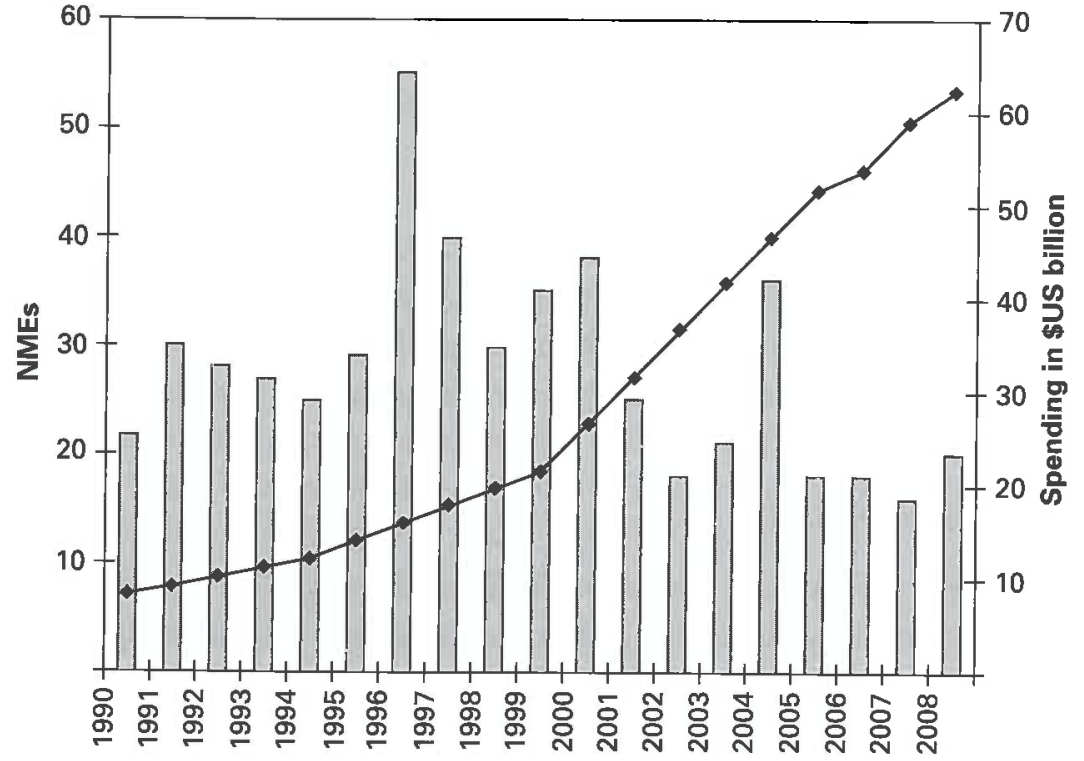

$\square$ Number of NMEs approved $\multimap$ $\longleftarrow$ R\& spending

Figure 3.1 Research and development (R\&D) spend and new molecular entity (NME) approvals (1990-2008)

earnings-per-share at companies with already large revenue bases. However, the pursuit of blockbusters (typically chronic-use medications for common conditions, such as hypercholesterolemia) was a generic strategy pursued by many new entrants in search of these lucrative market opportunities. ${ }^{12}$

In addition, the science underlying the development of new products to address the diseases associated with chronic illness and elderly patients became much more complex. As a result, clinical protocols became more complex, and clinical trials grew larger, more numerous, and longer in duration. In the face of continuing pipeline problems, pharmaceutical firms may have rushed compounds through development that were poorly optimized, leading to unexpected side effects and high failure rates in clinical testing. Narrowly defined PoC programs also failed to address important scientific questions. ${ }^{13}$ Coupled with these clinical issues, the FDA developed greater risk-aversion due to high-profile recall cases, such as Merck's Vioxx, and erected higher safety hurdles for new products, with more restricted launches and more approvable reviews.

Another related explanation is that many companies made strategic investments based on the decoding of the human genome and the proposed number of targets that discovery would unlock. The combination of several companies placing
tunities
microb
were po
were no
Finall
primary
benefits
evaluatic
greater $p$
divide bc
The c
describec
to the pr
more "bir
cnow for
ind purst
ipelines
ver, tack
equired $t$
ke place,
lodel will

\section{Deconstruction of the}

The decon has steadily handled in research or contract $\mathrm{m}$ generating formulation more archaj effectiveness make-versus whose funct are coordina cally turn to resources. 
Diversification in business approach for the pharmaceutical sector concedes that small molecules are not the future. Many companies are turning to biologics as a complementary set of products for both scientific and financial reasons. Large molecules often target different receptors or disease states, as well as command a premium price over small molecules. They are also more difficult to replicate and offer an opportunity to diversify the risks associated with drug discovery. In addition to biologics, companies are looking to areas such as vaccines, generics, diagnostics/devices, previously untreated diseases, nutrition, or consumer health potentially to provide a more consistent stream of revenues. Some of the new drugs approved by the FDA in 2011 tackle conditions lacking good treatments (e.g., lupus, hepatitis $\mathrm{C}$, metastatic melanoma), with the potential for annual sales of $\$ 1$ billion or more. ${ }^{15}$ While these investments may not offer the high returns of pharmaceuticals, they may be a more certain return to balance potential downturns. If nothing else, portfolio diversification offers a mechanism of spreading out a company's bets on the future.

At the same time, some large, diversified pharmaceutical firms (e.g., Pfizer) are considering the opposite strategy of de-diversification (unbundling): shedding business units no longer viewed as core to the firm. The rationale here is to focus on the core business of developing and marketing pharmaceutical drugs and vaccines, and to exit businesses in which the firm is not expert. ${ }^{16}$ Following its announcement that it would consider such divestitures, Pfizer's share price rose 18 percent. Coupled with the above argument for diversification, this suggests there may be a moderate range of diversification that is desirable - a suggestion supported by some empirical research (see below).

\section{Diversification in capabilities}

As companies take different strategic approaches to position themselves for the future, the industry will have to develop distinct sets of specific capabilities to maximize each opportunity. Given the different capabilities required by the different approaches, the industry will witness a diversification in tangible and intangible assets, strategies, and capabilities that tie them all together in (hopefully) productive ways. Although industry consolidation has accelerated in the past decade, this acceleration does have limits. In an attempt to rebalance, the current levels of M\&A will probably decelerate (in either deal size or volume) and refocus as each company takes a unique tactic based on its internal capabilities and external opportunities.
Am pipelir to sup! sector? nology appear: start-uj larger 1 distribu biotech. now set smaller New capabili abilities incentiv cracy, a summar

\section{Capture of synergie:}

Synergist M\&A. FC gests exer offset) th typically firms, and average cc tion), effor term cost back-offict reducing $\mathrm{b}$ rooted in $\mathrm{t}$ or leverage

\section{Expansion within devt}

Pharmacev generate $\mathrm{r} \epsilon$ 
maceutical sector concedes companies are turning to both scientific and financial stors or disease states, as well They are also more difficult 1e risks associated with drug re looking to areas such as intreated diseases, nutrition, onsistent stream of revenues. 11 tackle conditions lacking melanoma), with the poten2 these investments may not y be a more certain return to tfolio diversification offers a the future.

aaceutical firms (e.g., Pfizer) fication (unbundling): shedte firm. The rationale here is 1 marketing pharmaceutical ich the firm is not expert. ${ }^{16}$ ler such divestitures, Pfizer's sve argument for diversificaIge of diversification that is irical research (see below).

s to position themselves for ıct sets of specific capabilities it capabilities required by the iversification in tangible and at tie them all together in :onsolidation has accelerated re limits. In an attempt to bly decelerate (in either deal is a unique tactic based on its
Among the pharmaceutical sector's historical core strengths have been pipeline management, sales and marketing, and possessing the financial reserves to support development and commercialization. By contrast, the biotechnology sector's core capabilities appear to be rooted in discovery (encompassing technology, expertise, and culture). This portion of the life sciences industry thus appears to mirror the medical device portion where smaller, entrepreneurial start-up firms specialize in new and earlier phases of R\&D, while established, larger medical device firms specialize in later-stage $\mathrm{R} \& \mathrm{D}$ and control the key distribution channels (see Chapter 6). A similar division of labor exists in biotechnology between the smaller and larger firms. ${ }^{17}$ Pharmaceutical firms are now seeking to emulate the capabilities of biotechnology firms by developing smaller research units and better integrating their scientists (see end of chapter).

New capabilities are called for, according to recent industry reports capabilities more often found in smaller biotechnology firms. ${ }^{18}$ These capabilities include: managerial autonomy, research goals that are aligned with incentives, attraction and retention of creative talent, minimization of bureaucracy, and flexible organization. This constellation of capabilities can be summarized as an "innovation culture."

\section{Capture of synergies}

Synergistic combinations of businesses have often been mentioned as a driver of M\&A. For example, a recent analysis of Sanofi's acquisition of Genzyme suggests executives are looking for $\$ 600+$ million in synergies to help justify (and offset) the estimated 35 percent premium paid in the deal. ${ }^{19}$ Synergies are typically based on the complementarity of resources between the merging firms, and can be pursued in a number of ways, including: efforts to reduce the average costs of the two firms (e.g., economies of scale from pipeline consolidation), efforts to increase the revenues of the two firms, and efforts to reduce shortterm costs in the merged firm's combined operations (e.g., consolidating back-office and support functions). This cost-cutting can take the form of reducing headcount or real estate footprint. Less frequently, the synergies are rooted in the complementary capabilities of the merging firms that can be shared or leveraged.

\section{Expansion within developing markets}

Pharmaceutical firms have recently targeted developing countries both to generate revenues (e.g., increase penetration in the local markets) and to 
reduce costs (e.g., lower-cost manufacturing). While firms have invested based on the perceived opportunity in both areas, there is some question whether barriers to entry (e.g., the population's financial access to branded medicines, questionable protection of IP) are stronger than they initially appeared. There is also the question of what is the best approach to enter an emerging market given the divergent models followed across the industry.

What is clear is that sales growth in emerging markets far outweighs sales growth in core markets. Pharmaceutical firms have experienced double-digit sales growth in Latin America, Asia, Africa, and Australia as the first decade of the new millennium ended, compared to single-digit growth in the US, European Union (EU), and Japan. ${ }^{20}$ Pharmaceutical firms are not abandoning the latter markets, however, since some (e.g., Japan) are poised for growth and may be targeted as part of the firms' core strategy. ${ }^{21}$

\section{Summary}

Each of these strategic drivers in the pharmaceutical sector can point to $\mathrm{M} \& \mathrm{~A}$ as a possible solution. Yet the M\&A solution can be short-sighted as companies overly rely on deals rather than strategy to determine their direction and develop their capabilities. In the following sections, we examine the evolution of $M \& A$ within the pharmaceutical sector, the rationales for its pursuit, and the impact of M\&A on the performance of pharmaceutical firms.

\section{M\&A trends among pharmaceutical and biotechnology firms}

The history of M\&A in the pharmaceutical sector bears only slight resemblance to the historical waves of M\&A activity observed in the wider market (described below). First, pharmaceutical M\&A is only a recent activity, which did not occur in bull markets prior to the 1990s. The pharmaceutical sector had survived for nearly a century as a fragmented (unconcentrated) industry i.e., lots of firms each having a small share of the market. Second, there was indeed a lull in pharmaceutical M\&A activity during 1991-1993 that roughly corresponds to the recession in the economy that began in 1991. This period was also marked by uncertainty surrounding healthcare reform and possible price regulation inherent in President Clinton's healthcare reform (Health Security Act) and the consequent cost-cutting efforts by pharmaceutical firms. Third, there were additional waves of consolidation in the latter part of the 
e firms have invested based : is some question whether cess to branded medicines, ey initially appeared. There , enter an emerging market dustry.

markets far outweighs sales re experienced double-digit astralia as the first decade of e-digit growth in the US, al firms are not abandoning 1) are poised for growth and 21

eutical sector can point to ion can be short-sighted as trategy to determine their llowing sections, we examutical sector, the rationales serformance of pharmaceu-

\section{logy firms}

tor bears only slight resembserved in the wider market only a recent activity, which 3. The pharmaceutical sector (unconcentrated) industry ie market. Second, there was ring 1991-1993 that roughly tt began in 1991. This period althcare reform and possible 's healthcare reform (Health orts by pharmaceutical firms. ation in the latter part of the 1990s that correspond with the bull market, but these deals were also driven by pipeline problems.

The decades of the 1980s and 1990s marked the end of the "golden days" of the pharmaceutical sector. ${ }^{22}$ The industry had enjoyed steady price increases in a cost-neutral environment, few competitive worries from generic competition, relatively unrestricted access to physicians by pharmaceutical sales representatives, and, thus, a steady growth in earnings. However, more-hostile environmental conditions began to emerge in the 1980s and early 1990s that challenged this growth and earnings model. The Hatch-Waxman Act (1984) lowered the barriers for generic entry into the market (after patent expiration for the branded drug), but also extended patent terms for many approved drugs. Managed care and cost containment in the private sector became more prominent threats during the 1990s, as employers strove to contain their employee healthcare expenses. The recession, falling stock prices, and threats of healthcare reform scared away investors, and pharmaceutical firms made spending cuts in their R\&D, sales force, and marketing budgets. ${ }^{23}$ Finally, for a host of reasons not fully understood (addressed below), R\&D productivity began to fall by 50 percent over the decade of the $1990 \mathrm{~s}^{24}$

As an adaptive response to these new pressures, pharmaceutical firms turned to strategies of horizontal and vertical integration in the late $1980 \mathrm{~s}$ and early 1990s. The consolidation of the modern pharmaceutical sector began in 1987 with Roche's failed hostile takeover attempt of Sterling Drug. The first wave of M\&A - including American Home Products (AHP) and A. H. Robins (1987), Bristol-Myers and Squibb (1989), and SmithKline Beckman and Beecham (1989) - were largely designed rapidly to cut infrastructure costs. ${ }^{25}$ Such mergers created industry leaders with 3 percent to 4 percent global market share (measured as a percentage of worldwide sales).

Following a quiet period between 1990 and 1993, during which the initial round of consolidation was fully processed, a second wave of consolidation began. This wave was led by many of the same firms who had initiated M\&A in the first round: Roche and Syntex (1994), AHP and Cyanamid (1994), and the formation of Novartis (at the time the largest pharmaceutical company in the world) from Ciba-Geigy and Sandoz (1996). The top ten companies in 1996 had a combined global market share of 34 percent, up from 26 percent just ten years earlier. ${ }^{26}$

In 1998, a third wave of M\&A swept the industry, driven by an exacerbation of the environmental pressures mentioned earlier coupled with dry pipelines and steep, untenable growth targets. Between 1998 and 2001, pure acquisitions among leading players became more difficult across the industry due to 
the rapid rise in price-to-earnings multiples and therefore a rise in the price of acquiring a company. ${ }^{27}$ Consequently, M\&A activity moved almost entirely into the realm of "mergers of equals," as seen in the mega-mergers leading to the creation of Aventis (Hoechst and Rhône-Poulenc, 1999), AstraZeneca (Astra and Zeneca, 1999), and GlaxoSmithKline (Glaxo Wellcome and SmithKline Beecham, 2000). Acquisitions then resurfaced, pioneered by Pfizer's hostile bid for Warner-Lambert (2001) and its acquisition of Pharmacia (2002). In 2004, the top ten companies controlled nearly 50 percent of the market; for the first time, the industry leader (Pfizer) attained market share above 10 percent. These impressive figures have since receded despite the continuance of mergers, suggesting new companies (and different types of companies) are filling the gaps.

During the 2008-2009 recession, the pharmaceutical sector resumed its M\&A activity. Pfizer's announcement in January 2009 of their intention to buy Wyeth for $\$ 68$ billion was viewed as a beacon not only of a return to M\&A, but also a sign that banks were indeed willing to extend financing at a tenuous time in the credit markets. ${ }^{28}$ In March 2009, Merck followed with an announcement of its $\$ 41$ billion stock and cash bid for Schering-Plough, and Roche confirmed the trend in activity with its announcement to purchase the shares of Genentech it did not yet own for $\$ 48$ billion in cash and bonds. With worldwide M\&A in 2009 down by 28 percent to $\$ 2.1$ trillion, deals within healthcare (driven by pharmaceuticals and biotech) represented 11 percent of M\&A, putting pharmaceuticals among the top four industry sectors. ${ }^{29}$ Unlike earlier waves of M\&A, this one was unique as it occurred in an economic downturn, suggesting companies in a strong financial position were opportunistic in pursuit of deals that might add value.

Figure 3.2 shows the number of transforming M\&A deals in the biotechnology and pharmaceutical sectors between 1993 and 2010, where a transforming merger is defined as a transaction whose price exceeds $\$ 500$ million; Figure 3.3 shows the number of total M\&A deals regardless of transaction size. The mega-mergers of 2009 resulted in the top ten companies controlling 45 percent of the market, with Pfizer the industry leader at 7.6 percent market share. Despite this M\&A activity, the industry continued to exhibit low levels of concentration (see Figure 3.4).

Accompanying the M\&A trend within the pharmaceutical sector was a parallel trend toward strategic alliances (and later M\&A) between the pharmaceutical and biotechnology sectors. While small molecules had traditionally served as medicines for hundreds of years and had provided the cornerstone for the pharmaceutical sector, biologics began to play a more 
Ifore a rise in the price of y moved almost entirely mega-mergers leading to enc, 1999), AstraZeneca (Glaxo Wellcome and esurfaced, pioneered by and its acquisition of ttrolled nearly 50 percent (Pfizer) attained market Ive since receded despite ies (and different types of

utical sector resumed its 009 of their intention to 1 not only of a return to $\mathrm{g}$ to extend financing at a , Merck followed with an for Schering-Plough, and incement to purchase the 1 in cash and bonds. With $\$ 2.1$ trillion, deals within represented 11 percent of industry sectors. ${ }^{29}$ Unlike occurred in an economic al position were opportu-

[\&A deals in the biotechand 2010 , where a transrice exceeds $\$ 500$ million; ardless of transaction size. in companies controlling ader at 7.6 percent market inued to exhibit low levels

Irmaceutical sector was a M\&A) between the pharI molecules had tradition$s$ and had provided the ics began to play a more

\section{Figure 3.2}

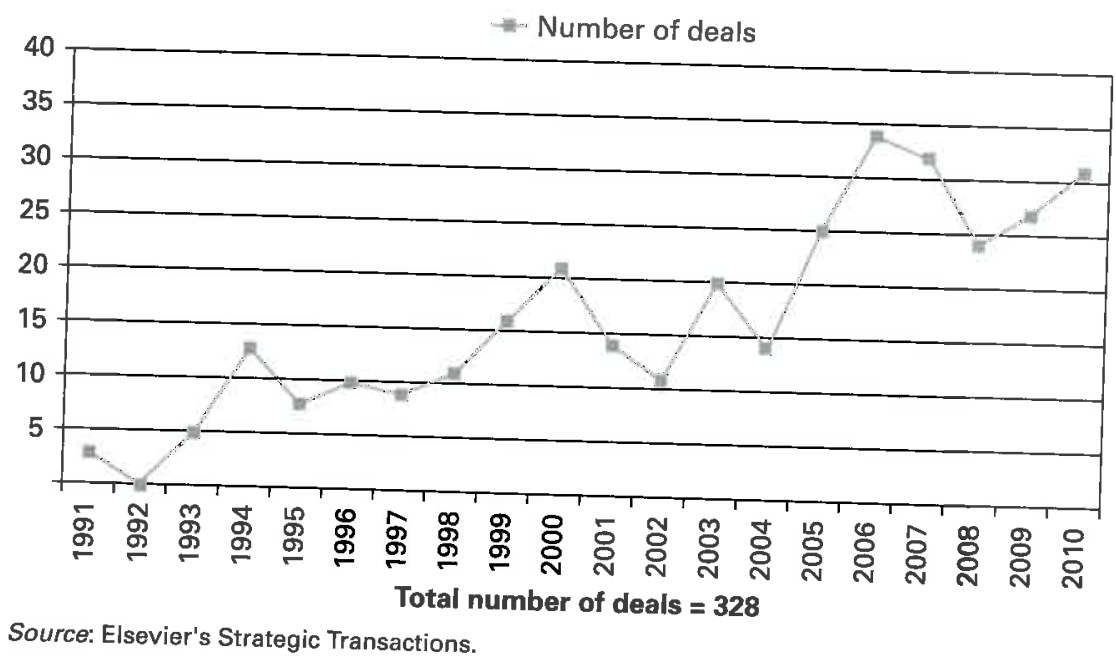

Source: Elsevier's Strategic Transactions.

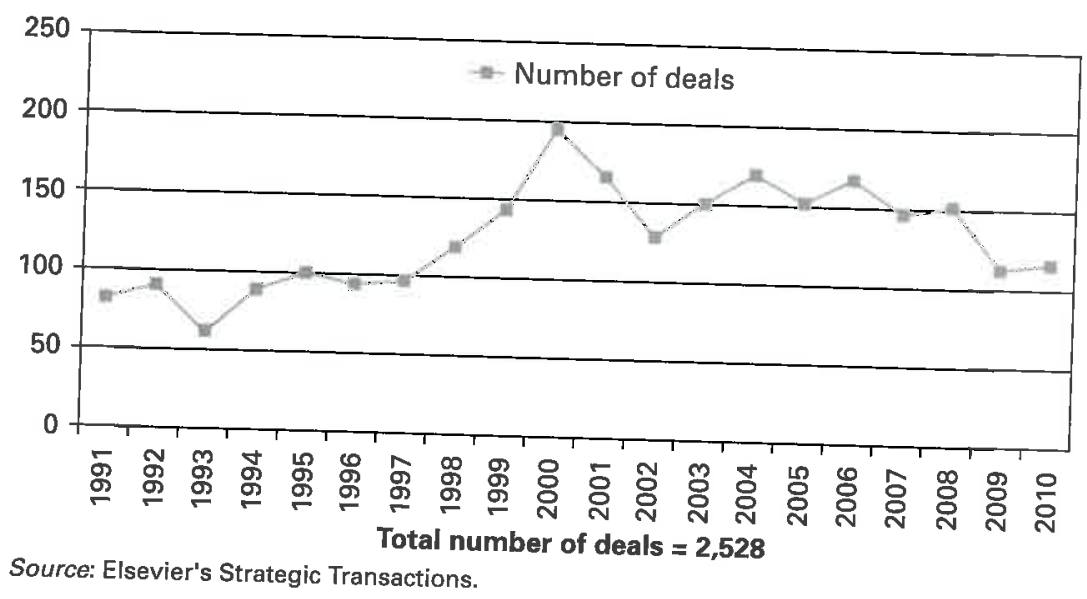

Figure 3.3 Pharma and biotech merger and acquisition (M\&A) deals (1991-2010) (deals of all sizes)

prominent role toward the end of the twentieth century with the launch of the first biotechnology drug, Humulin, in 1982. As biotechnology firms worked to establish their viability through the 1980 s, their biological approach to developing treatments remained distinct from the pharmaceutical sector's chemical approach. The commercial potential of the biotechs, however, was not lost on the pharmaceutical sector, which recognized the opportunity to partner with these new companies. 
응
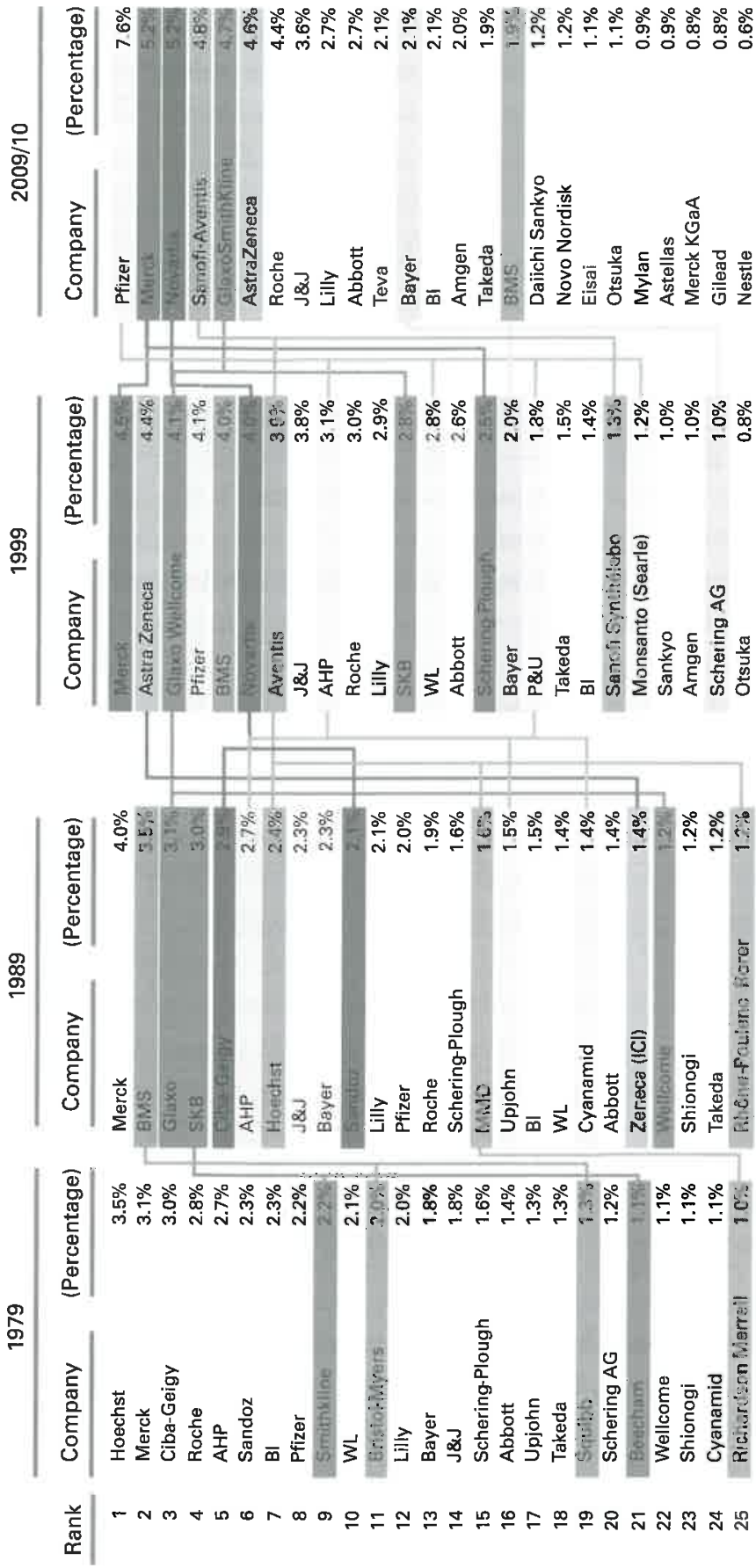

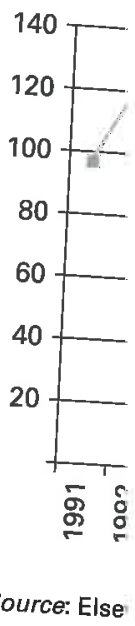

Pharma-pha

During biotechnol testing) in lines, and: along with Such allian, future $M \&$. mon until t decade. As between 20 became mo

Pharmac gics, as well more specia revenues an turned to aci history (in : product lanc typically dic biotech cultu However, th biotech and 1 been hard to 


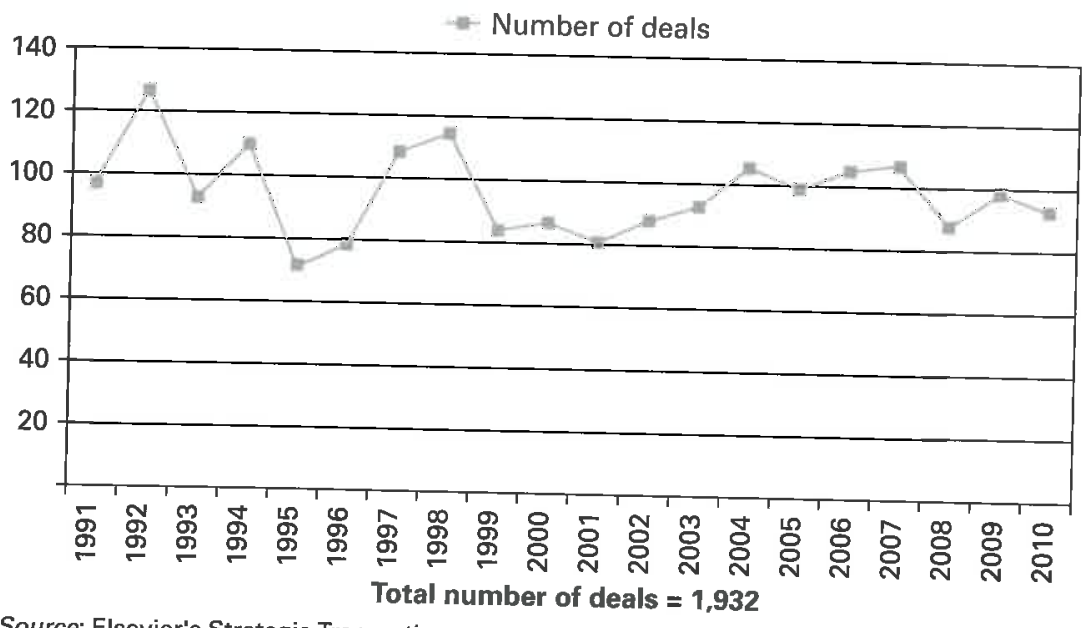

Source: Elsevier's Strategic Transactions.

Figure 3.5 Pharma-pharma strategic alliances (1991-2010)

During the 1990s, pharmaceutical firms undertook strategic alliances with biotechnology firms (e.g., in-licensing of biotech compounds in phase I, II, or III testing) in order to complement their portfolios, shore up their sagging pipelines, and source new R\&D efforts. These alliances picked up over the decade, along with alliances among the biotechnology firms themselves (see Figure 3.5). Such alliances served not only as a substitute to M\&A, but also as a forerunner to future M\&A between strategic alliance partners. ${ }^{30}$ While alliances were common until the early 2000s, M\&A became increasingly favored to close out the decade. As biotech revenues grew (11 percent compound annual growth rate between 2003 and 2007, outpacing pharma), the structure of the alliances became more innovative, with biotech companies retaining more value. ${ }^{31}$

Pharmaceutical companies also recognized this increasing value of biologics, as well as the price premiums that payers were willing to accept for these more specialized therapeutic approaches. To retain a greater percentage of revenues and to enable greater managerial control, pharmaceutical companies turned to acquisition to capture that value. Given the pharmaceutical sector's history (in small molecules) and relative unfamiliarity with the biological product landscape, strong post-merger integration strategy was critical and typically dictated the degree of success of the transaction. Retaining the biotech culture was often cited as instrumental to achieving desired outcomes. However, the appropriate balance between entrepreneurial science-driven biotech and the managerial and financial bent of its corporate parents has been hard to achieve. 
Pharmaceutical companies have attempted to achieve this balance in different ways. Initially, many companies folded the biotech acquisition into their organization. This approach, however, created many conflicts of interest. One of the reasons biotechnology firms had been successful was because of organizational freedoms (entrepreneurial culture, team environment, ownership) and financial limitations that elicited innovation and quick decision-making. These hallmarks were the opposite in many pharmaceutical companies, where organizational freedoms were limited by large size and bureaucracy, and where financial resources were abundant.

Once this mismatch in cultures was recognized, pharmaceutical companies made changes in their attempts at incorporating the biotechs into their organizations. For example, Pfizer made a significant investment in biologics through its establishment in 2007 of an independent Biotherapeutics and Bioinnovation Center (BBC) in California, in south San Francisco, a city that has become known as "The Birthplace of Biotechnology." Though the project was stalled with Pfizer's 2009 acquisition of Wyeth and that company's established biologics portfolio, it was recently revived through the establishment of a Center for Therapeutic Innovation - a more nimble and collaborative Bay Area R\&D hub near to both academic researchers and biotech companies. ${ }^{32}$

Because of the high prices, dearth of competitors, and current confusion with regard to generic competition (i.e., follow-on biologics - see Chapter 4), biologics will continue to be attractive to pharmaceutical companies as a means of long-term growth of their portfolios. In fact, the top six drugs are expected to be biotech products by 2014 , with biologics representing fifty of the top 100 drugs. ${ }^{33}$ Interestingly, five of those top six biotech products will be controlled by pharmaceutical companies. ${ }^{34}$

\section{M\&A rationales in industrial organization theory and research}

The academic field of industrial organization (IO) contains a rich literature on the rationales for M\&A, drawn both from theoretical considerations as well as from past empirical findings. These academic rationales can be compared to the stated rationales for M\&A among pharmaceutical firms to suggest the degree to which sector strategies have theoretical underpinnings that may translate into the degree of M\&A success. Prior research suggests that hospital systems have failed to achieve efficiencies in their combination efforts for precisely this lack of congruence. ${ }^{35}$ 
eve this balance in different :ch acquisition into their $y$ conflicts of interest. One ul was because of organizaironment, ownership) and ck decision-making. 'These al companies, where orga$\mathrm{d}$ bureaucracy, and where

sharmaceutical companies $\mathrm{g}$ the biotechs into their int investment in biologics ident Biotherapeutics and uth San Francisco, a city otechnology." Though the Wyeth and that company's ved through the establish1ore nimble and collabora$=$ researchers and biotech

ors, and current confusion biologics - see Chapter 4), aceutical companies as a fact, the top six drugs are logics representing fifty of six biotech products will be

\section{I research}

contains a rich literature on zal considerations as well as onales can be compared to utical firms to suggest the al underpinnings that may earch suggests that hospital eir combination efforts for
According to IO theory and research, there are several related reasons for pursuing M\&A. One of the most commonly cited reasons is the achievement of economies of scale (defined as decreasing average cost with expanded output). Such economies can have both production sources (e.g., the spreading of fixed costs over a larger volume of output in the combined firm, the use of more specialized, and thus more productive, labor, lower cost of holding inventories, improved utilization of capacity) and nonproduction sources (e.g., shared purchasing of inputs, shared marketing and promotion costs, shared research costs). ${ }^{36}$ Firms may also horizontally integrate to engulf a rival and thereby reduce competitive pressures, and to exert potential market power on buyers downstream or on suppliers upstream.

Another frequently mentioned reason are economies of scope, defined as cost savings derived from the same firm producing two or more products/ services in-house compared to separate firms producing those same products/services. Thus, a combined firm can presumably produce multiple outputs more efficiently than the pre-merged firms. Scope economies are a narrow form of "synergy," that is, the creation and capture of value generated by combining complementary assets and resources of two firms that could not be generated by the two firms independently. In this manner, the acquirer can make better use of the target's assets than the target firm could do alone. Synergies are often said to exist when potential economies of scale and/or scope are achieved via a merger; synergies can also be achieved through other means discussed above (e.g., cost savings from elimination of redundancies).

A third economic reason for M\&A is the need to confront operating problems. Among large firms, M\&A can serve to reduce excess capacity (in both human and physical capital); such excess capacity can result from patent expirations and gaps in the company's product pipeline. Among small firms, M\&A can serve as an exit strategy in response to financial trouble; such troubles can result from few marketed products and low sales. ${ }^{37}$

In addition to the internal economics of M\&A, companies pursue M\&A to put them in a position better to handle external economic uncertainties. One can liken a pharmaceutical company's portfolio to a financial portfolio of assets, with diversification offering potential for minimization of risk. Diversification, however, can mean different things to different companies. For some companies, diversification via M\&A is reflected through expansion into different products and therapeutic areas. For others, diversification involves entry into non-pharmaceutical businesses to enable the company to draw revenues from alternate sources. Diversification can also mean expansion into new markets 
geographically to diversify sources of revenue and to take advantage of new growth opportunities.

Firms can use M\&A to hasten entry into new markets, enter new markets without expanding existing capacity and increasing the number of competitors, and enter new markets in new countries (globalization strategy). This approach has become particularly important with the increased focus on developing markets. As developed markets have become increasingly competitive and regulated, pharmaceutical companies are strategically targeting emerging markets such as China and India, and are often using M\&A as an entry point.

There are several other benefits that M\&A may bestow beyond economies, synergies, and diversification. Acquirers may improve the productivity of the target's assets and impose greater discipline on the managers of the target firm.

Finally, there is another set of rationales for M\&A that does not necessarily bestow direct benefits. Historical evidence suggests successive waves of M\&A activity are tied to rises in the stock market. Both buyer and seller firms take advantage of these market upswings: (a) acquirers undertake acquisitions using their stock and its relatively high price-earnings ratio, while (b) target firms sell their assets at peak prices. Conversely, M\&A (at least for smaller biotechnology firms) can be tied to downturns in the availability of global credit and private equity, which make market exit via acquisition more attractive given the shrinkage of alternative sources of financing. ${ }^{38}$

Firms can also engage in M\&A to protect licensed intellectual property (IP) or to access IP that is otherwise inaccessible due to other licensing agreements. Firms can also engage in M\&A due to managerial self-aggrandizement (empire-building, enriched incentives) and the mistaken belief they can manage much larger enterprises (managerial hubris). Firms sometimes pursue M\&A when spurred on by investment bankers, who broker the deals and have strong incentives to maximize M\&A deal volumes. Finally, M\&A can serve a country's industrial policy by creating national or regional champions.

\section{M\&A rationales among pharmaceutical firms ${ }^{39}$}

The pharmaceutical sector trade literature suggests many of the rationales for M\&A cited in academic research, but also others. There is a clear sense from the trade literature that certain rationales are more adaptive and defensive in nature (particularly true for the earlier wave of M\&A in the 1990s), such as: combating cost pressures from buyers, cutting infrastructure costs, satisfying market
defendi
offensiv:
ing into
of scale :
disrupti
primaril

\section{Adaptive and defens}

Combat increased $\mathbb{E}$

The first 1

(1984). Tl

the lifecyc

more vigo

being cont

the increa:

imize econ

leading the

targets and

tions treate

This conve:

number of

with the sa

existing, ap]

and imitate

ceutical firm

and therape

rivalry and $s$

the need to $f$ tion was part the pharmace sales) to $\$ 24$ ?

The early 1 organized buy organizations i ing organizatic From 1988 to : sponsored hea 
to take advantage of new

larkets, enter new markets $g$ the number of competiobalization strategy). This th the increased focus on come increasingly compeare strategically targeting เre often using $\mathrm{M} \& \mathrm{~A}$ as an

bestow beyond economies, ove the productivity of the managers of the target firm. rA that does not necessarily s successive waves of M\&A buyer and seller firms take :ers undertake acquisitions nings ratio, while (b) target , M\&A (at least for smaller in the availability of global exit via acquisition more :es of financing. ${ }^{38}$ sed intellectual property (IP) , other licensing agreements. agerial self-aggrandizement istaken belief they can man3). Firms sometimes pursue ho broker the deals and have es. Finally, M\&A can serve a ir regional champions.

sts many of the rationales for $s$. There is a clear sense from ore adaptive and defensive in M\&A in the 1990s), such as: nfrastructure costs, satisfying market demands for earnings growth, maintaining competitive size, and defending against acquisition. Other rationales reflect a more proactive and offensive thrust (particularly in the later wave of the 2000s), such as: diversifying into new geographic markets and therapeutic areas, achieving economies of scale and scope, developing competitive capabilities in R\&D, and fostering disruptive change. There is also the clear sense that these rationales focus primarily on cost reduction and secondarily on revenue enhancement.

\section{Adaptive and defensive rationales}

\section{Combat increased profit pressures}

The first threat to pharmaceutical sector profits was the Hatch-Waxman Act (1984). The reality of increased generic competition placed a concrete limit on the lifecycle of a product's revenue stream and forced firms to search ever more vigorously for substantial sources of profits to replace those that were being continually lost after patent expiry. One result of this pressure has been the increasing focus of firms on blockbuster drugs - drugs that could maximize economic return over the fixed lifecycle of a drug's patent protection leading the R\&D departments of major competitors to converge on similar targets and drug classes with blockbuster potential (typically chronic conditions treated by primary care physicians, such as hypertension, arthritis, etc.). This convergence of pharmaceutical focus also resulted in an increase in the number of "me-too" drugs (chemically similarly compounds, or compounds with the same mechanism of action, introduced by competitors after an existing, approved chemical entity) during the 1990s, as firms could observe and imitate their competitors' R\&D efforts. The branded drugs of pharmaceutical firms were thus confronted with increased competition from generic and therapeutically similar versions. Both sets of pressures led to intensified rivalry and served as an impetus for consolidation, which, in turn, reinforced the need to focus on larger, blockbuster products. ${ }^{40}$ This increased competition was partially reflected in the increasing growth in $\mathrm{R} \& \mathrm{D}$ spending across the pharmaceutical industry, from roughly $\$ 9$ billion in 1991 (16.9 percent of sales) to $\$ 24$ billion in 1999 (20.8 percent of sales). ${ }^{41}$

The early 1990s also witnessed the consolidation of intermediaries into large, organized buyers of pharmaceutical products - such as health maintenance organizations (HMOs), pharmacy benefit managers (PBMs), and group purchasing organizations (GPOs) - along the value chain in healthcare (see Figure 1.1). From 1988 to 1996, for example, HMOs doubled their penetration of employersponsored health plans (firms with 200-plus workers) from 17 percent to 
33 percent. This growth placed additional pressure on pharmaceutical firm profits, as organized buyers negotiated large-volume discounts on drug prices, developed formularies of approved drugs, and pressured providers to prescribe generic versions or therapeutic equivalents of branded drugs whenever available. In certain cases, providers were even given personal incentives from payers for prescribing generic medicines. Pharmaceutical firms were also persuaded to hold down price increases in the US during the early 1990s under the threat of the Clinton Health Plan and the proposed creation of large buying networks at the state level. The period 1991-1995 therefore saw a big decline in the price increases of pharmaceutical firms. ${ }^{42}$

The combination of these factors increased the perceived pressures on both revenues and lifecycle durations of major branded drugs, resulting in weakened stock valuations, as evidenced by the drop in the S\&P drug index between 1991 and $1994 .{ }^{43}$ In response, pharmaceutical firms merged in order to increase their negotiating leverage with HMOs and PBMs. Mergers may also have been designed to combat the large buying groups proposed by the Clinton Health Plan. In addition to horizontal mergers, pharmaceutical firms attempted to mitigate the threat of buyer power through vertical integration into the PBM business. In 1993, Merck started the trend with its $\$ 6.6$ billion purchase of Medco, and was followed by similar PBM acquisitions by SmithKline-Beecham and Eli Lilly. ${ }^{44}$ However, this strategy proved less effective than hoped, as new regulatory restrictions limited the advantage a pharmaceutical company could gain with a PBM subsidiary. By 1999, the trend had passed, as SmithKline Beecham and Eli Lilly sold off their PBMs at a 60 percent to 70 percent discount from the original purchase price. ${ }^{45}$ Merck's Medco had been the only remaining pharma-owned PBM, though it too has since divested its PBM holdings.

While these external factors were placing pressures on the pharmaceutical industry, there were also internal challenges. The blockbuster model had taken advantage of many of the easier therapeutic targets and focused on the high-volume chronic diseases. This approach left behind the more difficult targets, as well as specialized treatments - products which would be more costly to develop and potentially yield lower volumes of sales. This challenge resulted in escalating costs of R\&D and greater risks of achieving success, which was borne out in the concomitant decrease in approvals of NMEs.

\section{Cutting infrastructure costs}

Economic recessions, proposed governmental reforms, and price pressures from both payers (HMOs) and buyers (PBMs) placed pharmaceutical firms in 
Ire on pharmaceutical firm 1e discounts on drug prices, sured providers to prescribe ed drugs whenever available. 1 incentives from payers for ; were also persuaded to hold 790 s under the threat of the large buying networks at the decline in the price increases

perceived pressures on both $d$ drugs, resulting in weaks $p$ in the $S \& P$ drug index aceutical firms merged in HMOs and PBMs. Mergers buying groups proposed by al mergers, pharmaceutical ower through vertical inte: started the trend with its by similar PBM acquisitions ?r, this strategy proved less sns limited the advantage a M subsidiary. By 1999, the Lilly sold off their PBMs at a al purchase price. ${ }^{45}$ Merck's ned PBM, though it too has

iures on the pharmaceutical "he blockbuster model had atic targets and focused on left behind the more difficult lucts which would be more imes of sales. This challenge - risks of achieving success, $e$ in approvals of NMEs.

iforms, and price pressures ıced pharmaceutical firms in a cost squeeze, which stimulated some of the early M\&A in the late 1980s and early 1990s. During the 1980s, the industry was reportedly suffering from excess capacity (as much as 30 percent across its major functional areas) and inefficiencies, which, along with a fragmented industry and redundant cost structure, made savings possible. Pharmaceutical firms experiencing relatively large increases in operating expenses were more likely to be involved in pooling mergers (i.e., mergers of equals) in the 1986-2000 time period, perhaps as a means of cutting costs. ${ }^{46}$ Historically, pharmaceutical firms rarely had to worry about infrastructure spending, enabling firms that had merged from a position of weakness (with subsequent overcapacity) to be in an even better position to realize cost synergies. Pharmaceutical executives believed that infrastructure cost-cutting between merged firms could provide bottomline earnings growth for two to three years after a merger's completion. In this manner, firms (particularly large pharmaceutical firms) that historically were unable to take out costs used the merger as a mechanism to become more streamlined and reduce excess capacity that had resulted from patent expirations and pipeline gaps. ${ }^{47}$

Such goals have played a role in recent mergers such as Roche's completed acquisition of Genentech. ${ }^{48}$ Moreover, analysts report that Wall Street lacks confidence in pharmaceutical firms' efforts to grow top-line revenues, and thus wants management to focus on cost reductions instead. Cost-cutting therefore provides firms with "breathing room" from Wall Street pressures. ${ }^{49}$

Infrastructure cuts could be made in $\mathrm{R} \& \mathrm{D}$ (close, consolidate, or sell laboratories), manufacturing (close, consolidate, or sell plants), and marketing (reduce the number of sales colleagues). Such cuts could improve the productivity of the remaining assets. Indeed, such anticipated savings were one justification for the recent merger between Merck and Schering-Plough. ${ }^{50}$ It should be noted here that R\&D is targeted as a source of short-term cost savings, not as a source of long-term productivity improvements (see below). By some estimates, up to 30 percent to 40 percent of the acquired company's cost base could be captured as earnings through infrastructure rationalization. ${ }^{51}$ Others put the estimated savings at 20 percent of the target firm's sales. Such savings may correlate strongly with the degree of overlap in the location of the two firms' headquarters, their geographic markets of operation, product focus, and concentration of business in the pharmaceutical sector - all of which lend themselves to reductions in duplication.

Given the similarities in therapeutic focus and overlaps in scientific pursuit, there were also many overlapping targets and research associated with their prosecution. As such, cuts could also be made as portfolio projects were 
consolidated. Access to these types of cuts may be lessening, however, as companies take diverging strategic bets on the future and pursue different targets (scientific, commercial, and geographic) for success.

Additionally, as companies have become leaner in the economic downturns of the 2000s, many of the above-mentioned opportunities for cuts in infrastructure may no longer exist. There has been a growing trend to make Big Pharma more operationally efficient during this decade. Most recently, in 2010, this trend took the form of large restructuring programs designed significantly to alter R\&D operations at many of the big pharmaceutical companies. For example, many companies now outsource $R \& D$, with an increasing dependence on CROs for a variety of functions. ${ }^{52}$ As companies work to contain escalating costs, many creatively shift costs to contract organizations (CROs, CSOs, and CMOs) and supplement with internal oversight.

\section{Satisfy the market mandate to maintain earnings growth in the face of pipeline problems}

A key objective in pharmaceutical M\&A is the maintenance of earnings growth. At the same time that cost pressures from buyers developed, competition became fierce, with multiple major players competing within almost all major therapeutic areas and also seeking gaps in more profitable niche disease markets. Market exclusivity periods (MEPs) - measured as the total time from launch that a drug enjoys market dominance until a competitor comes onto market with a me-too product or a next-generation therapy - have shrunk from up to ten years to an average of 2.5 years, and sometimes just one to two years. ${ }^{53}$ There are several explanations for the shorter MEPs. The HatchWaxman Act made it easier for generics to gain approval, which lowered the costs of imitation and sped up generic competition, and which thus pressured follow-on manufacturers to get their products to market sooner. Moreover, with increased drug coverage by health insurance plans, there was greater utilization of drugs and thus greater incentives for follow-on products to enter the market. Finally, given the intense competition among pharmaceutical companies to be first-in-class, more follow-on manufacturers filed patents earlier and earlier, while the hurdles to market grew, resulting in shorter time on the market and thus shorter MEPs. This competition also meant more follow-on products already in clinical testing when a new drug was approved. Adding to these pressures, generic firms usually file Paragraph IV challenges as soon as a branded drug's data exclusivity period expires in order to capture the large profits available to the generic firm provided with 180 days of exclusivity under the Hatch-Waxman Act. 
be lessening, however, as ıture and pursue different $r$ success.

in the economic downturns ortunities for cuts in infrayrowing trend to make Big ade. Most recently, in 2010, rrams designed significantly maceutical companies. For th an increasing dependence $s$ work to contain escalating izations (CROs, CSOs, and

\section{n the face}

$\geq$ maintenance of earnings buyers developed, competiompeting within almost all 1ore profitable niche disease isured as the total time from til a competitor comes onto tion therapy - have shrunk and sometimes just one to e shorter MEPs. The Hatchspproval, which lowered the $\mathrm{n}$, and which thus pressured , market sooner. Moreover, ıce plans, there was greater - follow-on products to enter ion among pharmaceutical manufacturers filed patents ew, resulting in shorter time mpetition also meant more in a new drug was approved. file Paragraph IV challenges d expires in order to capture provided with 180 days of
In addition to these trends, onetime shocks to a firm's revenue stream have also become an all too common headache for large companies trying to manage the market's expectations. For instance, product withdrawals due to safety concerns wiped out years of anticipated profits from such firms as Wyeth (Fen-Phen), Bayer (Baycol), Warner-Lambert/Pfizer (Rezulin), Merck (Vioxx), and Pfizer (Bextra). Late-stage clinical failures also left major gaps in firms' revenue projections. Pfizer suffered several late-stage clinical setbacks bringing its blockbuster antibiotic Trovan to market, thereby restricting its ultimate value in the market. Merck lost two blockbusters in phase III trial failures (MK-0869 for depression and MK-767 for diabetes), leaving the firm in a precarious position for midterm growth. Such problems become reflected in the firm's "desperation index" (i.e., declining values of products in the pipeline). ${ }^{54}$ The most visible clinical failure, though, may be that of torcetrapib, once touted by Forbes as one of five molecules that would change the world. ${ }^{55}$ At the time the trials were halted, Pfizer had spent over $\$ 800$ million in development for this cholesterol medication, which was expected to fill the gap in revenues after Lipitor had come off patent.

The combination of all of these factors has jeopardized the long-term stability and reliability of pharmaceutical firm revenue streams. Major gaps in revenue growth, either foreseen (e.g., patent expirations) or unforeseen (e.g., product withdrawals or pipeline failures), provide a critical challenge to management. The highly specialized sales and marketing personnel at integrated pharmaceutical firms become unproductive when patents expire and the R\&D organization does not deliver replacement products. However, reducing capacity to match a reduced revenue forecast is generally not an option because of the scope, complexity, and long timelines of infrastructure spending on drug discovery. Most firms therefore maintain the scale of their scientific spending, no matter how difficult present earnings challenges may be. With regard to sales, however, many companies are turning to CSOs to address specific needs and to complement their existing sales force, thus giving the companies more flexibility in staffing. ${ }^{56}$

Two separate academic studies provide empirical support for this hypothesis of M\&A to maintain earnings growth. A study of 202 biotechnology and pharmaceutical mergers between 1988 and 2001 found that pharmaceutical firms that had a relatively old portfolio of drugs, and therefore faced earnings pressure from patent expiration, were more likely to acquire another firm. ${ }^{57}$ A second study of 160 pharmaceutical transactions that occurred between 1994 and 2001 concluded that firms with a high "desperation index," as 
measured by the strength of their pipeline drugs and the amount of exclusivity remaining among their marketed drugs, were more likely to merge. ${ }^{58}$

As a result, in the face of incredible market pressure to produce consistent earnings growth, firms turn to M\&A to provide immediate fixes. M\&A may address some of the strategic threats (e.g., pricing pressures from payers). M\&A also provides the opportunity for accretive and external, as opposed to organic and internal, growth in earnings - and thus could theoretically maintain the 15 percent to 20 percent profit margins that pharmaceutical firms had historically enjoyed. A merger partner or an acquisition can also provide products, either marketed or in the pipeline, that are well timed to fill revenue gaps in either the short or medium terms. For example, Pfizer's hostile bid for WarnerLambert allowed it to capture the full revenue stream from the emerging cholesterol-lowering blockbuster Lipitor, a drug that the two companies co-marketed. The bid was likely motivated by a period of weakness for Pfizer, at a time of dim pipeline prospects and just after the FDA had heavily restricted Trovan's use (and market potential). Lipitor provided enough revenues to smooth over both of those issues in the medium term. ${ }^{59}$ The company, however, claimed other reasoning. In contrast to mergers of other companies, which were perceived as having been done from a position of weakness, Pfizer CEO Bill Steere asserted, "our view of this merger is that it is out of strength." ${ }^{\text {R0 }}$ Regardless of position, pharmaceutical firms had discovered that buying external products (and revenues) was cheaper and faster than growing them internally, as well as eliminating the inherent risks of development.

The problem with mergers is that they may be irrelevant responses to other threats (e.g., pipeline problems). Oftentimes, mergers beget more mergers, turning the pharmaceutical firm into a "mass-mergerer" (i.e., a serial consolidator). Mergers may set off leapfrog competition in a pharmaceutical sector with firms adopting an M\&A strategy to "not be left behind," believing that firms that fall in the size rankings are more vulnerable to takeover. ${ }^{61}$ As companies get larger, however, the absolute value of revenues required to replace lost revenues from patent expirations and still generate double-digit earnings growth also grows larger. By some estimates, the largest firms need to launch one to three blockbusters annually in order to maintain the pace of growth. ${ }^{62}$ So long as the pipeline productivity issue remains, satisfying the market mandate for growth will continue to require nonorganic solutions, such as consolidation, to help drive earnings forward.

M\&A thus represents a short-term strategy and solution for firms with blockbuster drugs that are coming off patent and/or with an insufficient pipeline to replace the blockbusters. ${ }^{63}$ Increased size resulting from past 
and the amount of exclusivity nore likely to merge. ${ }^{58}$

rressure to produce consistent e immediate fixes. M\&A may ; pressures from payers). M\&A :xternal, as opposed to organic uld theoretically maintain the irmaceutical firms had historion can also provide products, 1 timed to fill revenue gaps in Pfizer's hostile bid for Warnerte stream from the emerging ug that the two companies period of weakness for Pfizer, the FDA had heavily restricted orovided enough revenues to erm. ${ }^{59}$ The company, however, f other companies, which were of weakness, Pfizer CEO Bill s out of strength. ${ }^{360}$ Regardless t that buying external products ring them internally, as well as

a irrelevant responses to other nergers beget more mergers, -mergerer" (i.e., a serial conpetition in a pharmaceutical "not be left behind," believing a vulnerable to takeover. ${ }^{61}$ As alue of revenues required to nd still generate double-digit aates, the largest firms need to irder to maintain the pace of issue remains, satisfying the equire nonorganic solutions, rward.

and solution for firms with and/or with an insufficient sed size resulting from past mergers and continuing pipeline problems make this strategy less tenable
over time, as does the dis over time, as does the disruption associated with merger implementation and
integration.

\section{Maintain competitive scale and scope}

Serial consolidators can be an outgrowth of not only the need to maintain earnings growth, but also the competitive effects exerted by and onto others. Common wisdom within the industry holds that sales force scale and the size and scope of $R \& D$ efforts create powerful competitive advantages for leading firms. For example, sales force size reportedly gives a pharmaceutical firm greater share of voice with the prescribing clinician and correlates with sales force productivity. Indeed, companies discovered during the 1990s that "internally co-promoting" - that is, having multiple sales representatives detailing the same product to the same doctors - was very effective. ${ }^{64}$ Not surprisingly, sales force sizes skyrocketed in the late 1990s and early $2000 \mathrm{~s}$, rising from 38,000 in 1995 to over 101,000 by 2004 (the peak year). ${ }^{65}$ The top forty firms added 40,000 sales reps between 1992 and $2002 .{ }^{66}$ R\&D budgets followed suit, growing from 16 percent to 18 percent of sales between 1990 and 2000 , with a peak of 20 percent in $1998 .{ }^{67}$ By 2009 , the top ten pharmaceutical companies were averaging $\$ 6.3$ billion (Pfizer highest at $\$ 9.9$ billion) in annual R\&D spend or 19 percent of sales (Takeda highest at 26.4 percent). ${ }^{68}$ By 2008-2009, however, many company executives believed the correlation between the level of sales and the number of sales reps and their efforts had
broken down. ${ }^{69}$

In light of the increased spending on sales and scientific capabilities, and as leading firms consolidate, the gap in absolute spending between the first tier and the second tier has the potential to grow exponentially. This result threatens to leave smaller firms, who miss out on the consolidation trend, behind for good. Firms have mentioned the downside of being the "number 12 " player in the industry in terms of not being able to attract the best scientific
talent or strategic alliance partners.

In response, smaller players seeking a rapid way to achieve larger scale have turned to consolidation, creating a series of leapfrog mergers in the 1990s and 2000 s with new firms (and sometimes a returning group) setting the industryleading standard for scale every few years. As such, the necessity of merging for scale in response to the consolidation of competitors can be seen as a catalyst for M\&A after the initial waves. Examples of such mergers include with Warner-Lambert) in $2000,{ }^{72}$ GlaxoSmithKline (GSK) (from Glaxo
w $1996{ }^{71}$ Pfizer (after the merger 
Wellcome and SmithKline Beecham) in 2001, ${ }^{73}$ Pfizer (after merger with Pharmacia) in 2003, and Pfizer (after merger with Wyeth) in 2009 - each of which became the largest firm in the world at the time of the merger. The formations of Aventis and AstraZeneca created the second and third largest firms, respectively, at the time of the merger ${ }^{74}$ Smaller mergers, such as that between Pharmacia and Upjohn in 1995, witnessed the combination of two second-tier players simply trying to maintain their position given the burgeoning might of consolidating industry leaders. ${ }^{75}$

\section{Defense against acquisition}

Firms with relatively weak positions (e.g., smaller market share, greater financial problems and pipeline issues) make attractive takeover candidates; solid products and $\mathrm{R} \& \mathrm{D}$ projects can be harvested, while redundant infrastructure can be cut wholesale. For such firms, improving performance through organic growth sufficiently to block such takeover attempts is too difficult, and too slow, to provide an effective defense. On the other hand, a merger with another firm allows the corporation to maintain some semblance of control over its destiny, despite the loss of autonomy inherent in a merger. Another attractive takeover candidate is a firm that is, in fact, performing strongly, but which has not reached sufficient scale to avert a takeover. These firms may also look for partnerships to avoid a fate they cannot control.

The merger between American Home Products (a large firm struggling to find growth) and Warner-Lambert (a rapidly growing firm with a hot product, Lipitor) provides an example of both types of firms seeking refuge in a mutual partnership On November 4,1999, the two companies announced a deal dubbed the "merger of equals" valued at $\$ 72$ billion. Unfortunately, the decision to merge came too late to save Warner-Lambert, as Pfizer responded with an $\$ 80$ billion hostile bid for its Lipitor partner. ${ }^{76}$ Pfizer's unsolicited bid for the company (and its products) ultimately scuttled the initial deal with American Home Products, and Warner-Lambert effectively lost its independence.

The recent merger of Sanofi-Synthélabo with Aventis can be interpreted in the same light. Sanofi-Synthélabo, a firm with above-average R\&D productivity and a fairly strong pipeline, represented an attractive takeover candidate for larger firms looking for new growth engines. Sanofi's merger with Aventis served several ends: to maintain Sanofi's independence, to be a European champion, to consolidate Europe's pharmaceutical sector, to be the new number three firm in the industry, and to serve France's national pride (as well as leverage Sanofi's attractive pipeline more effectively over more countries). ${ }^{77}$ In Japan, Yamanouchi Pharmaceutical Company agreed to acquire
Fujisaw
home, 1
larger $g$
firm.
deal) ar
combin
tered by
guided i
integrate
Anoth
anumbe
3MS, wh
complica
cquisitio
xtend to
articular
orldwid

\section{Proactive and offensi}

Gain access to foreig Instead of many merg twentieth $\mathrm{c}$ building a $s$ with regulat from the gr firms with $s$ increasing $v$ Europe, and tical product way to gain capabilities o: were typicall Beckman (U؟ Upjohn (US) given the mar with Japanese (Japan) (2002 
Pfizer (after merger with I Wyeth) in 2009 - each of ie time of the merger. The he second and third largest naller mergers, such as that ied the combination of two eir position given the bur5

lller market share, greater ractive takeover candidates; ted, while redundant infrais, improving performance in takeover attempts is too fense. On the other hand, a o maintain some semblance nomy inherent in a merger. that is, in fact, performing le to avert a takeover. These te they cannot control.

is (a large firm struggling to ving firm with a hot product, is seeking refuge in a mutual impanies announced a deal 1. Unfortunately, the decision as Pfizer responded with an fizer's unsolicited bid for the re initial deal with American lost its independence.

Aventis can be interpreted in ove-average $\mathrm{R} \& \mathrm{D}$ productivittractive takeover candidate Sanofi's merger with Aventis sendence, to be a European tical sector, to be the new ¿ France's national pride (as : effectively over more counCompany agreed to acquire
Fujisawa Pharmaceutical Company in order to battle foreign competition at home, to become the number two player in Japan, to fend off takeovers by larger global firms, and to avoid becoming a Japanese subsidiary of a foreign firm. ${ }^{78}$ In support of these efforts, countries like France (in the Sanofi-Aventis deal) and Japan are encouraging their domestic pharmaceutical firms to combine, increase their regional scale and dominance, and avoid being battered by foreign companies. ${ }^{79}$ Of course, such encouragement can be misguided if it produces less-competitive, merged firms that do not actively integrate to reduce costs or promote growth.

Another defense against acquisition has been to partner with other firms in a number of licensing arrangements. This approach has been undertaken by $B M S$, which has diffused the risks of $R \& D$ and, in doing so, created a complicated network of partnerships. Though often rumoured as a potential acquisition target, the value BMS has created for itself may not necessarily extend to the acquirer. It will be interesting to observe what happens to BMS, particularly with the patent expiry in 2011 of its bestseller Plavix (second in worldwide pharmaceutical sales in 2009 with over $\$ 9$ billion in revenues).

\section{Proactive and offensive rationales}

\section{Gain access to foreign pharmaceutical markets}

Instead of (or in addition to) cutting costs and fending off price reductions, many mergers are motivated by efforts to increase revenues. For much of the twentieth century, domestic firms dominated national markets by steadily building a sales and marketing presence and by forming strong relationships with regulators and local researchers. The difficulty in building these capabilities from the ground up as a foreign entrant in an established market presented firms with serious barriers to international expansion. At the same time, the increasing value and scale of foreign pharmaceutical markets in the US, Europe, and Japan, combined with the universal marketability of pharmaceutical products, made expansion a strategic and economic priority. The fastest way to gain access to foreign markets, therefore, was to license or buy the capabilities of local firms. Examples of mergers partially driven by this rationale were typically US-European mergers, such as those between SmithKline Beckman (US) and Beecham (UK) (1989) or Pharmacia (Sweden/Italy) and Upjohn (US) (1995). US expansion was an important motive for non-US firms given the market size, high growth, and price realizations in the US. Mergers with Japanese firms, such as that between Roche (Switzerland) and Chugai (Japan) (2002), developed to foster entry to an important market where 
Western firms had generally struggled; however, now most Western firms have a strong base in Japan and do not need an acquisition. ${ }^{80}$

More recently, companies have looked to emerging markets as a source of untapped revenue, particularly within India. To gain access to the market and the distribution therein, companies are taking a similar approach to entry as they did for Europe, with the twist of seeking out generics partners. DaiichiSankyo led the way with their $\$ 4.2$ billion takeover of Ranbaxy in 2008. In 2010 , Abbott's purchase of the branded generics business of India's Piramal Healthcare for $\$ 3.7$ billion resulted in their becoming the leading pharmaceutical company in India. ${ }^{81}$ Other companies have approached entry into India with more conservative moves, but the trend is to look to enter non-traditional geographic markets and to do so with non-traditional products (e.g., generics). Central and Eastern Europe (19 percent compound annual growth rate, 2003-2006) are also cited as attractive markets for similar reasons. ${ }^{82}$ Such markets have attracted interest from the likes of Abbott (acquisition of Solvay in 2010), Teva (via Barr, acquisition of Pliva in 2008), Sanofi-Aventis (acquisition of Zentiva in 2008), Novartis (acquisition of Lek in 2002), and GSK (via GlaxoWellcome, acquisition of Polfa Poznań in 2000).

In addition to building sales in new markets, pharmaceutical firms are also seeking to develop the image of a fast-growing and global industry. Such a perception may help attract alliance and potential acquisition partners. Global reach, combined with capabilities in rapid product launch, can also translate into a reduction of years to peak product sales and, thus, higher revenues.

\section{Extend capabilities to new therapeutic areas}

As firms grow, they have typically expanded the scope of their portfolio across a number of therapeutic areas. Most major pharmaceutical firms now have products in many major therapeutic areas (e.g., cholesterol, hypertension, depression, antiulcerants, diabetes, inflammation). However, this breadth results as much from the consolidation trend as from organic growth. Building capabilities in a therapeutic area - in terms of R\&D expertise, sales force presence, and physician relationships - can take years or even decades. Capabilities also tend to flow from scientific innovation, which is not always predictable. In order quickly to become a player in a major market with innovative capabilities, acquisition is often the fastest approach. For instance, Pfizer's merger with Pharmacia in 2002 improved its presence in inflammation (by capturing 100 percent of revenues from the co-marketed rheumatoid arthritis drug Celebrex, as well as the same potential for next-generation Bextra before that product was removed from the market) and added assets in oncolo ted Pfize system, d October 2 maceutica tion prodi M\&A n technolog biotechno] molecules. $\mathrm{R} \& \mathrm{D}$ to th little know tical partn in large $\mathrm{ms}$

\section{Achieve economies o} Economies value chain believe that marginal $\mathrm{r} \epsilon$ ished. Partic that "more s representati Larger scale leading to hi to scale ecos physician sp of economie sales force si and possibly either greate1

There is $\mathrm{n}$ pharmaceuti consolidatior to scale there which a mini allows compa of bets across investment ( $\mathrm{F}$ 
w most Western firms have ion. $^{80}$

ging markets as a source of in access to the market and imilar approach to entry as generics partners. Daiichiver of Ranbaxy in 2008. In business of India's Piramal ing the leading pharmaceuipproached entry into India ook to enter non-traditional tional products (e.g., generapound annual growth rate, for similar reasons. ${ }^{82}$ Such lbbott (acquisition of Solvay 008), Sanofi-Aventis (acquif Lek in 2002), and GSK (via 2000).

harmaceutical firms are also and global industry. Such a I acquisition partners. Global ict launch, can also translate nd, thus, higher revenues.

scope of their portfolio across armaceutical firms now have g., cholesterol, hypertension, ion). However, this breadth Id as from organic growth. terms of R\&D expertise, sales in take years or even decades. novation, which is not always yyer in a major market with astest approach. For instance, ved its presence in inflamma1 the co-marketed rheumatoid potential for next-generation the market) and added assets in oncology, endocrinology, and ophthalmology; these products complemented Pfizer's existing strengths in cardiovascular disease, central nervous system, depression, and erectile dysfunction. Pfizer's purchase of Wyeth in October 2009 resulted in the company's further diversification beyond pharmaceuticals with the acquisition of biologics, consumer healthcare, and nutrition products.

M\&A may also serve as a vehicle to extend the firm's capabilities to new technologies possessed by the target firm. Pharmaceutical firms' acquisition of biotechnology companies represents a major effort to gain capabilities in large molecules. Some researchers suggest this strategy reflects an outsourcing of R\&D to the biotechnology firm, a claim supported by recent evidence that little knowledge is transferred from the biotechnology firm to its pharmaceutical partner. ${ }^{83}$ The biotechnology firm thus serves as the center of excellence in large molecule research.

\section{Achieve economies of scale and scope in R\&D, sales, and marketing}

Economies of scale are believed to exist in some portions of the pharmaceutical value chain (e.g., sales and marketing) more than in others. Industry executives believe that larger commercial scale has continued to demonstrate positive marginal returns, though the magnitude of those returns has rapidly diminished. Particularly during the mid-1990s to mid-2000s, their thinking has been that "more sales representatives can call on more doctors more times," or "more representatives can sell more drugs to more doctors leading to more scripts." Larger scale may also facilitate faster product launches across larger markets, leading to higher revenues. Larger size in the form of multiple products can lead to scale economies through the marketing of multiple products to the same physician specialty. ${ }^{84}$ Finally, larger scale may pose a barrier to entry by virtue of economies in selling, general, and administrative (SG\&A) expenses - large sales force size, promotional spending, and direct-to-consumer advertising and possibly provide some advantage in conducting clinical trials (through either greater efficiency or access to a broader network of investigators).

There is more debate surrounding the presence of economies of scale in pharmaceutical $R \& D$, which is thus probably not a major factor driving consolidation. Many observers speculate that instead of increasing returns to scale there is a "critical mass" of research spending - a threshold level at which a minimum efficient scale is attained. This threshold level of spending allows companies to acquire key technologies and place the requisite number of bets across fixed research assets in order to achieve an adequate return on investment (ROI). This critical mass would also allow companies adequately 
to fund both early-stage research, as well as expensive, later-stage development, without making trade-offs between short-term and long-term spending priorities. Other observers believe that "more is better" - that is, higher R\&D outlays translate into placing even more bets on more projects and technologies, and, thus, increased likelihood of success, particularly for phase II and phase III research projects where a firm's prior R\&D experience is relatively important. ${ }^{85}$ In this light, higher R\&D spending is viewed as "risk management" (diversifying the portfolio of projects and the risks of any given project) rather than improved ROI.

Regardless of the above, commentators believe that these thresholds have already been reached by most major firms - perhaps as little as $\$ 100$ million in research spending, which at around 25 percent of a total $R \& D$ budget would imply R\&D spending of just $\$ 400$ million per year. ${ }^{86}$ Most major players currently spend at least ten times this amount on their R\&D efforts. More recently, the growing prominence of smaller biotechnology firms in developing NMEs suggests that the scale requirements of drug discovery are falling rather than rising.

There are other presumed benefits of mergers that involve economies of scale. Increased scale from a merger may allow a firm to spread the costs of acquiring any future technologies or biotechnology firms across a larger base. The combined sales forces of the merged firm may permit more intensive marketing to leverage the target firm's products and more cheaply sell a wider range of products. ${ }^{87}$ Larger firms may also be better able to leverage the technology, R\&D, and skill-sets of these future target acquisitions. Finally, pharmaceutical firms may make strategic acquisitions of firms operating in a specific therapeutic area in order to gain scale and thereby compete with larger firms which devote a lower proportion of their R\&D to this area. Analysts suggest that scale economies exist within (but not across) therapeutic areas and that pharmaceutical firms can leverage knowledge across multiple states within the same disease family (narrow but deep focus) ${ }^{88}$

Economies of scope may offer some ongoing advantage to larger firms. Pharmaceutical companies may seek to apply the capabilities of their biotechnology acquisitions to their own operations or combine their own fledgling programs in large molecules with those of their new partner. They may also enjoy a broader product line that allows them access to a greater number of physicians in the market, which may offset some of the power of organized buyers. Firms that place a larger number of bets across a number of therapeutic areas and technologies may also be more likely to create a new drug than those with a more narrow scope. 
nsive, later-stage develop$\mathrm{m}$ and long-term spending tter" - that is, higher R\&D nore projects and technolarticularly for phase II and \&D experience is relatively is viewed as "risk managee risks of any given project)

that these thresholds have is as little as $\$ 100$ million in a total R\&D budget would rear. ${ }^{86}$ Most major players n their R\&D efforts. More :chnology firms in develop$\mathrm{f}$ drug discovery are falling

that involve economies of firm to spread the costs of yy firms across a larger base. may permit more intensive ad more cheaply sell a wider better able to leverage the target acquisitions. Finally, tions of firms operating in a thereby compete with larger R\&D to this area. Analysts ot across) therapeutic areas vledge across multiple states focus). ${ }^{88}$

advantage to larger firms. capabilities of their biotechzombine their own fledgling eir new partner. They may $n$ access to a greater number ne of the power of organized $s$ across a number of theraz likely to create a new drug
All the same, after fifteen years of consolidation, pipeline productivity continues to decline, and the extent of scope advantages for merging firms is difficult to estimate. This outcome may be due to the fact that merging firms often cut out large groups of development projects that cannot satisfy new criteria for high potential sales; one analysis showed that post-merger firms had almost one-third fewer projects in development three years after merging as their pre-merger baseline. ${ }^{89}$ It may also stem from the disruption to R\&D processes and projects that often occurs in a post-merger environment. This disruption is hard to quantify and often does not present until many years post-merger. Finally, as noted above, M\&A may not even address the unknown root causes of declining pipeline productivity, but rather serve other short-term palliative needs.

\section{Create a competitive advantage in $R \& D$ productivity}

Long-term improvements to R\&D productivity, as opposed to short-term cost savings and earnings boosts, are often cited by executives at the time of a merger. Mergers are heralded as the beginning of a new research engine to drive organic growth in the future. However, such improvements have been the most elusive of all the stated benefits of consolidation. Consistently, these same companies have returned to mergers again and again in order to shore up weak pipelines and gaps in market portfolios. Serial consolidators such as American Home Products (A. H. Robbins in 1989, Cyanamid in 1994, and a failed attempt to merge with Warner-Lambert in 2001), Pfizer (Warner-Lambert in 2001, Pharmacia in 2003, Wyeth in 2009), and GSK (a merged combination of entities Glaxo, Wellcome, SmithKline, Beckman, and Beecham) have proclaimed at every juncture that their newly formed ventures would be better positioned to grow organically - and independently - for the future; yet subsequent mergers reveal still more weakness in product flows. ${ }^{90}$

The R\&D productivity crisis has deepened despite the M\&A activity described above. It may take more time than expected to assimilate the new technologies and firms acquired and may extend beyond the terms of the executive teams committed to the mergers. In the short term, the combined earnings stream of the merged firms may provide a more consistent flow of internal funding for $\mathrm{R} \& \mathrm{D}$ to offset the volatile cash flows from blockbusters. ${ }^{91}$

\section{Foster disruptive change}

The final rationale for M\&A that we discuss is the opportunity for disruptive change. As noted above, M\&A is often pursued for defensive reasons to 
correct underlying weakness and decline in the combining firms. Mergers provide an external impetus and logic for restructuring each firm's assets that might otherwise encounter greater internal resistance. In this manner, the two firms can "start with a clean slate," conduct a company-wide review, reallocate assets to more productive areas, re-engineer processes, reduce headcounts, and undertake changes that neither firm could do prior to the combination. ${ }^{92}$ Indeed, the merger event serves to justify the enormous disruption costs. ${ }^{93}$ In this manner, merged firms may achieve the economies of scale and savings that individual firms cannot, or take out costs that the individual firm cannot, as well as do so with financial merger-related accounting. In a similar vein, M\&A can be undertaken to change the "activity footprint" of a firm in order to track migration of profit pools, control profit choke points, or execute a new value proposition necessitated by changes in the economics of an industry. ${ }^{94}$

\section{Summary of rationales: is there a problem here?}

The above review suggests that M\&A can be motivated from multiple sources. This conclusion is supported by industry surveys of pharmaceutical firms who report having multiple M\&A goals: grow the core business, realize cost synergies, acquire new technologies, gain competitive advantage, generate fiscal advantage, and so on. ${ }^{95}$ Such a phenomenon is not unique to pharmaceutical firms; firms in other healthcare sectors and other industries typically have multiple objectives in pursuing M\&A. ${ }^{96}$ It is possible, of course, that many positive aspirations are voiced to disguise underlying motivations for cost synergies (i.e., reductions).

The problem with multiple rationales noted in these other industries may also pertain to pharmaceuticals: the lack of a clear focus in the merger and the presence of conflicting agendas. In the presence of multiple goals, the intentions of the two firms (particularly if one acquires the other) are likely to diverge, if not conflict. Moreover, there may be a simultaneous (and confusing) effort to cut costs while pursuing growth. Other problems that stem from multiple rationales concern the merger integration effort - for example, the difficulty in mapping out the implementation steps due to the need to accommodate a variety of potentially conflicting interests and directions. Multiple rationales may thus prove dysfunctional during the merger transition and lead to unresolvable conflicts. Industry analysts argue that one party in clear control, with a dominant economic rationale, a simple program, great communication, and excellent execution, is the critical ingredient for M\&A success. ${ }^{97}$
The impact of

There
of pha
enougl
mental
ceutical
M\&A.
tions wi
integrat
"multip
found.
different
first coll
A sec
managet
lines and
to engag
impact o
they did
industry
Early resear
inputs to the
diversific:
attemptec
Third,
M\&A fros
may be ap
section of
implemen
A fourtl
firm scale,
makes it hi

Review of the evidenct

Relationship between 
ombining firms. Mergers sturing each firm's assets esistance. In this manner, t a company-wide review, Igineer processes, reduce irm could do prior to the to justify the enormous ray achieve the economies or take out costs that the financial merger-related ndertaken to change the migration of profit pools, e proposition necessitated

ated from multiple sources. f pharmaceutical firms who core business, realize cost etitive advantage, generate $\mathrm{n}$ is not unique to pharmaid other industries typically is possible, of course, that underlying motivations for

ese other industries may also cus in the merger and the nultiple goals, the intentions ther) are likely to diverge, if us (and confusing) effort to is that stem from multiple - for example, the difficulty the need to accommodate a rections. Multiple rationales transition and lead to unreparty in clear control, with a , great communication, and [\&A success.

\section{The impact of M\&A on the performance of pharmaceutical firms}

There is a growing body of research evidence that tests the presumed advantages of pharmaceutical firm scale and M\&A strategy, although it is not developed enough to test all of the rationales enumerated above. There are several fundamental difficulties, however, in isolating the benefits of M\&A. First, pharmaceutical firms may pursue other strategies whose effects are entangled with M\&A. For example, during the early 1990s, Glaxo pursued horizontal acquisitions with both pharmaceutical and biotechnology firms and considered vertical integration into the PBM industry. ${ }^{98}$ Evaluation researchers label this problem "multiple treatment interference"; economists refer to it as a statistical confound. The evidence reviewed below cannot truly disentangle the impacts of different strategies pursued simultaneously by pharmaceutical firms without first collecting data on all of the strategies and estimating competing risk models.

A second difficulty is that mergers do not occur randomly but are chosen by managers. Firms whose growth prospects are threatened (due to weak pipelines and/or marketed drugs at risk of losing patent protection) are more likely to engage in M\&A activity. ${ }^{99}$ This observation makes it difficult to isolate the impact of a merger, because firms that merge may have fared poorly even if they did nothing. Conversely, a merged firm may fare poorly compared to industry averages, but might perform better than it otherwise would have. ${ }^{100}$ This outcome may be especially true for companies that pursue M\&A for diversification or geographic expansion. As a result, recent research has attempted to model the propensity to merge as well as the effects of M\&A.

Third, it may be difficult to distinguish limitations of the strategy of M\&A from the limitations of the strategy's execution. That is, the strategy may be appropriate, while the execution and implementation flawed. A later section of this chapter explores some of the important processes in merger
implementation. ${ }^{101}$

A fourth difficulty is that research studies have utilized several measures of firm scale, $R \& D$, and M\&A performance. ${ }^{102}$ This variability in research design makes it hard to compare published results.

\section{Review of the evidence from academia and consulting firms}

Relationship between scale and R\&D inputs

Early research conducted across industries examined the impact of firm scale on inputs to the $R \& D$ process, such as the intensity of $R \& D$ (e.g., $R \& D$ expenditures 
as a percentage of sales). Some researchers found positive effects of scale on R\&D intensity while others found threshold effects (i.e., positive effects up to a certain level of scale, after which the effects become zero or negative). Subsequent research results have generally been inconclusive. Overall, size appears to exert only a minute effect on R\&D intensity and explains little of the variation. ${ }^{103}$ Instead, R\&D intensity appears to be a function of the firm's prior cash flows and profits. ${ }^{104}$ One study that examined mergers in all industries between 1976 and 1995 concluded that firms that merged experienced the same growth in R\&D spending subsequently, on average, as firms that did not merge. ${ }^{105}$

As noted earlier, the pharmaceutical industry has devoted an increasing percentage of its revenues to R\&D. This "research intensity" grew markedly from 12.4 percent (in 1970) to 21.6 percent (in 1996), falling slightly to 19.2 percent (in 2005). Such investment is nearly seven times the intensity of the pharmaceutical industry's all-manufacturing counterparts. ${ }^{106}$ Investigators naturally asked whether increased scale is associated with such increased spending.

Recent academic research has found that pharmaceutical M\&A does not lead to increased R\&D expenditures. Mergers during the period 1988-2001 exerted no impact on the growth rate of $R \& D$ spending in the first three years following a merger in large pharmaceutical and biotechnology firms, and exerted a negative impact in small firms. ${ }^{107}$ Other researchers have suggested that R\&D intensity may be a driver (cause) of increased size through M\&A, rather than a result. Firms with higher R\&D spending are more likely to engage in acquisitions as a means of diversifying their research portfolios, and use outsourced R\&D to complement their internal R\&D. ${ }^{108}$ Research on corporate strategy has found that firms need the "absorptive capacity" of knowledge gained from internal $R \& D$ in order to gauge the value of potential knowledge stocks in external research programs (found in target firms). ${ }^{109}$ Consultants have likewise found no relationship between scale and R\&D intensity in the pharmaceutical industry. ${ }^{110}$

\section{Relationship of scale with R\&D outputs}

The vast bulk of the evidence also suggests that scale (defined in multiple ways - see below) has only a weak impact on various measures of R\&D productivity. While larger firms may (or may not) undertake the bulk of innovative investment, they are not the source of the majority of innovations, or at least the most distinctive innovations in a therapeutic area. ${ }^{111}$ This result is made obvious by the preponderance of new pipeline drugs being in-licensed by large pharmaceutical companies from the biotechnology sector. 
itive effects of scale on R\&D sitive effects up to a certain , or negative). Subsequent 'verall, size appears to exert as little of the variation. ${ }^{103}$ e firm's prior cash flows and adustries between 1976 and 1 the same growth in $R \& D$ 1 not merge. ${ }^{105}$

has devoted an increasing 1 intensity" grew markedly 2.1996), falling slightly to y seven times the intensity acturing counterparts. ${ }^{106}$ zale is associated with such

maceutical M\&A does not ring the period 1988-2001 ading in the first three years 1 biotechnology firms, and researchers have suggested creased size through M\&A, sending are more likely to heir research portfolios, and rnal R\&D. ${ }^{108}$ Research on he "absorptive capacity" of gauge the value of potential ; (found in target firms). ${ }^{109}$ ip between scale and R\&D

t scale (defined in multiple . various measures of $R \& D$ not) undertake the bulk of the majority of innovations, erapeutic area. ${ }^{111}$ This result eline drugs being in-licensed technology sector.
Economists have found that a firm's scale defined as overall R\&D spending is not associated with the discovery of new drugs - measured either as the probability of success of NDAs or the number of NMEs per firm per year. ${ }^{12}$ There is, however, some evidence of R\&D scale economies within a therapeutic area. ${ }^{113} \mathrm{R} \& \mathrm{D}$ intensity may exert a positive impact on $\mathrm{R} \& \mathrm{D}$ productivity, but only up to a small threshold-level of investment reached early on. Over the long term, R\&D intensity may be a driver of firm profits. ${ }^{114}$ Firm size may be associated with the production of knowledge, however. The overall level of a firm's research spending has been found to be associated with the number of patents in its drug discovery programs. ${ }^{115}$ Moreover, the quality and focus of these patents (i.e., number of patent citations, smaller number of patent claims) may be positively related to the number of new product introductions. ${ }^{116}$

A recent study, however, does find a positive relationship between a firm's experience in conducting clinical trials (measured by the number of ongoing research projects or the number of drugs the firm has developed independently or in an alliance) and the likelihood that a drug will successfully complete phase II and/or phase III trials (weak or no relationship between experience and the likelihood a drug will complete phase I). ${ }^{117}$ Firms that had developed twenty-five and thirty phase II and phase III drugs, respectively, had the highest success probabilities. ${ }^{118}$ Therefore, if a firm that is below these thresholds can absorb the development experience of the acquired firm, acquisitions could improve $\mathrm{R} \& \mathrm{D}$ productivity.

Academics, consultants, and investment analysts have repeatedly found albeit in a disparate set of studies - that firm scale defined in terms of market value or sales force size has little impact on R\&D productivity. ${ }^{119}$ Pisano reports there is no relationship between the size of biotechnology firms and the novelty of their drugs in development. ${ }^{120}$ In a study prepared for a large pharmaceutical firm, analysts at the Boston Consulting Group (BCG) found that firm scale in the pharmaceutical sector had no relationship with innovation productivity (i.e., more predictable flow of NMEs) or with the ability rapidly to develop blockbuster drugs. ${ }^{121} \mathrm{BCG}$ analysts have also found scale to be unrelated to both the value and output of R\&D. ${ }^{122}$ Analysts at Booz-Allen report that the scale of a firm and its investment in R\&D is unrelated to the marginal return on innovation investment, while McKinsey analysts find no relationship between the scale of $R \& D$ spending and return on investment (measured as the NPV of products out of research). ${ }^{123}$ Analysts at Goldman Sachs found that three of the top five pharmaceutical firms, measured in terms of the net present value (NPV) of their late-stage pipelines, scored below the global sector average in productivity (pipeline NPV divided by capitalized 
R\&D). ${ }^{124}$ Finally, a recent analysis shows that pharmaceutical firms that relied heavily on M\&A lagged behind others in their NME output; acquisitions primarily helped small companies, but not large ones. ${ }^{125}$

Finally, there is mixed evidence regarding the impact of increased scale via M\&A on R\&D investment, R\&D productivity, project portfolios, and project success. One recent (but preliminary) academic study reports that mergers during the period 1990-2007 increased the chances of success of projects initiated post-merger in all three phases - an effect independent of the effect of firm scale. ${ }^{126}$ Conversely, a CenterWatch study of eleven large combinations between 1988 and 1999 found a drop in R\&D spending growth from 7.7 percent pre-merger to 3 percent post-merger; while growth in $R \& D$ spend increased after three years to pre-merger levels, the spending level lagged industry averages. CenterWatch also reported a small rise in the number of NDAs one-year post-merger but a 10 percent drop in the number of development projects; three years post-merger they reported a one-third drop in NDAs and a 34 percent reduction in total development projects. ${ }^{127}$ Another study suggests that larger firms are slower to terminate unsuccessful or outlived research efforts. ${ }^{128}$ In both reports, these findings are viewed as having negative implications for R\&D productivity. Indeed, some pharmaceutical firms now believe there are diseconomies of scale in research, and have experimented over the past decade with smaller, more disease-area-focused organizational models (e.g., centers of excellence for drug discovery, or CEDDs, at GSK).

Based on such findings, Roger Longman (then managing director of pharma at Elsevier Business Intelligence) concluded that, "The combination of two large but relatively weak players makes it more difficult to rejuvenate the now combined R\&D program as it simultaneously increased the value required from new products. A $\$ 10$ billion company needs a much bigger product to grow 10 percent than does a $\$ 5$ billion company." 129 Similarly, CenterWatch concludes that M\&A disrupts internal operations.

\section{Relationship between scale and stock price, sales, market share, and profitability}

A spate of recent academic studies has reached different conclusions regarding the impact of M\&A on financial outcomes. One study of 160 pharmaceutical acquisitions between 1994 and 2001 found they created positive shareholder value. The acquirer's cumulative abnormal stock market return for deals involving biotechnology or technology companies was 2.8 percent, the return for non-biotechnology R\&D firms was 4.3 percent, and the return for firms with mature products and R\&D capabilities was 5.3 percent. ${ }^{130}$ Abnormal returns were higher under certain circumstances: when the acquiring firm 
rmaceutical firms that relied NME output; acquisitions ones. $^{125}$

mpact of increased scale via :oject portfolios, and project study reports that mergers inces of success of projects zct independent of the effect of eleven large combinations ding growth from 7.7 percent th in R\&D spend increased nding level lagged industry se in the number of NDAs the number of development ne-third drop in NDAs and a ts. ${ }^{127}$ Another study suggests ccessful or outlived research d as having negative implicanaceutical firms now believe ve experimented over the past organizational models (e.g., )s, at GSK).

then managing director of ided that, "The combination $t$ more difficult to rejuvenate ineously increased the value mpany needs a much bigger lion company." 129 Similarly, :rnal operations.

\section{t share, and profitability}

ifferent conclusions regarding study of 160 pharmaceutical r created positive shareholder ock market return for deals es was 2.8 percent, the return :ent, and the return for firms ras 5.3 percent. ${ }^{130}$ Abnormal zes: when the acquiring firm made equity payments to the target, when the acquiring firm had prior strategic alliance experience with the target, and when the acquiring firm had prior sales and research experience in the same therapeutic category as the target firm. The abnormal stock return methodology captures investors' perceptions of the impact of mergers at the announcement date, rather than actual performance of the combined firm following the merger.

Conversely, a study of 405 mergers among US pharmaceutical firms between 1981 and 2004 found positive abnormal returns in the short term for acquisitions involving single units or products, but not for mergers. Acquisition deals yielded improvements in operating cash flow return but not return on equity. While mergers did not add value, they also did not destroy value. ${ }^{131}$

Another study of sixty-five pharmaceutical deals (with transaction values over $\$ 500$ million) between 1985 and 1996 showed that, on average, these deals also created little shareholder value. Target firms experienced a positive 13.3 percent average abnormal stock market return (over a three-day window), acquiring firms experienced a negative 2.2 percent abnormal return, and the combined firm reported a positive 0.6 percent abnormal return. ${ }^{132}$ This pattern of positive returns to investors of the acquired firm, negative returns to investors of the acquiring firm, and essentially no combined effect, is also observed in another study of twenty-six pharmaceutical mergers as well as the general industry literature on abnormal stock market returns following merger announcements. ${ }^{133}$ Some of the pharmaceutical M\&A deals fared better than others, however. The greatest shareholder value was created in large horizontal mergers involving the top thirty firms and cross-national transactions; the greatest shareholder loss was generated in vertical mergers involving PBMs.

An additional study of 202 pharmaceutical and biotechnology deals between 1988 and 2001 involving transaction values over $\$ 500$ million reported that mergers exert little impact on a firm's growth in sales, operating profit, and enterprise value (market value of a firm's equity plus book value of their debt) in the first and second years following a merger. For a typical pharmaceutical firm, a merger reduces operating profits by 52 percent in the third year following a merger compared to a similar firm that did not merge. ${ }^{134}$ For a distressed firm, however, a merger increases operating profit in the third year following the merger, perhaps because of different implementation. For small firms, M\&A leads to lower growth in profits in the first year post-merger. This study highlights the importance of controlling for a firm's propensity to merge (or probability of merging). Firms with a high probability of merging (based on a firm's pre-merger characteristics) experience relatively slow growth in sales, employees, and R\&D over the next three years regardless of whether or not they actually 
merge. If one failed to control for the differences between firms that do and do not merge, mergers would appear to have an even worse impact on a firm's performance.

Likewise, research conducted by consultants and analysts tends to report little financial impact of M\&A. BCG, for example, found no impact of M\&A on ten-year shareholder returns or growth in market share. While mergers might avoid big declines in share price, they still underperformed the pharmaceutical index and suffered lower compound annual sales growth rates. ${ }^{135}$ Another BCG study reported no impact of pharmaceutical firm size on gross margins, net margins, or ten-year total shareholder returns. ${ }^{136}$ McKinsey consultants similarly reported no impact of firm size on shareholder returns from 1994 to 1999 and on market capitalization, and lower annual growth rates among merged firms from 1989 to $1999 .{ }^{137}$ Consultants at A. T. Kearney found no association between M\&A and economic returns in the late 1990s; indeed, none of the firms in the top quartile of their overall "value creation index" (summary measure of economic returns and probable value of pipeline and marketed products) had pursued an M\&A strategy at the time of their study. ${ }^{138}$ Pharmaceutical firms that had merged had average economic returns of 1.6 percent, while the return of firms that had not merged was 7.6 percent. These consultants attribute the lower return among merged firms to lower sales growth and higher SG\&A expenses, intangibles, and depreciation. Other studies from the same period found that M\&A did not improve the market shares of pharmaceutical firms between 1992 and 1997, did not improve their market valuations during the 1990s, and sometimes hurt them, and did not buffer firms from downturns in the market. ${ }^{139}$ Finally, Moody's Investors Service suggests that M\&A financed by debt - and in the face of patent expiries and productivity problems - can pressure the credit ratings of big pharmaceutical firms. ${ }^{140}$

Some consulting firms concur with academic studies that a pharmaceutical firm's success in generating value (e.g., development of blockbusters) is tied not to size or M\&A, but rather to its prior experience in the relevant drug category. Such experience - whether it is internally developed or externally acquired in strategic alliances (e.g., in-licensing) - reportedly helps the firm to devise superior clinical trials with faster speed and to incur lower costs in most phases of discovery, development, and commercialization. ${ }^{141}$

\section{Relationship of scale and scope with efficiency}

The academic evidence is weak and inconsistent regarding the presence of economies of large scale and scope in the pharmaceutical sector. One set of 
veen firms that do and do worse impact on a firm's

analysts tends to report ound no impact of M\&A ret share. While mergers iderperformed the pharual sales growth rates. ${ }^{135}$ eutical firm size on gross er returns. ${ }^{136}$ McKinsey e on shareholder returns nd lower annual growth isultants at A. T. Kearney returns in the late 1990s; ir overall "value creation robable value of pipeline itegy at the time of their had average economic lat had not merged was urn among merged firms atangibles, and depreciat M\&A did not improve 1992 and 1997, did not ad sometimes hurt them, rket. ${ }^{139}$ Finally, Moody's lebt - and in the face of isure the credit ratings of

ies that a pharmaceutical t of blockbusters) is tied nce in the relevant drug - developed or externally portedly helps the firm to incur lower costs in most zation. $^{141}$

zgarding the presence of eutical sector. One set of researchers concludes there are scale and scope economies in drug discovery and scope economies in drug development. ${ }^{142}$ Scope effects (e.g., the diversity of research programs) thus seem to be more evident than scale effects, suggesting the importance of internal knowledge spill-overs between programs. Nevertheless, both scale and scope effects are weak predictors compared to a firm's prior research track record (e.g., past success in a therapeutic class, the accumulated stock of patents in a therapeutic program). They suggest that scale and scope effects may also be small relative to enduring idiosyncratic features of a firm's organization and management of the development process. Evidence from consulting firms likewise suggests few economies in drug development. Firm size does not appear to promote either speed or efficiency in the conduct of clinical trials. ${ }^{143}$

Two other sets of researchers conclude there is only weak evidence that mergers drive cost efficiencies in pharmaceutical firms via scale and scope economies. One study observes that small firm size is associated with the probability of making an acquisition, suggesting that such transactions may result in some economies of scale. ${ }^{144}$ A second study finds that firms that merge do not experience a lower operating expense growth rate in the first, second, or third years following a merger compared to similar firms that do not merge. ${ }^{145}$

Academic evidence does point to cost efficiencies from mergers, however. One study of seven mergers during the period 1989-1996 found that merging firms experienced a lower percentage increase in cost per NME than nonmerging firms. ${ }^{146}$ Savings from horizontal mergers yield average cost reductions ranging from 11 percent to 29 percent of the target firm's sales. As a percentage of sales, mergers achieve cuts in administration (from 5 percent to 2 percent), marketing/sales (from 30 percent to 25 percent), in R\&D (from 15 percent to 13 percent), and cost of goods sold (from 30 percent to 20 percent) - yielding an increase in operating profit from 20 percent to 40 percent. ${ }^{147}$ Much of these savings result from a reduction of 8 percent to 20 percent in the combined workforce. Other analysts report consistent figures, such as an average of 11 percent cost savings and workforce reductions of 6 percent to 18 percent from M\&A. ${ }^{148}$ Workforce savings may be more difficult to achieve in friendly mergers, where no one side may be in charge, perhaps necessitating the search for efficiencies through additional mergers. ${ }^{149}$ Other savings come from the consolidation, closing, or sale of both R\&D laboratories and manufacturing plants. However, there do not appear to be any economies of large scale pharmaceutical manufacturing - other than the utilization of excess capacity. Analysts report that firm size is not associated with the manufacturing efficiency 
of small molecules. There may be efficiencies in increased plant size for large molecules among biotechnology firms, where manufacturing capacity is lack. ing. ${ }^{150}$ It remains puzzling, however, why merging firms do not experience a growth in profitability if they are able to realize the costs savings enumerated above. One explanation is that the onetime implementation and restructuring costs associated with mergers may offset the cost savings. Other evidence suggests that management in the combined firm retains most of the pipeline, physical assets, and R\&D talent of the target - all of which limits savings and increases the difficulty of decision-making. ${ }^{151}$

Economies in sales and marketing may be more tangible and evident. Larger firms are able to launch drugs faster than middle-sized firms, reaching as many markets in the first year as smaller firms can reach in two years, which may facilitate more global launches. ${ }^{152}$ Having superior sales and marketing muscle also helps larger firms to in-license more effectively: on average, large firms in-license the top products and earn 15 percent more revenue per licensed product than smaller firms. One example is Pfizer, which has often been viewed as a "partner of choice" given the company's strength in the area of commercialization. The activity that earned Pfizer this reputation was a series of very successful co-promotion agreements, where Pfizer would help commercialize a competitor's drug for a share of the profits. Pfizer used the size and strength of its global sales force to negotiate for marketing rights; with Pfizer as a partner, sales of the drug could significantly exceed what the original company could achieve on its own. In the late 1990s, Pfizer helped turn several of these partnered drugs into top sellers, including WarnerLambert's Lipitor, Eisai's Aricept, and Monsanto's Celebrex.

There is conflicting evidence whether or not large firms in-license more products overall. ${ }^{153}$ One explanation is that there was no measurable licensing "magnet effect" ten years ago, unlike the situation today. Scale allows large firms to dominate share of voice, build larger sales forces, and generate a greater numbers of sales calls per product and sales per representative. ${ }^{154} \mathrm{This}$ effect seemed most pronounced, again, at product launch, allowing superior rates of market uptake. It does not necessarily translate to higher levels o performance after launch. In any case, marginal returns on additional sales reps, though declining, remain positive, which is perhaps the strongest argument of all that larger sales forces do create value for leading firms. ${ }^{15}$

There is other evidence that suggests the scale requirements for drug discovery and early-stage drug development are, at best, modest. Strategic alliances between pharmaceutical and biotechnology firms have grown increasingly popular and may represent a substitute strategy for M\&A.
Alliances in which the pharmaceutical firms in-license the compounds developed by biotechnology firms allow the former to "buy the candy but not the store." Academic researchers argue that scale economies are also unlikely to hold given the rising number of new products developed by smaller biotechnology companies. If firms merged to achieve scale economies, one would expect smaller firms to be more likely to be involved in mergers. In fact, larger firms, as measured by the market value of their stock and debt, were more likely to be involved in M\&A in the 1980s and 1990s. Large firms apparently believe that there are advantages to growing even larger. ${ }^{157}$

\section{Summary of the empirical evidence: is there a disconnect with the rationales?}

The findings regarding the benefits of pharmaceutical M\&A presented by academic researchers and consulting firms are fairly consistent with one another. Firm scale has little relationship with R\&D intensity (inputs) and at best, a small impact on R\&D productivity (outputs) - arguably the two industry value drivers. Two academic studies and the bulk of the consulting firm evidence suggest little impact of M\&A on the firm's value, shareholder returns, margins, sales growth, or growth in market share. Finally, the evidence suggests there are limited economies of scale/scope in drug discovery and development, but more pronounced economies in sales and marketing. $M \& A$ does appear to help in reducing infrastructure costs in the short term.

To be sure, the empirical evidence does not test all of the hypothesized rationales for M\&A presented in the earlier section. The available evidence provides limited support for the ones tested, however. For example, M\&A does not improve R\&D productivity; instead, low R\&D productivity prompts M\&A. M\&A does not serve to increase either profit margins or firm earnings, although it may help to keep them stable by substituting short-term infrastructure savings for imminent gaps in product revenue streams (a hypothesis not examined). ${ }^{158}$ Similarly, M\&A does not lead to pronounced economies of scale or scope, particularly within R\&D, although it may help small firms to achieve some economies and help large firms- to maintain competitive scale and scope. Finally, there is no evidence one way or the other regarding the financial and performance impacts of $M \& A$ when used to foster disruptive change, provide a defense against acquisition, gain access to foreign markets, and extend capabilities to new therapeutic areas. However, based on the mixed economic track record of merged entities, it is likely that these rationales are employed as much to address strategic, organizational, political, or even personal priorities as to increase shareholder value. Thus, 
mergers serve to increase a firm's market share and perhaps satisfy the need to be among the leaders.

The empirical evidence does not speak to the possible verity of newer rationales for M\&A. For example, some have argued that larger size may help pharmaceutical firms pay for comparative effectiveness research that may be increasingly needed to justify drug approval by the FDA and other regulatory agencies (the UK's National Institute for Health and Clinical Excellence, or NICE), as well as reimbursement from payers. ${ }^{159}$

The inquiry into scale economies for large pharmaceutical firms and their M\&A activity has continued for nearly two decades. However, in recent years, there have been growing calls for pharmaceutical firms to downsize in several areas, including:

- number of therapeutic areas; ${ }^{160}$

- number of sales representatives; ${ }^{161}$

- number of researchers; ${ }^{162}$

- number of research sites: ${ }^{163}$

- size of real estate assets; ${ }^{164}$

- size of R\&D teams. ${ }^{165}$

There have also been calls for pharmaceutical firms to outsource/outlicense therapeutic programs to external firms (e.g., GSK's CEDDs), create pathwayfocused drug performance units (DPUs) using a virtual proof-of-concept approach with several outsourced activities (e.g., chemistry, assays, drug metabolism, and pharmacokinetic experiments), and develop investment boards with external CEOs and venture capitalists. ${ }^{166}$

\section{Is M\&A part of the problem?}

Several recent reports suggest that, rather than being a solution, M\&A may be causing part of the productivity problem inside the pharmaceutical industry. There are at least three basic rationales for this view. First, M\&A creates larger scale, which may hurt early-stage R\&D creativity in several ways. ${ }^{167}$ For example, it may be hard to get science done in a large firm where research priorities are driven by executives above. Scientific results below may accrue more slowly than do changes in what senior managers think is important Scientists may spend more time in larger firms on internal lobbying, meetings, networking around larger and more numerous R\&D sites, discovering who makes decisions, and getting results on the radar screen of the right people.
Second, R\&D is craft work based heavily on serendipity, preparedness, and luck; it is not a process that is easily optimized using rules, engineering, and formal standardization methods ("Taylorism"). ${ }^{168}$ For example, firms have developed new institutional rules to screen out unattractive compounds that have problems, and to screen in ideal drug compounds (e.g., "rule of five: molecular weight under 500 , no more than five oxygens or nitrogens").

Third, M\&A reduces the number of firms in the market, which may reduce the chances for innovation. Unlike the pharmaceutical sector, the biotechnology sector has thousands of small firms. According to one veteran industry executive:

By virtue of their number, small firms collectively can explore far more directions, and investigate areas that their larger, more conservative competitors avoid. However, only a small fraction of these small companies will be rewarded with an FDA approval. Individually, they are a much less reliable source of NMEs than large companies, but collectively, they produce more, for less. ${ }^{169}$

M\&A can hamper R\&D productivity in several other ways as well, With a merger, the new head of R\&D may shift research priorities and jettison promising projects, especially at the target firm. Scientists who are asked to drop their ongoing research may leave. Scientists may also be asked to pass along their prior research to other labs and sites, but may not be willing to share years of effort. M\&A also requires extensive and time-consuming reviews of the R\&D programs at each firm - scientific issues of safety and efficacy, commercial issues such as potential duplication and possible antitrust, strategic issues such as the merged firm's future direction - all of which slow down decision-making, hiring, and early-stage R\&D. M\&A typically also leads to layoffs and site closures, which can disrupt the work of scientists and loss of continuity in the interactions among professional networks; indeed, sometimes the closed sites were the source of prior drug discoveries. ${ }^{170}$ Finally, the many meetings involved in M\&A can distract scientists and disrupt their research. Managers at the target firm may also leave, especially if they have been more accustomed to science management in their smaller firm and sense a business management culture in the acquiring firm.

\section{Broader evidence on the value of size, concentration, and integration}

M\&A is an instance of what the field of industrial organization (IO) calls "horizontal integration." The vast literature on horizontal integration reveals 
that the majority of mergers fail to increase the value of a firm, fail to earn back within three years the equity capital invested, and earn an average negative return of (minus) 20 percent by year four. ${ }^{171}$ Only a fraction of firms engaged in mergers maintain their revenue growth post-merger and even fewer actu. ally accelerate this growth. The literature on pharmaceutical M\&A is consistent with the broader evidence.

M\&A also results in larger size and greater industry concentration (smaller number of larger firms). ${ }^{172}$ The ten largest pharmaceutical firms accounted for 45 percent of worldwide sales in 2009 - up substantially from 26 percent in 1979 (see Figure 3.4). The 10 literature has concluded that neither size nor concentration is a strong or consistent predictor of innovation. ${ }^{173}$ In theory, size might promote innovation via scale economies in $R \& D$, complementa. rities between R\&D and other activities, and access to financing for risky projects. ${ }^{174}$ Conversely, size can create bureaucracy, scale diseconomies, and stall points. ${ }^{175}$ In theory, concentration might promote innovation through enhanced profits and security that lead to greater R\&D investments; conversely, investments in R\&D might promote market power and concentration that lead to higher profits.

In practice, researchers observe no difference in $\mathrm{R} \& \mathrm{D}$ productivity between the larger pharmaceutical firms and their smaller biotechnology firm counterparts. Between 1985 and 2004, there was no difference between the two sectors in the cost of bringing a compound to market and the novelty of their products. ${ }^{176} \mathrm{M} \& \mathrm{~A}$ may, in fact, retard innovation by overemphasizing financial and systemic controls that promote greater managerial risk aversion. ${ }^{17}$ M\&A deals (or even just discussions) can also choke off the efforts of licensing departments to in-source new compounds, as well as overshadow opportunities for strategic alliances. ${ }^{178}$ Some researchers have suggested, however, there may be an interaction effect between size and concentration - large firms are more innovative in concentrated industries, while small firms are more innovative in unconcentrated industries. ${ }^{179}$ This relationship has not been tested in the pharmaceutical sector but is certainly consistent with the M\&A rationales espoused above. Increased size can pose a barrier to entry by new competitors, a characteristic of the pharmaceutical sector for a good portion of the twentieth century until the entrance of biotechnology firms. ${ }^{180}$

Other researchers suggest that $M \& A$ has increased industry concentration and reduced the number of firms active in R\&D. While this may not impac innovation at the firm level, it may retard innovation at the industry level. Recent evidence reveals a positive, nonlinear association between aggregate NME output and the number of companies: NME output rises more than proportionally with industry size. Industry executives hypothesize that more competitors accelerate knowledge spill-overs that increase the productivity of all firms. ${ }^{181}$ Alternatively, a greater number of firms may spawn greater portfolio diversity and increase the chances of finding new drugs. ${ }^{182}$

Overall, variations in firm-level innovation may be explained less by scale and M\&A activity and more by internal organization characteristics, idiosyncratic technological capabilities accumulated over time, drug development experience, past track records of R\&D success in therapeutic areas, and interfirm alliances and contracts that promote complementarities between internal and external sourcing of ideas and capabilities. ${ }^{183}$ These variations may also be explained better by execution of the M\&A strategy, including both pre-merger and post-merger integration processes. The next section examines these possibilities.

\section{Sources of value in M\&A: building capabilities to enhance} future performance

The strategy of M\&A may only be as valuable as the quality of its implementation (or execution). Execution is now considered to be the key concern of corporate executives and a key source of competitive advantage - both for the same reason: it is hard to do. Industry observers suggest that the importance of M\&A execution in the pharmaceutical sector is enhanced by the need for increased communication, speed of decision-making, fewer (rather than more) key performance indicators, putting new structures into place quickly, and boldness in creating change. ${ }^{184}$ Such agility is believed to increase shortterm savings and efficiencies from cost-cutting efforts, although its impact on long-term productivity is unknown.

Execution consists of several components, such as: strategic intent, horizontal (cross-boundary) networking, iterative idea testing and problemsolving, clarified decision rights, the ability to make decisions in uncertain environments, the ability to adapt to unforeseen events, performance milestones and metrics, etc. It also relies on managerial structures that permit decentralized decision-making, managerial autonomy within local business units, and high-performance cultures. ${ }^{185}$

There is considerable research on the M\&A process that impacts the M\&A outcomes reviewed above. One important issue is the strategic intent of a merger. An earlier section of this chapter suggested that pharmaceutical deals may have multiple rationales. Case evidence from the 2004 merger of Sanofi and 


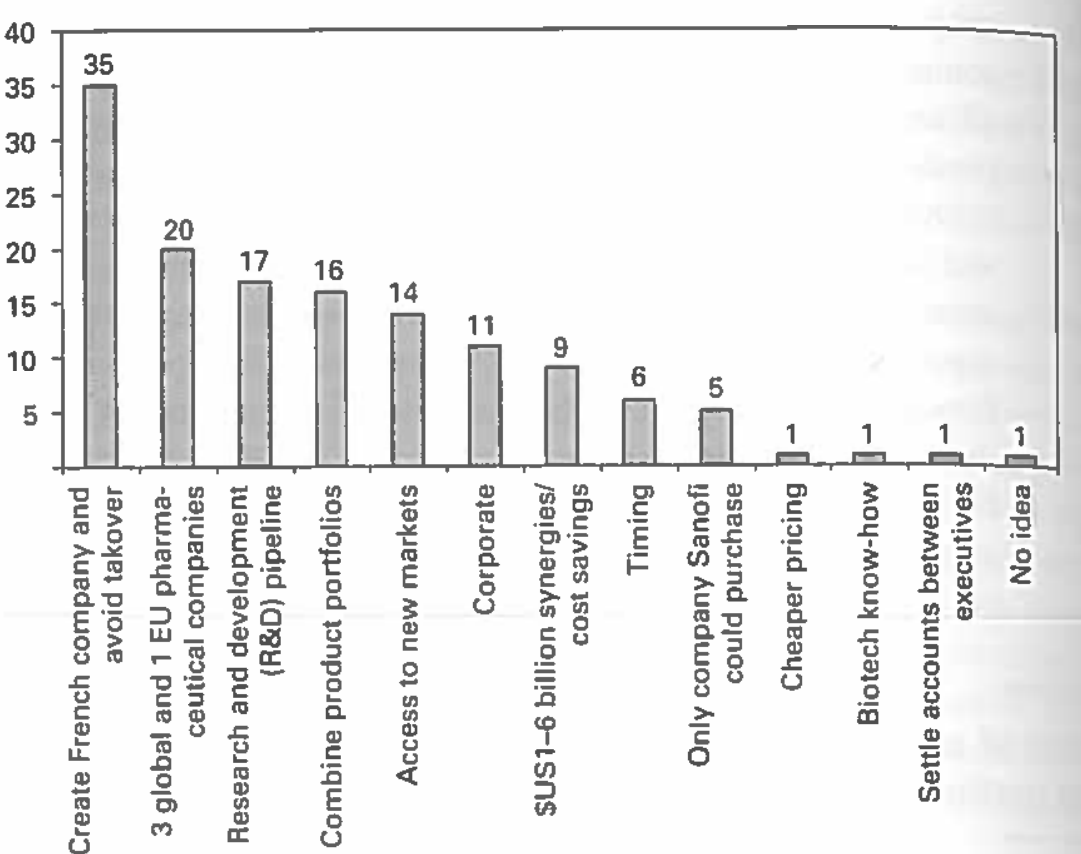

Figure 3.6 Top rationales for 2004 merger of Sanofi/Aventis

Aventis suggests that M\&A is not always characterized by rational management and consensus. Instead, the case describes the competing social, political, and commercial rationales and logics among the multiple stakeholders. ${ }^{186}$ Indeed, executives from the target firm in this deal, who were surveyed during an executive education course, mentioned several defensive reasons for the merger particularly the avoidance of takeover by the smaller acquiring firm, but many others as well (see Figure 3.6). This lengthy list suggests there has been a failure on the part of the acquiring firm to communicate a clearly articulated rationale, an omission mentioned several times by the executives. The downside is potential confusion and conflicting agendas. Moreover, as researchers have emphasized, the realization of any synergy from a combination requires a commonly shared strategic vision (clear and sometimes imposed) that serves as a continuous guide to the merger's operating plans - for example, what the synergies are and how they are to be realized. ${ }^{187}$

This approach may not be as straightforward as it sounds. Executives at large pharmaceutical firms claim that roughly 50 percent of their firms market value is comprised of the synergies among the pieces of their business (different therapeutic areas, product markets, and technologies). Combining these pieces with the pieces from another firm whose synergies one may not understand leads to a combined firm with a high proportion of intangible assets that have unproven productivity.

Strategic intent may also be hard to crystallize given the balancing act that pharmaceutical firms must do among their different strategies. M\&A is but one strategy taking place amidst other strategic initiatives such as alliances, licensing deals, and internal R\&D efforts. Firms need to combine and coordinate all four strategies to generate sufficient dynamic capabilities - their capacity purposefully to create, extend, or modify their internal base of resources. ${ }^{188}$ At the same time that firms search for new products, firms are also searching for new markets, such as satisfying unmet clinical needs (e.g., new therapeutic focus on specialty products and rare diseases) and exploiting emerging markets. This combination of demands is a lot of change for pharmaceutical firms to balance; it is unclear whether they can manage this change process and whether it will indeed create a sustainable business model. ${ }^{189}$

Of course, articulation of a merger's strategic intent is one part of the due diligence process. Another element is the selection of a merger partner. M\&A deals are notoriously vulnerable to problems of information asymmetry (i.e, the target firm knows more about itself than does the acquirer). Deals done out of haste or for defensive reasons may short-circuit the due diligence process of gathering information. Academic research suggests that access to information about the target during the pre-acquisition period is critical to the acquirer's success. Such access is critical in evaluating the target's intangible assets (early-stage pipeline, research capabilities, and technologies) and in avoiding overpaying for them. ${ }^{190}$ How is this information actually acquired? It may come through prior strategic alliances with the target, through conduct of research that parallels that of the target, and through prior sales experience within the same therapeutic area as the product(s) involved in the acquisition. This prior experience helps the acquirer better to evaluate the products, technologies, and capabilities it gains from the merger, as well as their "fit" with its own portfolio of assets. However, in order for this experience to benefit the acquiring firm and to become a capability, there must be management continuity and good processes of organizational learning.

On the post-acquisition side, a critical capability may be the leveraging of diverse knowledge both within and across therapeutic areas in the combined firm. Pfizer's recent acquisition of Wyeth justified the deal partially on the basis of the latter's capability in the manufacturing of biologics. ${ }^{191}$ Such economies of scope in ideas can result from the development of several integrative devices: ${ }^{192}$ 
- cross-therapeutic knowledge repositories that capture research data an reports;

- cross-knowledge networks built upon standardized and integrated information technology systems; ${ }^{193}$

- common central reporting process to monitor the progress of clinical projects across therapeutic areas;

- data-sharing and other forms of resource pooling; ${ }^{194}$

- internal research conferences to promote idea exchange;

- communities of practice that convene scientists across therapeutic areas with common interests;

- cross-disciplinary teams of scientists within therapeutic areas;

- intra-disciplinary teams of scientists across therapeutic areas;

- product strategy teams co-led by clinicians and senior commercial representatives; ${ }^{195}$

- collaborative discovery models that improve knowledge transfers and personal interactions between different types of scientists (e.g., biologists and chemists); $;^{196}$

- parallel R\&D efforts in both large molecules and small molecules;

- cross-team sharing of targets and compounds;

- cross-team discussions of whether compounds for initial indications that fail can be applied to secondary indications:

- interdigitation between early- and later-stage researchers using shared financial incentives (e.g., pay research scientists out of a bonus pool based on the number of drug compounds that proceed to testing each year), and or use of incentives to reward scientists for solving major problems or advancing potential drugs to proof-of-concept stage; ${ }^{197}$

- decentralized control over R\&D funding and decisions to initiate/terminate projects; $^{198}$

- parallel processing of various compounds for efficacy in different disease areas; ${ }^{199}$

- parallel processing of adjacent steps in the pharmaceutical value chain (eg, involvement of clinician teams in discovery, involvement of scientists in the preclinical and clinical stages, involvement of chemists in the manufacture of large molecules); ${ }^{200}$

- integration of certain functional areas (e.g., sales and marketing); ${ }^{201}$

- co-location of interdependent researchers within the firm;

- co-location of R\&D laboratories with external biotechnology clusters and non-profit research institutes; ${ }^{202}$
- teams of clinicians and scientists and mathematicians that analyze the compounds that fail in testing; ${ }^{203}$

- teams drawing on gene-based discovery research and clinical R\&D in "experimental medicine" programs; ${ }^{204}$

- focus on learning from others inside and outside the firm rather than on acquiring new technologies; ${ }^{205}$

- experimental R\&D or new R\&D operating models to get to proof-ofconcept more quickly (e.g., Eli Lilly's Chorus effort); ${ }^{206}$

- development of scientist middle managers in R\&D units to balance strategic intent of top executives with innovative proposals from researchers below to make critical investment decisions on a daily basis; ${ }^{207}$

talent renewal using post-doctoral programs. ${ }^{208}$

Such collaboration is believed to reduce both the time and cost of drug discovery and development, to promote serendipity in the discovery process through the free flow of ideas, and to increase a firm's stock of IP. ${ }^{209}$ Indeed, the recent spike in FDA new drug approvals in the first half of 2011 - twenty approvals in six months versus twenty-one approvals in all of 2010 - is being attributed in part to collaborative efforts between pharmaceutical firms and outside partners. ${ }^{210}$

Of course, there is the empirical question of the most effective mechanisms to document and leverage the knowledge and capabilities of the firms engaged in the M\&A. A long-drawn-out process is difficult to manage and keep on track. Success may hinge more on pre-merger planning, the rapid (and sometimes dictated) pace of combination, integration of systems across the merged firms, and often separate management of the target firm in order to preserve its intellectual capital.

Recent network research suggests two interesting caveats to these conclusions, however. First, based on research conducted in physician clinics, informal networks may be more important than the formal structural devices used to develop collaboration and stimulate consultation. ${ }^{211}$ Second, professionals may be more willing to learn from external rivals than from internal colleagues for reasons of status and self-esteem. ${ }^{212}$ The power of the network and its evolving nature are therefore critical for pharmaceutical companies to be better able to take advantage of accessing their customers.

Post-merger integration of the firms involved in the combination may be the critical requirement for M\&A success and the most important predictor of synergy realization. A major reason is that mergers must generate cost-savings in order to offset the premium paid to the shareholders of the target firm, as well as the costs of combination. ${ }^{213}$ Another reason is that the degree of 
interaction and cooperation between the firms may facilitate the consolidation of operations and transfer of capabilities needed to achieve any economie as well as reduce the time of that transition. Post-merger integration is difficil regardless of the M\&A strategy chosen. A "string of pearls" strategy of acquiring multiple smaller firms is difficult due to the limited number of desirable target acquisitions, the issue of repeated cultural assimilation, and the questionable ability to move the earnings needle. Conversely, a single large acquisition strategy is difficult due to the costs of disruption, integration, and culture clash. ${ }^{214}$

Research in industry suggests that 40 percent of mergers with a high potential for combination achieve low levels of integration. ${ }^{215}$ One major problem is that the executives of the acquiring firm do not spend sufficient time on the post-merger integration process. Executives may not appreciate the importance of this integration process, perhaps believing that the job is done when the financial consolidation takes place. Such executives me perceive the integration process as a "cost-shaving exercise." Other common problems that detract from synergy realization include the slow pace of integration, integration of different systems for drug discovery, integration of diverse cultures, the loss of key executives and scientists from the target firm, the perception of a takeover on the part of the target firm, disruptions to ongoing operations, harnessing best practices that reside in the target, and failures to communicate merger progress throughout the organization. ${ }^{216}$

Solutions to these problems are time-intensive and costly. One factor that may reduce costs includes the degree of post-merger cooperation between executives of the acquiring and target firms. Such cooperation may be facilitated by prior strategic alliances and working relationships between the two firms. ${ }^{217}$ From this viewpoint, prior alliances not only serve to foster greater access to information about the target but also provide greater familiarity with its personnel. ${ }^{218}$

Pharmaceutical firms face multiple options regarding how to integrate their respective operations. Some have taken an "absorption' approach (Pharmacia and Upjohn), while others have taken a 'symbiotic' approach (P\&U and Monsanto), while still others have taken a "preservation" approach. ${ }^{219}$ Researchers suggest that mergers between pharmaceutical and biotechnolog firms may need to follow different post-merger integration approaches based on the acquisition motives of the pharmaceutical firm, the competencies and tacit knowledge of the biotechnology firm, and the respective cultures of both sides. In general, pre- and post-merger integration strategies suggest the critical importance of "execution."
Finally, there may be other strategies beyond mergers that confer value on pharmaceutical firms. One may be the simple avoidance of M\&A and its distractions - for example, eschewing the acquisition of genomics companies as well as the automation technologies (high-throughput screening, combinatorial chemistry) discussed in Chapter 5 . There are huge disruptions and costs entailed in shifting to a genomics-focused R\&D approach. ${ }^{220}$ The payoffs from such a shift for gene-based drug discovery may be ten to fifteen years down the road, leading some critics to label it an expensive fiasco. ${ }^{221}$

Another strategy of "drug-hunting" may involve the hiring of additional drug discovery scientists to increase talent and expertise on projects in order to: improve the understanding of the disease and be able to better model it, to identify the right targets for prosecution, and to both increase the number of compounds and improve their quality. ${ }^{222}$ These talented individuals tend to serve as substitutes (rather than as complements) to a firm's collaborative and intellectual capital. ${ }^{223}$ A related strategy of "disease hunting" is seeking out areas of unmet clinical need and subsequently developing research teams to address them. ${ }^{224}$

A third strategy is speed: earlier termination of unfruitful research projects and the shortening of times a drug spends in each phase of research (e.g., smallscale clinical trials on experimental medicines). Recent research suggests that phase II and phase III attrition is the single biggest contributing factor to R\&D productivity; efforts to terminate unfruitful projects earlier may help. ${ }^{225}$ While such an approach increases the absolute number of failures, these failures are celebrated and viewed as an important source of learning. ${ }^{226}$ Executives at El Lilly attribute their recent pipeline success to these attributes. ${ }^{227}$ The Chorus Group, an autonomous division within Lilly, has specifically been charged with designing and implementing a lean approach to generating clinical proof-ofconcept (PoC) data as quickly and cost-effectively as possible. ${ }^{228}$

A fourth, related, strategy is greater mastery and closer integration across the internal value chain of the pharmaceutical firm - from ideation to project selection to development to commercialization. ${ }^{229}$ This approach would entail a better understanding of new business opportunities (including a view of what is happening at a firm's periphery), improved valuation and governance of new research projects, balancing rigorous business decision-making with good science, efficient project management and parallel processing of tasks, and integration of marketing personnel into the prior steps.

A fifth strategy is "do more with less." That is, focus on a smaller number of compounds selected for development and reduce the number of ongoing projects (but staff them more intensively). Related to this approach is the effort to cut R\&D spending, make fewer, larger bets in untrammelled areas of 
pharmacology that are truly breakthroughs (i.e., the opposite of the pursuing me-too products in blockbuster areas), and meet previously unmet clinical needs. ${ }^{230}$ A sixth strategy is labeled "jumpstarting" - finding new uses for existing but underexploited compounds, and reformulating existing products. ${ }^{231}$ A seventh strategy, commonly pursued today, is effective in-licensing of new products from biotechnology companies. Strategic alliances are an entire alternative strategy to M\&A that require enormous managerial attention. ${ }^{232}$

A final strategy is diversification - in effect, M\&A applied to firms making different types of products (e.g., generics, vaccines). ${ }^{233}$ Some observers now believe that diversification is the only avenue open to pharmaceutical firms at present to move the needle on earnings and maintain consistent cash flow. ${ }^{23}$ Others believe that diversified pharmaceutical firms should divest their non. core businesses. ${ }^{235}$ However, for the first time in recent history, there is now a divergence in the pharmaceutical sector's business models. ${ }^{236} \mathrm{~A}$ concomitant development has been the emergence of a "strategy master" position within the life sciences firm. ${ }^{237}$ While diversification means increased size, some firms have been pursuing de-diversification and smaller size by shedding some of their products and businesses. ${ }^{238}$ A prominent example is Pfizer's announcement in July 2011 that it will explore "strategic alternatives for its Animal Health and Nutrition businesses based on its recent business portfolio review to determine the optimal mix of businesses for maximizing share. holder value. The company is considering options that may include, among others, a full or partial separation of each of these businesses from Pfizer through a spin-off, sale or other transaction. ${ }^{239}$ Historical evidence suggests that de-diversification (also known as focus) has occurred since the 1980 s and may be associated with higher plant productivity. ${ }^{240}$

\section{The future of pharmaceutical M\&A and the value chain perspective} on innovation

The above review of the literature suggests that M\&A activity has exerted little impact on R\&D productivity and new innovation. Indeed, as other chapters in this volume make clear, the bulk of the innovation now occurring in the pharmaceutical market is being in-sourced from biotechnology firms using a variety of mechanisms (in-licensing, strategic alliances, acquisitions). There is a growing consensus that the task of drug discovery and development has become too complex for a single firm to handle on its own, and that it must now be accomplished through inter-firm collaborative models and deals - an

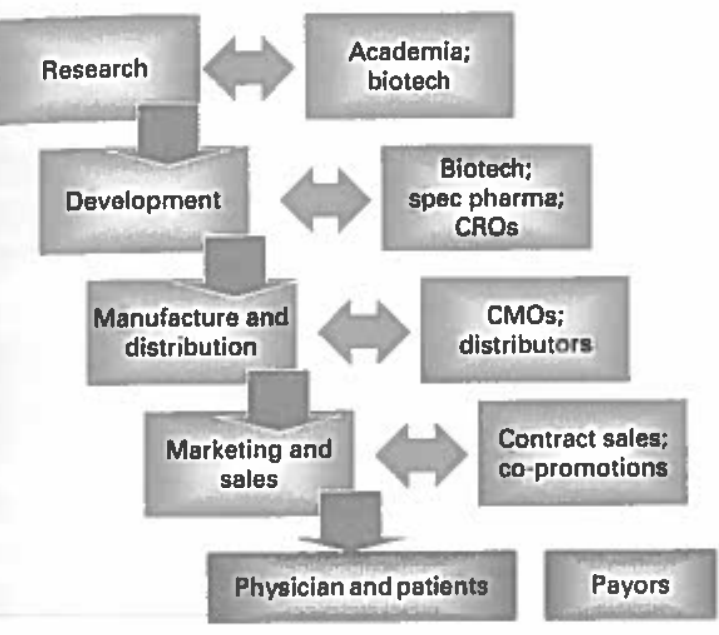

A closed system
Open, smal, nimble mode Imternally and externally focused innovation from an where Blockbuster capabla Risk sharing Intellectual property

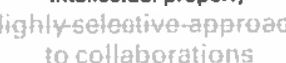

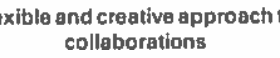

Qurt 3.7 Open-source innovation in pharma business model

instance of what is commonly referred to as "open source innovation" or innovation from anywhere. ${ }^{241}$ Some pharmaceutical executives refer to this as the shift from a closed-system to an open-system model of innovation where there is a much greater reliance on business development to create strategic alliances globally in discovery and development, manufacturing, and clinical trials involving more sharing of risk and IP. ${ }^{242}$ The goal is no longer internal structure and control but rather the development of innovative medicines that regulators will approve and payers will cover and reimburse. This interdependence inherent in open-source innovation is illustrated in Figure 3.7. Deal structures are depicted in Figure 3.8.

One reason for the growing prevalence of in-licensing is the consistency of the evidence that alliances improve pharmaceutical R\&D productivity, contrasted with the inconsistent evidence that mergers improve $R \& D$ productivity. By the time a product reaches consideration for an alliance, it will have a lowe risk than a compound in drug discovery. This decreased risk is attractive to companies, which seek to improve their overall success rate of bringing drugs to market. To that end, several academic studies conclude that drugs developed in an alliance are more likely to reach the market than drugs developed independently by an originating company. One study that examines 1,900 compounds developed by over 900 firms between 1988 and 2000 concludes that drugs developed in an alliance have a 9 percent and 14 percent higher probability of successfully completing phase II and phase III, respectively, than drugs developed by a single company. ${ }^{243}$ These positive effects are even stronger when the 


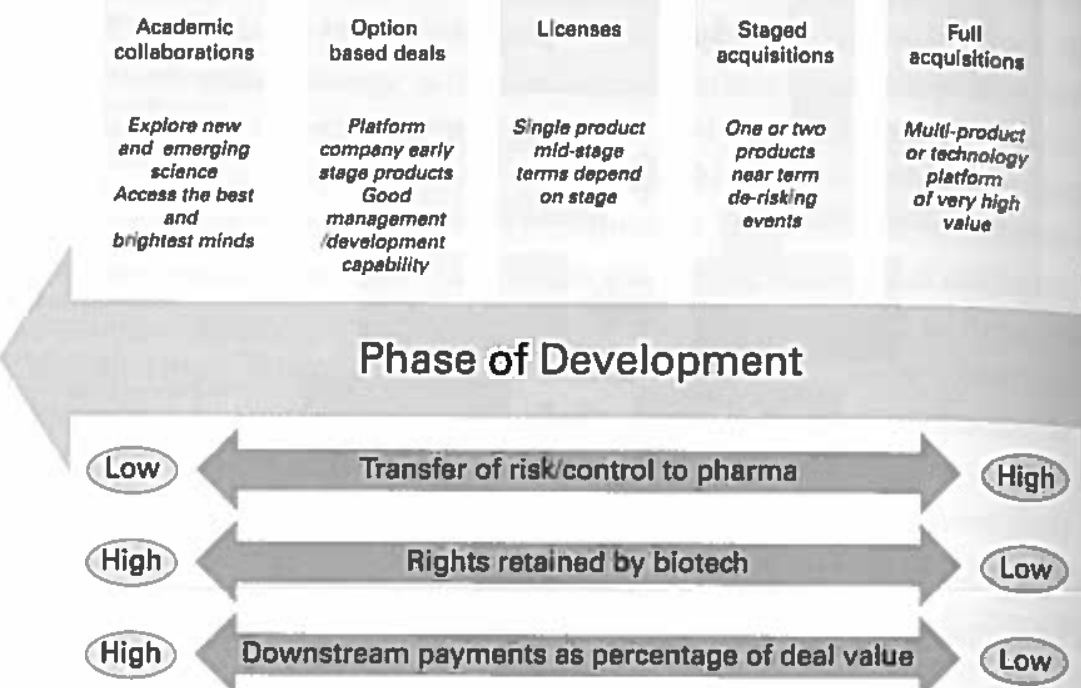

Figure 3.8 Deal structures in open-source innovation

in-licensing firm has considerable experience in drug development (in terms of the number of total compounds, not in terms of category-specific therapeutic experience). Two other studies arrive at similar results using slightly different samples and time periods: in-licensing is just as or more successful as in-house drug development of compounds. ${ }^{244}$ Moreover, large firms that are successful at in-licensing products from others can offer payers and pharmacy benefit managers a broad range of products for inclusion in formularies at discounted prices. In this manner, large firm scale leads to preference as a licensing partner which in turn leads to formulary access and thus greater sales. ${ }^{245}$

The problem with licensing, however, is that the available pool of late-stage licensing compounds is shrinking, while early-stage licensing is an entirely different game. This problem is particularly challenging for a company such as Forest Laboratories, which does not pursue drug discovery but instead relies exclusively on in-licensing its products. Although innovative in approach and risk-limiting, Forest's strategy faces increasing competition for later-stage products. Another problem with licensing is that the pharmaceutical firm diverts a significant portion of in-house R\&D funding toward innovation efforts elsewhere. While this approach saves the firm costs in the short term (fewer R\&D colleagues, fewer hard assets and physical facilities) and shares with others the growing risks of $R \& D$ and clinical trials, it may also threaten innovation prospects in the long term. ${ }^{246}$
Another problem with open-source innovation and in-licensing is that the capabilities needed for external alliances diverge from the capabilities needed for internal R\&D. The two systems require different organizational models, cultures, incentives, processes, and tools. While a company needs strong scientists to evaluate scientific opportunities and design drugs to prosecute targets, it requires a totally different skillset to manage people and oversee external R\&D. Strong scientific candidates may no longer be attracted to join a given pharmaceutical company if they will not actually be carrying out any research, and good managers within that company may not have the skills to design viable drug design schemes. The result is a slippery slope with (potentially) a continued decrease in $R \& D$ productivity. As for external capabilities, pharmaceutical firms may cede some of their current power to suppliers of candidates, the best of whom will eventually be able to command a high pricepoint. Thus, while in-licensing may be economical now, it is unclear whether the finances will remain that way.

To the degree that firms pursue a balance of internal and external R\&D, they must align open-source research (fully integrated pharmaceutical network, or FIPNet) with internal R\&D and overall business strategy (fully integrated pharmaceutical company, or FIPCO). ${ }^{247}$ To do so is not straightforward. Internal R\&D teams and therapeutic area teams feature elaborate industrial development operations, rational decision-making, best practices, and efficiency-management techniques to increase speed and throughput. Business development groups, by contrast, remain primarily transactionoriented teams that focus on filling pipeline gaps; as a result, they are less industrialized, less rational, and more oriented to chasing after and competing for compounds. ${ }^{248}$ The work of business development teams needs to be closely articulated with internal R\&D in order to access the external science, manage both internal and external projects as a portfolio of early stage $R \& D$, maximize the value of assets and investments wherever the returns are higher. ensure flexibility in contracting and deal structures, and actively nurture networks between internal scientists and those in biotechnology firms and academia. ${ }^{249}$

One unique model is ViiV Healthcare, a joint venture between GSK and Pfizer. The global specialist HIV company was formed by breaking down corporate barriers and sharing IP and assets from the complementary portfolios of the two parent companies. ${ }^{250}$ This approach enabled the new company to devote greater focus to this therapeutic area and develop new drugs Although ViiV is only one example, this model has been successful to date and may act as a blueprint for similar opportunities in the future. 
Merger activity is nevertheless likely to continue in the pharmaceutical sector for several reasons. First, the industry is still fairly unconcentrated leaving room for additional consolidation. Second, pharmaceutical firm continue to play a game of leapfrog using the latest merger to catapult then to a leadership position in global market share as well as to promote positive feedback. ${ }^{251}$ Third, a pattern of mergers historically tied to swings in the stock market (evident in other industries) may become more regular in the phar maceutical sector. Fourth, mergers in other sectors of the healthcare industry (e.g., among wholesalers and/or GPOs outside of the US) may prompt drug manufacturers to increase their size and thereby their bargaining leverage. Fifth, increasing use of pharmacogenomics to develop drugs targeted for specific genotypes, as opposed to a one-size-fits-all approach, may create stronger scale economies in drug development and sales as firms require more-specialized personnel. Sixth, pharmaceutical firms may need to experiment with new business models, thus requiring them to acquire or dispose of assets (and capabilities) along their internal value chain. ${ }^{252}$ Seventh, costcontainment pressures are likely to accelerate worldwide. Hopefully, the potential for real cost-savings will accelerate as well. Though the pursuit of operational efficiency may have its limits, it forces companies to think innovatively in challenging the productivity frontier.

Further merger activity may also be spurred by the growing activism of payers (public sector outside of the US, both public and private inside the US), fiscal intermediaries (HMOs, PBMs), and their costcontainment efforts. Payers are currently focused on containing the costs of specialty pharmaceuticals, which have grown from 24 percent to an estimated 27 percent of total drug spend between 2007 and 2010, using a variety of strategies (prior authorization, clinical guidelines, case management, specially formularies, specialty pharmacy contracting, and co-insurance). ${ }^{253}$ Payers have also focused their cost-containment efforts on pushing brands to lower tiers on formularies (with higher co-insurance) and converting prescriptions from branded to generic drugs. Increased size may help pharmaceutical firms to finance investments in assembling data and detail teams to call upon payers (and physicians) to demonstrate their drugs are worth paying for. ${ }^{254}$ Larger size and dominance in regional markets in the world may help to buffer pharmaceutical firms from public criticisms regarding rising healthcare costs and the contribution made by new drugs and their prices to those rising costs. Issues of national pride, fears of foreign takeover, and protection of domestic industries may also spur M\&A, as evidenced by recent events in France and Japan.
Closer collaboration with payers (at least in the USA) may make sense for other reasons as well. Reports indicate the FDA will rely on the databases held by insurers as well as large delivery systems for purposes of drug surveillance and safety. ${ }^{255}$

These considerations suggest that future value creation in the pharmaceutical sector may be tied to the broader value chain in healthcare (see Figure 1.1), and larger firms may be better positioned to deliver value in this new environment. Larger firms may seek to develop partnerships with payers/ purchasers of healthcare; however, these relationships may not have been well organized or well managed in the past. ${ }^{256}$ Pharmaceutical firms have often used such partnerships to protect and sell their pills by getting them on the payer's formulary and then agreeing to meet some patient spending targets or participate in risk-sharing arrangements. ${ }^{257}$

The ability of pharmaceutical manufacturers to maintain their prices and finance their merger activity depends on the willingness of payers to continue to pay for the innovation, which itself may be tied to the ability of pharmaceutical R\&D to deliver on value (and not just on product line extensions). ${ }^{258}$ There have already been some efforts in the US and in Europe to assess the clinical effectiveness of new drugs and consider tying these assessments to payer coverage for the products. The National Institute of Health and Clinical Excellence in the UK has rejected several new drugs in 2011 for lupus, cancer, and multiple sclerosis on the grounds that they are not worth the price. ${ }^{259} \mathrm{This}$ approach is a variant of a wider movement called "pay for-performance" in the provider arena, where hospitals and physicians get reimbursed or differentially reimbursed for the quality of care they deliver to patients. As part of the December 2003 Medicare Modernization Act, the US Congress barred the Medicare program from using head-to-head clinical trials to make decisions about which drugs to reimburse. Nevertheless, government officials are still calling for "practical clinical trials" (phase IV) that compare the risks and costs and benefits of alternative interventions. ${ }^{260}$ Industry observers have also called for an increasingly pragmatic approach to $R \& D$ to meet the needs of payers and regulators. ${ }^{261}$

A similar model might be applied to the reimbursement or payment coverage for new drugs based on their cost-effectiveness. Manufacturers have already begun to make "total cost arguments" for their products (i.e., that the superior clinical benefits of their products warrant higher prices) based on their own pharmacoeconomic studies. For the purposes of credibility and public payment, however, manufacturers may have to submit their products for outside evaluation and comparison with those from rival firms. Such 
comparisons might include a host of diverse outcomes including symptom alleviation, health status and lifestyle improvements, workplace productivity gains, substitution for more expensive therapies, and long-term health risks One of the first examples of this approach in practice is Effient, a drug co developed by Daiichi Sankyo and Eli Lilly, where the cost-effectiveness of this therapy was demonstrated as part of the clinical trials. ${ }^{262}$

Pharmaceutical firms might also consider how they can assist payers in their cost-containment efforts. Employers and insurers believe that national health expenditures (NHE) and prescription drug expenditures are increasing at a rate that is not sustainable. Indeed, recent estimates from CMS in the US show that between 2009 and 2019 NHE will increase 6.1 percent, while retail pharmaceutical spending will increase 6.3 percent. The annual growth rate in the latter will slow down in the first part of the 2010-2020 decade with patent expirations and the use of generics, but will then accelerate in the later part of the decade due to the arrival of new drugs and biologics. ${ }^{263}$ Consequently, payers feel they need to protect the affordability of prescription drugs for their enrollees. Some of the measures they are considering include more rigorous cost-effectiveness analyses of new drugs, a focus on patient outcomes, innovative utilization management programs, and reference pricing. ${ }^{264}$ Such efforts are especially likely as the newer (and relatively expensive) biotechnology drugs become available to patients. However, pharmaceutical companies are also being creative in how they maximize both profits and patient access. One example is with Novartis's Gilenya, which is the first oral treatment for relapsing forms of multiple sclerosis, approved by the FDA in September 2010. Priced at $\$ 48,000$ per year, Novartis offered to cover patients' entire co-pay to enable greater access to this novel treatment. "It seems the best strategy for a pharmaceutical company is to price their drug as high as they possibly can and offer that co-pay assistance broadly to insulate consumers." 265 At present, insurers have limitations on accessing information on how the co-pay portion of a patient's prescription is covered. As such, they are unable to determine true affordability of medicines for their enrollees, though a change in this arena would result in a further evolution of the coverage landscape.

Pharmaceutical firms must collaborate with managed care organizations on diagnostic prescribing requirements for new expensive biologics, and then agree to market within those criteria. They must also work on ensuring proper drug utilization, adherence, and compliance, and stringent utilization management programs to control costs. They can also help payers with pharmacoeconomics, modeling tools for evidence-based medicine, and technology assessment. ${ }^{266}$ For example, pharmaceutical and managed care companies can seek to model patient outcomes using their own respective data from Ingenix and IMS (as well as simulations), share their results, and refine each other's understanding of the disease and treatment process. They can then try to customize the results to the managed care plan's enrollees, develop joint programs, aid clinicians in their decision-making and perhaps gain greater credibility in the eyes of clinicians. ${ }^{267}$ Pharmaceutical and biotechnology firms may choose to partner with "specialty pharmacy providers" who physically distribute these biological products and/or support/train providers in their utilization. ${ }^{268}$ Pharmaceutical firms may also seek to work with employer coalitions on pain management or rheumatoid arthritis to improve worker productivity and decrease workmen's compensation costs.

Currently in the US, both federal and state governments are funding demonstration programs in some of these areas in order to reduce the costs of healthcare. Pharmaceutical firms are well-positioned to assist them in these efforts due to the massive amounts of information and understanding they have developed on diseases, the drug therapies applied to them, and patient compliance with those therapies. They have also developed capabilities in dealing with doctors and patients and providing them with information, which can be important to payers in terms of providing greater access and outreach to underserved populations. As is evident by Pfizer's past partnership with the State of Florida's Medicaid program in the early 2000s, pharmaceutical firms can engage in innovative programs with payers whereby the former gains formulary benefits and the latter limits their financial risk. However, this program was recently suspended, so the trajectory of these payer-pharmaceutical partnerships is unclear.

The difficulty facing pharmaceutical firms is that there are fifty different state customers in the Medicaid program. Moreover, these customers are acutely conscious of their Medicaid spending, since it consumes the second largest percentage of state-generated revenues (21 percent overall, 12 percent net of the federal government's share), second only to state spending on education. Moreover, average annual rates of growth in Medicaid spending during the past decade (2000-2009) were highest for prescription drugs ( 11.7 percent), compared to acute care ( 9.6 percent) and long-term care (5.8 percent). ${ }^{269}$ Pharmaceutical firms will need to develop customized solutions to each state's fiscal problems and form partnership networks with officials, legislators, clinicians, and patient interest groups in each state. Most significantly, these customers want services and solutions, not products. ${ }^{270}$ 
On a global front, pharmaceutical firms will need to target European governments and their ministers about governmental budgets and limits on drag spending. While rationing has succeeded in holding down national health expenditures as a percentage of gross domestic product, it has also discouraged firms from launching some drugs in Europe, has delayed the launch date of other drugs, and has led to the loss of $R \& D$ jobs and their associated economic benefits to the US. It is conceivable, therefore, that European health policies have actually reduced overall welfare in those countries. ${ }^{271}$

There are other potential benefits from value chain alliances between pharmaceutical firms and payers. These benefits include collaboration in the design and provision of other clinical integration programs (e.g., health knowledge access, case management), the establishment of more cost-effective clinical protocols, and the development of consumer-enabling tools. ${ }^{272}$ Indeed, as these alliances develop, and depending on the growth of the consumerism movement, pharmaceutical firms may offer more interactive information on diseases/products/treatment options, more information on disease state awareness, compliance assistance and reminders, and assistance with high-cost products. ${ }^{273}$ The role of social media as a tool in these com. munication efforts is currently being defined as pharmaceutical companies seek new ways to connect with their customers. Thus, manufacturers and payers may need to adopt a new, shared paradigm that focuses more on patients and less on products, focuses on helping to prevent and cure disease, reviews the innovation pipeline at its early phases and assesses how drugs generate value to patients, and cooperatively designs clinical trials that address the cost-effectiveness questions of interest to payers. ${ }^{274}$ As part of this dialogue, pharmaceutical firms may need to recognize that not all innovative programs they pursue are worthwhile from the payers' perspective, just as payers may need to recognize that certain innovations and breakthrough products deserve fast-track approval and adequate reimbursement.

Value chain alliances with both payers and patients will increase in importance as the pharmaceutical sector shifts from a one-size-fits-all approach based on blockbuster drugs to more of a customized therapeutic approach focused on specific diseases and more narrow patient populations. In this latter model, competitive success may rely more on intimate customer knowl. edge and relationships, especially if the customers (physicians, patients, payers, intermediaries) exert more influence in the prescribing decision. Success may also hinge on the types of customized services pharmaceutical firms can provide these different customer segments, including information education, and management support. ${ }^{275}$
In addition to value chain alliances with payers, pharmaceutical firms will need to develop traditional value chain alliances with new types of physicians and new value chain alliances with traditional physician customers. With regard to the former, pharmaceutical firms will have to supplement their marketing efforts directed toward primary care physicians with marketing efforts directed at specialists. This move will be necessitated by the growing prominence of biotechnology products that target higher severity conditions in smaller patient populations that are typically treated by specialists (e.g., HIV, congestive heart failure, multiple sclerosis). ${ }^{276}$

With regard to the latter, pharmaceutical firms may further supplement their traditional model of drug discovery leading to new clinical treatments. For example, pharmaceutical firms are extending and deepening their networks with academic medical center (AMC) physicians and researchers in order to access basic biology, test the potential of novel targets in man quickly, monitor clinical studies that lead to breakthroughs in basic biomedical sciences, improve understanding of the mechanisms involved in disease (treatments that lead to new discovery), and reduce the attrition rate from proof-of-mechanism to early phase II. ${ }^{277}$ In this manner, there can be a bidirectional flow of knowledge and learning between bench scientists and clinicians. Such physician-scientists may be essential for pharmaceutical firms' search for new drugs. ${ }^{278}$ A Town Hall convened in Kansas City, Missouri in July 2010 explored how universities and non-profit organizations can define new models of working with life sciences companies to enhance drug development efforts and bring safer, more-effective drugs to market. ${ }^{279}$

Pfizer has taken a different approach by forming centers for therapeutic innovation across eight cities in the US to accelerate the translation of biomedical research into medicines and feed Pfizer's pipeline of biologics. These centers are designed to be equal partnerships doing joint studies on novel compounds with physical lab space to promote co-location of Pfizer scientists with academics. ${ }^{280}$ In 2009 , Pfizer became the "first pharmaceutical company to be accredited by the Association for the Accreditation of Human Research Protection Programs (AAHRPP) for ensuring the protection of human subjects taking part in early stage clinical trials." ${ }^{281}$

There are numerous examples of such fruitful interaction. The Cleveland Clinic laboratory developed intravascular ultrasound imaging technology to study plaque build-up. Pharmaceutical firms are now using this technology to test their atherosclerosis drugs. Similarly, the paclitaxel-coated coronary stent (see Chapters 1 and 6) was developed by asking physicians different kinds of questions, such as "what does the body do to these stents and why do they 
fail?" The answers provided by clinicians helped device makers to solve the scar tissue problem of earlier stents. ${ }^{282}$ In addition, there is growing involve. ment of children's hospitals, universities, and non-profit research institutes in drug discovery and early-stage development (e.g., phase I clinical trials) Hospitals which conduct a minority of clinical research are expanding their research capacity and can act as new partners. Their efforts serve to accelerate the translation of new compounds from discovery into clinical use, as well a to handle some of the risks of development that pharmaceutical firms do not want to shoulder. ${ }^{283}$

Nevertheless, there are obstacles to deepening research ties with clinicians and hospitals. First, due to managed care pressures on their incomes, physicians are spending more time seeing patients and less time as clinical researchers. According to the Federation of American Societies for Experimenta Biology (FASEB), the number of physicians listing research as their primary activity dropped 6 percent between 1980 and 1997 . Second, a growing number of AMCs are blocking or threatening to block access to their physicians by pharmaceutical sales representatives. The clinical research monies they get from drug companies pale in comparison to NIH funding, while the rising costs of new drugs represent one of the fastest growing components of hospital spending. Third, the US government has paid increasing scrutiny to industry relationships with physicians due to concerns about conflicts of interest that might generate more or inappropriate utilization. ${ }^{284}$

What is not clear in these future scenarios is the value of large pharmaceutical firm size. Drug companies need to evaluate the impact of future M\&A on the efficiency of their own internal value chain as well as their ability to collaborate in the external healthcare value chain. Executives may rightly believe that larger scale provides a seat at the table and, thus, a greater voice in any discussions with payers and consumers. However, they may also need to document how their increased scale serves to address major policy issues of importance to these other constituencies: how to reduce the cost of care (or at least contain the rise in spending), how to improve quality of care and reduce medical errors, and how to increase access to healthcare for the underserved. Moreover, given the risin cost of pharmaceuticals and their growing share of national healthcare budgets, pharmaceutical firms may need to document how their products simultaneously address two of these policy issues (e.g., cost-effective therapies).

Additionally, in the face of diminishing productivity and pressures on their profits, pharmaceutical companies will be forced to manage themselves in ways that other firms now do. They will need to increase their efficiency in procurement (e.g., by consolidating purchases across departments and regions), automate their transaction processing, and consider outsourcing non-core functions (e.g., information technology, human resources, finance, manufacturing). ${ }^{285}$ In this manner, pharmaceutical firms will confront whether or not they need to remain fully integrated companies and deliberate the key issue in corporate strategy: make (in-house) versus buy (on the market). This issue is already on their doorstep in the form of whether to develop the capabilities of biotechnology firms themselves or partner with these firms in alliances. It is also an issue that has proven troublesome for many Fortune 500 firms, as evidenced by the massive unbundling and de diversification of their businesses in the late 1980s and early 1990s. The issue may ultimately dwarf the importance of whether or not to engage in M\&A.

Finally, it will be interesting to observe the evolution of the pharmaceutical sector as companies place differing strategic bets on their futures. Although M\&A has historically been associated with an increase in size (and thus conveys the accompanying benefits and challenges of size), the current drivers of pharmaceutical innovation may shift M\&A from being a goal to being a tool. This transition would result in increased creativity in identifying innovative opportunities for growth, and a more dynamic landscape within the pharmaceutical sector.

Lina Saigol, "Consolidation is Key to Pharma Stability," Financial Times (Mar. 10, 2009): 20-21. 2. The chapter deals with mergers among large pharmaceutical firms, since these have been the historical focus of academic researchers and consultants. Acquisitions of biotechnology firms by pharmaceutical firms are of growing prominence and importance due to (a) the pipeline gap in big pharma and the concentration of the industry pipeline in the hands of

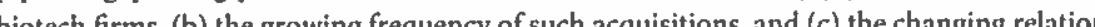
ships between pharmaceutical and biotechnology firms over the past decade (see Chapter 4 below). Future research should study these mergers as well.

3. Another important topic not squarely addressed here is the in-licensing of products and the comparative effectiveness of M\&A and in-licensing. Thus, for example, the researcher might inquire whether licensing is a more effective way of enhancing performance, and whether licensing is a vible oplion given the industry's pipeline squeeze There is case evidence, cited below in the chapter that M\&A can be triggered by the need to protect licensed revenue streams (Pfizer and Lipitor). The comparative effectiveness of licensing versus M\&A hints at the possible need for new intermediate models of R\&D such as the "orchestrator of a network of autonomous research units," which might more effectively connect intellectual property assets with infrastructure and experience without compromising entrepreneurialism. These issues are discussed toward the end of the chapter. 
4. The authors wish to thank Martin Reeves at the Boston Consulting Group for his input in developing this section.

5. NME: an active pharmaceutical ingredient that has never before been marketed in the US in any form. US Food and Drug Administration, www.fda.gov/Drugs/informationondrugs ucm079436.htm\#N. IND: an application to the US Food and Drug Administration (FDA prior to initiating clinical trials that contains information in three broad areas: animal pharmacology and toxicology studies, manufacturing information, and clinical protocol and investigator information. US Food and Drug Administration, Investigationai New Dh (IND) Application, www fda gov/dust (IND) Appliciton, we andapproved/approvalapplications/investigationalnewdrugindapplication/defaulthtm. FHH: limited, early-stage clinical studies; start of Phase I trials. PoC: an NME that survived early clinical testing (for safety and pharmacokinetics) will progress to small trials in a patient population (Phase II). Generally, the "PoC study" is designed such that the sponsor will have good idea whether the NME is actually going to work for the intended indication Phase

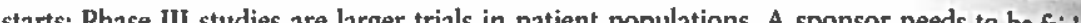
chance the confident that the NME is safe and eftetive in order to justify the investment needed for Phase III. NDAs: a company typically files an NDA with positive data from Phase III trials.

6. Jeff Goldsmith, "Has the US Health Technology Sector Run Out of Gas?", Harvard Business Review Blog (Apr, 12, 2010)

7. Twenty new molecular entities (NMEs) were approved by the FDA in the first half of 2011, which may signal a turnaround in the industry's productivity.

8. Jerry Cacciotti, Jeff Hewitt, and Bill Shew, Shadow of a Drought (New York: Oliver Wyman 2011).

9. Business Insights, The Evolving Pharma Mot A Landscape (Reading: Sept. 22, 2009).

to. FirstWord Dossier, "Pharma 2.0 - De-Risking the Business Model," A FirstWord Market Intelligence Report (May 2010).

11. Bernard Munos, "Lessons From 60 Years of Pharmaceutical Innovation," Nature Reviews Drug Discovery, 8 (Dec. 2009): 959-968.

12. Academic research offered a different, market-based explanation for R\&D productivity: the induced innovation hypothesis. According to this view, the level of product demand (i.e., the market size) induces product innovation. In this case, the pharmaceutical firms committed systematic errors in estimating the potential market size and introduced drugs at a rate that exceeded market growth. Daron Acemoglu and Joshua Linn. "Market Size in Innovation: Theory and Evidence from the Pharmaceutical Industry," Quarterly fournal of Economics, 119(3) (2004): 1049-1090; Henry Grabowski and John Vernon, "The Determinants of Pharmaceutical Research and Development Expenditures," Journal of Evolutionary Economics, 10 (2000): 201-215.

13. Cacciotti, Hewitt, and Shew, Shadow of a Drought.

14. AllinnceBernstein, The New Industrial Revolution: De-verticalization on a Global Scate (New York: AllianceBernstein, 2005).

15. Jonathan Rockoff and Ron Winslow, "Drug Makers Refill Parched Pipelines, ${ }^{n}$ Wall Strect Journal (July 7, 2011): AI, A12.

16. Matthew Herper, "Pfizer's Radical Surgery," Forbes (May 23, 2011); 86-91; Peter Loftus, "Pfizer Weighs Options for Animal Health, Nutrition Units," Wall Street Journal (July 8,
2011). Available at http://online.wsj.com/article/SB10001424052702303544604576431691372 039986.html. Accessed Oct. 4, 2011.

17. Anna Levine, "Licensing and Scale Economies in the Biotechnology Pharmaceutical Industry," unpub. manuscript (Apr. 2009).

18. Nils Behnke and Norbert Hueltenschmidt, "Changing Pharma's Innovation DNA," In Vivo (Feb. 2011): 56-60; Bernard Munos, "How to Avert Biopharma's R\&D Crisis," In Vivo (Mar. 2011): 58-62.

19. Ellen F. Licking, "Sanofi/Genzyme: Emblematic of What Big Pharma's Buying Now," In Vivo (Mar. 2011): 48-57.

20. Patricia Danzon, "The Pharmaceutical Industry: Trends and Strategy," Presentation to the Wharton School (Fall 2010). Source: IMS Health data.

21. Indeed, Japanese consumption on pharmaceuticals is expected to grow due to its rapidly aging population and a domestic rise in consumer demand (e.g., for pain medications). Japan is also attractive to pharmaceutical firms due to growing price pressures in the US and EU, the country's cadre of well-trained physicians and advanced hospitals, decreasing drug approval times, and favorable changes to Japan's health insurance system that protect pricing for innovative drugs. Jonathan Rockoff and Miho Inada, "Drug Firms Up Ante in Japan," Wall Street Journal (Sept. 30, 2011): B1-B2.

22. Antonio Regalado, "Drug Development's Preclinical Bottleneck," Start-Up (Dec. 1997): 26

23. David Cassak, Roger Longman, and Antonio Regalado, "Merger Mania - Faith or Folly? In Vivo (Sept. 1996): 4-8.

24. Whereas the proposed Clinton health plan limited price increases on the part of the pharmaceutical industry, the Obatma healthcare reform in 2010 did not allow government intervention, limitation of drug price increases, or importation of drugs from abroad. Though the impact of this legislation has not yet been realized, it is milder on the pharmaceutical industry than had been feared. Given that the pharmaceutical industry relies on federal government programs (Medicare, Medicaid, Veterans Administration, etc) for 31 percent of its revenues ( 2009 data), it will be interesting to observe the trend in prices beyond 2010 and whether margins will increase. Rebecca Trager, "Big pharma Scores in US Healthcare Reform," Royal Society of Chemistry - Chemistry World - News (Mar. 25, 2010). Available at www.rsc.org/chemistryworld/News/2010/Mar./25031003.asp. Accessed June 21, 2011.

25. Roger Longman, "Have Problem? Try M\&A," In Vivo (Mar. 1999): 59-68.

26. McKinsey \& Company, "Does Market Concentration Create Market Value?" In Vivo (May 1998): 33.

27. Longman, "Have Problem? Try M\&A."

28. Ben Steverman, "M\&A: Will the Recession Spark a Rebound?" Business Weck (Jan. 27, 2009). Available at www.businessweek.com/investor/content/jan2009/pi20090126_262047.htm. Accessed Feb, 6, 2012.

29. Thomson Reuters, "Mergers and Acquisitions Review," Thomson Reuters - Legal Advisors (Q4, 2009). Available at http://dmi.thomsonreuters.com/. Accessed Feb. 6, 2011.

30. Henry Grabowski and Margaret Kyle, "Mergers and Alliances in Pharmaceuticals: Effects on Innovation and R\&D Productivity," in Klaus Gugler and B. Burcin Yurtoglu (eds.), The Economics of Corporate Governance and Mergers (Northampton, MA: Elgar Publishing 2008): 262-287. 
31. www.prlog.org/10744425-global-top-10-biotechnology-companies-industry-financial and-swot-analysis-published.html. Accessed June 21, 2011.

32. Carolyn Said, "Pfizer to Open Research Center in SF's Mission Bay," San Francisoo Chronicle (July 22, 2011): DI.

33. Ben Hirschler, "Top 6 Drugs Tipped to be Biotech Products by 2014," Reuters (June 17, 2009). www.reuters.com/articlefidUSTRE55G4PI20090617. Accessed June 21, 2011.

34. Trista Morrison, "Best Selting Drugs Will Soon be Biologics, But Not Owned by Biotechs" BNET Pharma (July 23, 2009): Blog post.

35. Lawton R. Burns and Mark Pauly, "Integrated Delivery Networks: A Detour on the Road to Integrated Health Care?" Health Affairs, 21(4) (2002): 128-143.

36. David Besanko, David Dranove, and Mark Shanley, Economics of Strategy, 2nd edn (New York: John Wiley, 2000).

37. Patricia Danzon, Andrew Epstein, and Sean Nicholson, "Mergers and Acquisitions in the Pharmaceutical and Biotech Industries," Managerial and Decision Economics, 28 (2007) 307-328.

38. Jeanette Marchant, Biotech M\&A Strategies (London: Business Insights, 2008).

39. In contrast to the earlier section in the chapter on "drivers," this section provides a more thorough discussion of the defensive and offensive strategies pursued by drug firms and the forces behind them.

40. Despite these pressures, pharmaceutical firms in the US performed quite well financialth during the 1990s. According to Martin Reeves, continued price increases and faster rollouts of products more than compensated for cost containment pressures and unfavorable legislation involving generics.

41. Standard \& Poors, Industry Surveys: Healthcare - Pharmaceuticals (New York: Aug. 22 1991); Standard \& Poors, Industry Surveys: Healthcare - Pharmaceuticals (New York: Juty 29. 1999).

42. David Ravenscraft and William Long, "Paths to Creating Value in Pharmaceutical Mergers," in Steven Kaplan (ed.), Mergers and Productivity (Chicago, IL: University of Chicago Press, 2000), pp. 287-326. The decline in price escalation may be true for existing products, whereas price realizations may have escalated in the 1990 s for new products (Martin Reeves, personal communication).

43. Ravenscraft and Long, "Paths to Creating Value"; Susan Pulliam and Elyse Tanouye, "Drus Industry Consolidation May Not be Over," Wall Street Journal (May 4, 1994): C1, C2. The actual impact of these pressures on revenues and patent lives is suspect. There is evidence that patent life was fairly constant during the 1990 s and that total revenues increased due to the fact that faster ramp-up of revenues (e.g., quicker roll-outs) outweighed faster sales declines in postpatent lapse periods (Martin Reeves, personal communication).

44. Standard \& Poors, Industry Surveys. Healthcare - Phormaceuticals (New Yorke Oat 6, 1994).

45. Standard \& Poors, Industry Surveys: Healthcare - Pharmaceuticals (New York: July 29 1999).

46. Danzon, Epstein, and Nicholson, "Mergers and Acquisitions."

47. Ibid. For smaller firms, M\&\&A served as an exit strategy in response to financial trouble

48. Roger Longman, "After Roche/Genentech: Pharma's Focus on Efficiencies, Not Innovation," In Vivo (July-Aug. 2008): 22-23.
49. Jami Rubin, Florence Tsang, and Sebastian Paquette, The Mega-Merger Disconnect: A Fork in the Road to Growth (New York: Goldman Sachs, 2010); Roger Longman, "Merck Buys Schering-Plough - and Time," In Vivo (Mar. 2009): 26-32.

50. John Jannarone, "Merck Tests an R\&D Remedy," Wall Street Journal (Mar. I0, 2009): C10.

51. William Pursche, "Pharmaceuticals: The Consolidation isn't Over," McKinsey Quarterly, (1996): 110-119.

52. Kalorama Information, Pharmaceutical and Biopharmaceutical Market to 2015 Pipeline Report (Rockville, MD: Kalorama, July 2010).

53. Tufts Center for the Study of Drug Development, Impact Report, 11(5) (Sept.-Oct. 2009).

54. Matthew Higgins and Daniel Rodriguez, "The Outsourcing of R\&D Through Acquisitions in the Pharmaceutical Industry," Journal of Financial Economics, 80 (2006): 351-383.

55. Matthew Herper, "Five Molecules That Will Change The World," Forbes (July 2, 2003) http://www.forbes.com/2003/07/02/cz_mh_0702molecules.html. Accessed June 16, 2011.

56. "Pharmatical Sales Controt Companies - A Great Way to Break into Pharmaceutical Sales" www.pharmaceutical-rep.com/pharmaceutical-sales-contract-companies.html. Accessed June $16,2011$.

7. Danzon, Epstein, and Nicholson, "Mergers and Acquisitions."

58. Higgins and Rodriguez, "Outsourcing of R\&:D." This observation complicates the analysis of M\&A performance, since the sample of firms that merge is not representative of the industry overall.

59. Nikhil Deogun, Gardiner Harris, Steven Lipin, and Robert Langreth, "In Biggest Hostile Bid, Pfizer Offers $\$ 80$ Billion for Warner-Lambert," Wall Street Journal (Nov. 5,1999 ): A1.

60. Steven Lipin, et al., "Mixing it Up," Wall Street Journal (Nov. 5, 1999): A1.

61. Elyse Tanouye, "Mergers Will Keep Shuffling Rankings of Drug Makers," Wall Stree Journal (Mar. 15, 1995): B4.

62. Jon Northrup, personal communication.

63. Ravenscraft and Long "Paths to Creating Value"

64. Martin Reeves, personal communication.

65. Data from Verispan indicate the number of sales representatives dropped after the peak figure of 101,000 in 2004 to 95,000 in 2007. Pharmaceutical firms may have trimmed thei sales forces as part of the move to outsourcing to CSOs.

66. Amy Barrett, "Big Pharma: Getting Too Big for its Own Good?" Business Week (July 29, 2002): 74 .

67 "PhRMA Touts Medications' Efficacy," Chain Drug Review, 24(9) (2002): RX2.

68. EP Vantage, "Pharma Industry Cutting its R\&D Cloth to More Sustainable Levels" (EvaluatePharma Ltd, London: July 7, 2010). Available at www.epvantage.com/Universal/ View.aspx?type=Story\&id=217946\&isEPVantage=yes. Accessed June 16, 2011.

69. Ad Rawcliffe, personal communication.

70. Personal communication to the author from pharmaceutical company executives.

71. Roger Longman, "Renewing Novartis," In Vivo (Jan. 2001): 17

72. IMS Health, "Pfizer Still Ahead after GlaxoSmithKline Merger" (IMS Health: Jan. 4, 2001).

73. "GlaxoSmithKline Merger Completed as Trading for New Company Begins," Chemical Market Reporter (Jan. 1, 2001). Available at hitp://web.ebscohost.com/ehost/pdfviewer/ pdfviewer?vid $=4 \&$ hid $=107 \&$ sid $=13 \mathrm{~b} 15035-\mathrm{fbd} 4-410 \mathrm{l}-8$ f40-381 e2227b $16 \mathrm{~b} \% 40$ sessionmg 111. Accessed June 16, 2011. 
74. Alexandre Bilous, "French and Germar Unions Respond to Hoechst/Rhône-Poulenc Merger," European Industrial Relations Observer, 14(1) (Feb. 1999). Available at want. eurofound.europa.eu/eiro/1998/12/feature/fr9812146f.htm. Accessed Sept. 12, 201 Kerry Capell, "AstraZeneca: A Drug Megamerger that's Working," Business Week (Now 15, 1999). Available at www.businessweek.com/1999/99_46/b3655243.htm. Accessed June 16,2011 .

75. Thomas Burton, Steven Lipin, and Stephen Moore, "Upjohn and Pharmacia Sign $\$ 6$ Billion Merger," Wall Street Journal (Aug. 21, 1995): A3.

76. Lipin, et al., "Mixing it Up."

77. Andrew Sorkin, "Sanofi Makes its Bid for Aventis; It is Quickly Rejected as "Inferior,"' New York Times (Jan. 27, 2004): C1-C2; Melanie Senior and Christopher Morrison, "The Best Defense is a Good Offense: Sanofi's Bid for Aventis," In Vivo (Feb. 2004): 76-82

78. Kazuhiro Shimanura and Jason Singer, "Japanese Drug Makers to Combine," Wall Streed Journal (Feb. 25, 2004): A2

79. Peter Landers, "Japan is Urging its Drug Firms to Merge, Citing Need for Heft," Wall Street Journal (Sept. 4, 2002): B2.

80. "Roche and Chugai Blaze a 'Trail ... but Will Anyone Follow?" In Vivo (Jan. 2002): 39. Peter Landers, "Merck, Pfizer Battle in Japan," Wall Street Journal (Oct. 2, 2003): B4.

81. Sumeet Chatterjee and Bharghavi Nagaraju, "Abbott to pay $\$ 3.7$ billion for Unit of India's Piramal," Reuters (May 21, 2010). Available at www.reuters.com/article/2010/05/21/us. piramal-abbott-idUSTRE64K6DF20100521. Accessed June 16, 2011. Abbott press retease (Sept. 8, 2010): www.abbott.com/news-media/press-releases/Press_Release_0890.htm Accessed Feb. 7, 2012.

82. Raymond De Vré, Simon Goeller, and Christian Pawlu, "Pharma's Generics Opportunity in Central and Eastern Europe, ${ }^{n}$ McKinsey Quarterly (Aug. 2008): 1-9.

83. Lars Schweizer, "Knowledge Transfer and R\&D in Pharmaceutical Companies: A Case Study," Journal of Engincering and Technology Management, 22 (2005): 315-331.

84. Levine, "Licensing and Scale Economies in the Biotechnology Pharmaceutical Industry.

85. Patricia Danzon, Sean Nicholson, and Nuno Sousa Pereira, "Productivity in BiotechPharmaceutical R\&D: The Role of Experience and Alliances," lournal of Healith Economics, 24(2) (2005): 317-339.

86. Rajesh Garg, Roy Berggren, and Michele Holcomb, "The Value of Scale in Pharma's Future," In Vivo (Sept. 2001): 78-83.

87. Knowledge@Wharton, "Take Two Advil and ... What Ills Can the Pfizer-Wyeth Merger Cure?" Knowledge@Wharton Feb. 4 (2009). Available at http:/knowledge.wharton.upen. edu/article.cfm?articleid=2150. Accessed June 21, 2011. Longman, "Merck Buys Scherin Plough."

88. A.T. Kearney, Saint loseph's University Pharmaceutical Marketing Strategy (New Yort A. T. Kearney, 1999); Steve Arlington, Sam Barnett, Simon Hughes, and Joe Palo, Pharma 2010: The Threshold of Innovation (New York: IBM Business Consulting Services, 2003) Martin Reeves, "The R\&D Productivity Challenge," presentation to the New York Pharm Forum, Sept. 17, 2003.

89. "Troubling Numbers for Big Pharma Consolidation," In Vivo (July/Aug. 2000): 2. 0 course, some of these reductions may be due to overlaps and consequent elimination of redundancies.
90. Jeffrey Dvorin, "Creating Glaxo Wellcome," In Vivo (Mar. 1999): 5-16.

91. Ravenscraft and Long, "Paths to Creating Value."

92. Lawrence Fisher, "Post-Merger Integration: How Novartis Became No. 1," Strategy + Business, 11(Q2) (1998): 2-10

93. Ravenseraft and Long, "Paths to Creating Value.

94. We thank Martin Reeves for this insight.

95. A.T. Kearney, Saint Joseph's University Pharmaceutical Marketing Strategy.

96. Besanko, Dranove, and Shanley, Economics of Strategy.

97. Martin Reeves, personal communication.

98. Ravenscraft and Long, "Paths to Creating Value."

99. Danzon, Epstein, and Nicholson, "Mergers and Acquisitions;" Higgins and Rodriguez, "Outsourcing of R\&D."

100. It is, of course, possible that a merged firm may also fare well compared to the industry average and better than it otherwise would have.

101. The researcher also faces the challenge of measuring against the right set of metrics in the right time period. For example, the underlying problem to be addressed (e.g., high overhead cost, lagging $R \& D$ productivity) varies by historical era and by the length of payback period.

102. Accenture, Achieving High Performance in Pharmaceuticals (New York: Accenture, 2007). Available at www.accenture.com/SiteCollectionDocuments/PDF/RDWhitePaperFINAL. pdf. Accessed June 16, 2011.

103. Wesley M. Cohen and Richard C. Levin, "Empirical Studies of Innovation and Market Structure," in R. Schmalensee and R.D. Willig (eds.), Handbook of Industrial Organization, Vol. 2 (Amsterdam: Elsevier, 1989), pp. 1059-1107.

104. John Vernon, "Price Regulation, Capital Market Imperfections, and Strategic R\&D Investment Behavior in the Pharmaceutical Industry: Consequences for Innovation," $\mathrm{Ph}$.D dissertation, Wharton School, 2003.

105. Bronwyn Hall, "Mergers and R\&D Revisited," unpublished manuscript, University of California at Berkeley, 1999.

106. Frederic M. Scherer, "Pharmaceutical Innovation," Working Paper Series rwp07-004 (Boston, MA: Harvard University, John F. Kennedy School of Government, 2007).

07. Danzon, Epstein, and Nicholson, "Mergers and Acquisitions."

108. According to Martin Reeves, "it is certainly conspicuous that some of the most successful firms in the industry have engaged in acquisitions in spite of enormous and unproductive internal R\&D" (personal communication).

109. Higgins and Rodriguez, "Outsourcing of R\&D."

110. Jay Istvan and Roger Wolcott, "Is Bigger Really Better?" In Vivo (Mar. 1996): 11,

11. Cohen and Levin, "Empirical Studies"; William Comanor, "The Political Economy of the Pharmaceutical Industry" Journol of Economic Literature, 24 (Sept. 1986): 1178-1217.

12. Lehman Brothers, Pharma Pipelines (New York: Lehman Bros, 2002).

113. lain Cockburn and Rebecca Henderson, "Scale and Scope in Drug Development: Unpacking the Advantages of Size in Pharmaceutical Research," Journal of Health Economics, 20(6) (2001): 1033-1057; Elizabeth Jensen, "Research Expenditures and the Discovery of New Drugs," Journal of Industrial Economics, 36(1) (1987): 83-95.

114. Vernon, "Price Regulation." 
115. Rebecca Henderson and Iain Cockburn, "Scale, Scope, and Spillovers: The Determinants of Research Productivity in Drug Discovery," RAND /ournal of Economics, 27(1) (1996): 32-59.

116. Gideon Markman and Maritza Espina, "Patents as Surrogates for Inimitable and NonSubstitutable Resources," Journal of Management, 30(4) (2004): 529-544.

117. Danzon, Nicholson, and Pereira, "Productivity in Pharmaceutical-Biolechnology R\&D" Grabowski and Kyle, "Mergers and Alliances in Pharmaceuticals"; Ashish Arom Alfonso Gambardella, Laura Magazzini, and Fabio Pammolli, "A Brenth of Fresh Air? Fimp Type, Scale, Scope, and Selection Effects in Drug Development," Management Science, 55/10) (2009): 1638-1653. Arora, et al. find that "irm scale" (defined as the number of ongoing projects across all indications) is associated with project success, but that "program scale" (number of prior projects for that indication) is negatively associated with project success

118. It should also be noted however that 50 percent of the increase in costs per NDA over 1990 s has come from research and preclinical testing. The R\&D productivity challenge is therefore largely an early-stage phenomenon, perhaps more so than experience in run. ning clinical trials.

119. Gilbert Mertens, Beyond the Blockbuster Drug (London: Business Insights, 2005).

120. Gary Pisano, Science Business: The Promise, The Reality, and The Future of Biolect (Boston, MA: Harvard Business School Press, 2006).

121. Boston Consulting Group, "Historical Value of Size" (confidential client report).

122. Reeves, "The R\&D Productivity Challenge."

123. Alexander Kandybin and Martin Kihn, "Raising Your Return on Innovation Investment," Strategy + Business, 35 (2004): 38-49; Amy Barrett and Kerry Capell, "Big Pharma Getting Too Big for jts Own Good?" Business Week (July 29, 2002): 74.

124. Vikram Sahu, Mark Tracey, John Murphy, et al., "Tracking the 'X Factor' - Pipdine Valuations," Global Equity Research Report (New York: Goldman Sachs, Sept. 23, 2002)

125. Munos, "Lessons From 60 Years of Pharmaceutical Innovation."

126. Grabowski and Kyle, "Mergers and Alliances in Pharmaceuticals."

127. CenterWatch (2000) analysis of twenty-two merged companies, reported in "Troubling Numbers for Big Pharma Consolidation," In Vivo, 18(7) (2000): 2, 6 .

128. Istvan and Wolcott, "Is Bigger Really Better?"

129. Longman, "Have Problem? Try M\&A."

130. Higgins and Rodriguez, "Outsourcing of R\&D."

131. Mahmud Hassan, Dilip Patro, Howard Tuckman, and Xiaoli Wang, "Do Mergers and Acquisitions Create Shareholder Wealth in the Pharmaceutical Industry?" International Journal of Pharmaceutical and Healthcare Marketing, 1 (1) (2007): 58-78.

132. Ravenscraft and Long, "Paths to Creating Value."

133. Grant Skrepnek and Kenneth Lawson, "The Effect of Merger and Acquisition Activity on Shareholder Returns in the Pharmaceutical Industry," Journal of Research in Pharmaceutical Economics, 11(1) (2001): 19-38; Gregor Andrade, Mark Mitchell, and Erik Stafford, "New Evidence and Perspectives on Mergers," Journal of Economic Perspectives, 15(2) (2001): 103-120; R. Bruner, "Does M\&A Pay? A Survey of Evidence for the Decision Maker," Journal of Applied Finance, 12 (2002): 48-68; Michael Bradle, Anend Deri, and E Han Kim "Synertstic Gains from Corporate Acquisitions and thet An Economics, 21 (1988): 3-40.
134. Darzon, Epstein, and Nicholson, "Mergers and Acquisitions."

135. Boston Consulting Group, "Historical Value of Size."

136. Istvan and Wolcott, "Is Bigger Really Better?"

137. Sumit Agarwal, Sanjay Desai, Michele Holcomb, and Arjun Oberoi, "Unlocking the Value in Big Pharma," McKinsey Quarterly, 2(2001); 64-73; McKinsey and Company, "Does Market Concentration Create Market Value?" In Vivo (Mny 1998): 33.

138. A.T. Kearney, Snint Joseph's University Pharmacetutical Marketing Strategy. See also Raymond Hill and Markus Peterseim, "Maximizing Pharmaceutical Health," In Vivo, 17(5) (1999): 34-42. Available at http://sis.windhover.com/buy/abstract.php?id=1999800125. Accessed June 212011 ; A. T. Kearney, A Prescription for Pharmaceutical Health (Chicago, IL: A.T. Kearney, 2002).

139. Cassak, Longman, and Regalado, "Merger Mania"; Jim Gilbert, Preston Henske, and Ashish Singh, "Rebuilding Big Pharma's Business Model," In Vivo (Nov. 2003): 73-80.

140. Chris Kay, "Drugmaker Acquisitions to Weigh on Credit Ratings, Moody's Says," Bloomberg (Nov. 17, 2010). Available at www.bloomberg.com/news/2010-11-17/drug maker-acquisitions-to-weigh-on-credit-ratings-moody-s-says.html. Accessed Feb. 7, 2012.

141. Gilbert, Henske, and Singh, "Rebuilding Big Pharma's Business Model."

142. Henderson and Cockburn, "Scale, Scope and Spillovers"; Cockburn and Henderson, "Scale and Scope in Drug Development."

143. Boston Consulting Group, "Historical Value of Size."

144. Ravenscraft and Long, "Paths to Creating Value."

145. Danzon, Epstein, and Nicholson, "Mergers and Acquisitions."

146. Michael Koenig and Elizabeth Mezick, "Impact of Mergers and Acquisitions on Research Productivity within the Pharmaceutical Industry," Scientometrics, 59(1) (2004): 157-169. 147. Ravenscraft and Long, "Paths to Creating Value."

148. Carl Seiden, "Bigger is Better: Why Pharma Consolidation Makes Sense - and Will Continue." Available at www.cpsnet.com/reprints.

149. Longman, "Have Problem? Try M\&A.

150. Boston Consulting Group, "Historical Value of Size"; Agarwal, et al., "Unlocking the Value in Big Pharma"; Ameet Mallik, Gary Pinkus, and Scott Sheffer, "Biopharma's Capacity Crunch," McKinsey Quarterly, special edn., Risk and Resilience (2002): 9-11.

151. Preston Henske and Tim van Biesen, "Collaborating for Better R\&D Productivity," In Vivo (Feb. 2009): 60-65.

152. Garg, et al., "Value of Scale in Pharma's Future"; Agarwal, et al., "Unlocking the Value in Big Pharma."

153. Garg, et al., "Value of Scale in Pharma"s Future"; Agarwal, et al., "Unlocking the Value in Big Pharma."

154. Lehman Brothers, Pharma Pipclines.

155. Garg, et al., "Value of Scale in Pharma's Future."

156. Grabowski and Kyle, "Mergers and Allinnes in Pharmaceuticals: Effects on Innovation and R\&D Productivity."

157. Danzon, Epstein, and Nicholson, "Mergers and Acquisitions."

158. It should be noted that revenue growth is dependent on a few products for even the largest pharmaceutical frrms. The systematic value of $M \& A$ and other strategic actions may therefore 
be masked by the success or demise of individual products, the firm's starting point, and the option value of its available strategic moves (Martin Reeves, personal communication), 159. Knowledge@Wharton, "Take Two Advil."

160. Shirley Wang, "Wyeth to Focus Research Efforts on Fewer Diseases," Wall Street loum (Oct. 29, 2008). Available at http://online.wsj.com/article/SB122521391663176635.htmen? mod=googlenews_wsj. Accessed June 17, 2011.

161. Deloitte, "Pharma's New US Commercial Model: Promoting the Science Not the Swag" (New York: Deloitte Touche Tohmatsu, 2009). Available at www.deloitte.com/assets Dcom-UnitedStates/Local\%20Assets/Documents/

us_lshc_NewCommercialModels_072509.pdf. Accessed Feb. 7, 2012.

162. Jonathan Rockoff, "Pfizer Plans Layoffs in Research," Wall Street Journal (Jan. 14, 2009). Available at http://online.wsj.com/article/SB123186230445977567.html. Accessed June $17,2011$.

163. Jeanne Whalen, "Sanofi Overhauls R\&D to Help Costs, Pipeline," Wall Street Journal (ILth 1, 2009): B3.

164. Mahlon Apgar, "What Every Leader Should Know about Real Estate," Harvard Business Review (Nov. 2009): 100-107

165. Richard Welton, "Wanted: New Molecules - How Large Pharma Sources Innovation" Pulse Magazine (2010): 13-16; Pete Lawyer, James Andrew, Peter Tollman, and Martin Silverstein, "Payback: Making Innovation Count in Uncertain Times," In Vivo (Jan. 2007): 1-8; Melanie Senior, "GSK's Virtual Proof-of-Concept Unit in Tune with

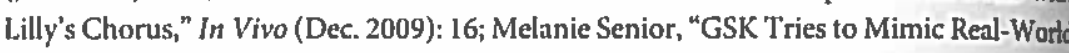
Biotech," In Vivo (Feb. 2009): 46-52.

166. Roger Longman, "Can Out-Partnering Help Vault Pfizer over the 'Second Cliff?", In Viro (May 2008): 28-34; Alex Lash, "Sanofi Mikes its Biggest 'External' Play Yet with Long-Term Regeron Deal," In Vivo (Dec. 2009): 12-13; Senior, "GSK's Virtual Proof-of-Concept Unit in Tune with Lilly's Chorus"; Senior, "GSK Tries to Mimic Real-World Biotech."

167. Behnke and Hueltenschmidt, "Changing Pharma's Innovation DNA."

168. Cacciotti, Hewitt, and Shew, Shadow of a Drought.

169. Munos, "Lessons From 60 Years of Pharmaceutical Innovation," p. 965.

170. John LaMattina, "The Impact of Mergers on Pharmaceutical R\&D," Nature Reviews Dru Discovery, 10 (Aug. 2011): 559-560.

171. Mark Sirower, The Synergy Trap: How Companies Lose the Acquisition Game (New York Free Press, 1997); R. Barfiedd, "Creating Value through Mergers," Banker (July 1988): 24 25; David Ravenscraft and F. M. Scherer, "The Profitability of Mergers," International Journal of Industrial Organization, 7 (1989): 101-116.

172. While M\&A serves to increase industry concentration, at least three countervailing forces can compress concentration levels. Patent expirations and generic competition erode the sales of the top pharmaceutical firms and thus their global market shares. In addition, the rapid growth of dedicated biotechnology firms like Amgen eats into the market shares of the incumbent pharmaceutical firms. Henry Grabowski and Margaret Kyle, "Mergers Acquisitions and Alliances," in Patricia Danzon and Sean Nicholson (eds.), Handbook on the Economics of the Biapharmaceutical Industry (Amsterdam: Elsevier, fortheoming)

173. Cohen and Levin, "Empirical Studies."
174. Gautam Ahuja, Curba Lampert, and Vivek Tandon, "Moving Beyond Schumpeter: Management Research on the Determinants of Technological Innovation," Academy of Management Anmals, 2(1) (2008): 1-98.

175. Larry Greiner, "Evolution and Revolution as Organizations Grow," Harvard Business Review (July-Aug., 1972): 37-46.

177. Michael Hitt, R. Duane Ireland, and Jeffrey Harrison, "Mergers and Acquisitions: A Value Creating or Value Destroying Strategy?" in Michael Hitt, R. Edward Freeman, and Jeffrey Harrison (eds.), The Blackwell Handbook of Strategic Management (Malden, MA: Blackwell Business, 2001), pp. 384-408.

178. Longman, "Have Problem? Try M\&A."

179. Z. I. Acs and D. B. Audretsch, "Innovation, Market Structure, and Firm Size," Review of Economics and Statistics, 71 (1987): 567-574.

180. Rebecca Henderson, Luigi Orsenigo, and Gary Pisano, "The Pharmaceutical Industry and the Revolution in Molecular Biology: Interactions armong Scientific, Institutional, and Organizational Changes," in David Mowery and Richard Nelson (eds.), Sources of Industrial Lendership (Cambridge University Press, 1999), pp. 267-311.

181. Munos, "Lessons From 60 Years of Pharmaceutical Innovation."

182. LaMattina, "The Impact of Mergers on Pharmaceutical R\&D."

183. Richard Nelson and Sidney Winter, An Evolutionary Theory of Economic Change (Cambridge, MA: Harvard University Press, 1982); J. Jewkes, D. Sawers, and R. Stillerman, The Sources of Invention (London: Macmillan, 1958); Cohen and Levin, "Empirical Studies."

184. Andrew Jack, "Pharma Split on Nature of Mergers as Kill or Cure," Financial Times (June 2, 2009). Available at www.ft.com/cms/s/0/282d50a6-40c-11de-8c10-00144feabde0. html|̈axzzl lhrZBfyY. Accessed June 17, 2011. Haig Simonian, "Making Drugs Faster," Financial Times (May 9, 2010): 33.

185. Michael Beer, High Commitment, High Performance (San Francisco, CA: Jossey-Bass, 2009)

186. James Mittra, "The Socio-Political Economy of Pharmaceutical Mergers: A Case Study of Sanofi and Aventis," Technology Analysis and Strategic Management, 18(5) (2006): 473-496.

187. Sirower, Synergy Trap

188. James Mittra, "Life Science Innovation and the Restructuring of the Pharmaceutical Industry: Merger, Acquisition and Strategic Allinnce Behaviour of Large Firms," Technology Analysis and Sirategic Management, 19(3) (2007): 279-301; Jaideep Anand, Raffaele Oriani, and Roberto Vassolo, "Alliance Activity as a Dynamic Capability in the Face of Discontinuous Technological Change," Organization Science, 21(6) (2010): 1213-1232.

189. Ellen F. Licking and Christopher Morrison, "Pharma: Serious About Change?", In Vivo (Oct. 2010): $34-40$

190. Higgins and Rodriguez, "Outsourcing of R\&:D." The experience of some analysts seems to contradict the role of information access, however. Martin Reeves reports there is no correlation between prior knowledge of the target and deal success in biotech acquisitions. He suggests instead that many deals are undertaken to access intellectual property that would otherwise be unavailable due to licensing relationships with other firms.

191. Knowledge@Wharton, "Take Two Advil." 
192. Jeffrey Jung and Andy Wang, Rx for Pharmaceutical Companies: Internal Collaboration is the Key to Improved Innovation (Somers, NY: IBM Institute for Business Value, 2002); Jeffrey Jung, Creating Breakthrough Innovation During a Pharmaceutical Merger or Acquisition (Somers, NY: IBM Institute for Business Value, 2002); Gary Pisano, or Development Factory (Boston, MA: Harvard Business School Press, 1997).

193. Deloitte Research, Collaborative Knowledge Networks: Accelerating Pharmaceutical RøD in the New Millennium (New York: Deloitte Research, 2002).

194. Knowledge@Wharton, "Eli Lilly's Sidney Taurel: "Tailored Therapeutics' - the Pharmaceutical Industry's Next Blockbuster?" Knowledge@Wharton (Mar. 13, 2008). http://knowledge. wharton.upenn.edu/article.cfm?articleid=1915. Henske and van Biesen "Collaborating for Better R\&D Productivity"; Eric David, Amit Mehta, Troy Norris, et al, "New Frontiers in Pharma R\&D Investment," McKinsey Quarterly (Feb. 2010); 1-12

195. Mntthew Boyle, "Growing against the Grain," Fortune (May 3, 2004): 148-156.

196. Deborah Erickson, "Amgen Moves Beyond Proteins," In Vivo (Mar. 2004): 18-26.

197. Jean-Pierre Garnier, "Rebuilding the R\&:D Engine in Big Pharma, ${ }^{n}$ Harvard Business Review, 86(5) (May 2008): 69-76; Robert Huckman, Gary Pisano, and Mark Rennella, Wyeth Pharmaceuticals: Spurring Scientific Creativity with Metrics, Case 9-607-008 (Boston, MA: Harvard Business School Publishing, 2007).

198. Rebecca Henderson and lain Cockburn, "Measuring Competence? Exploring Firm Hffects in Pharmaceutical Research," Strategic Management Journal, 15 (1994): 63-84, Peter Landers, "Merck Ends Research on Once Promising Antidepressant," Wall Street Journal (Nov. 13, 2003): Bl, B2; Garnier, "Rebuilding the R\&D Engine in Big Pharma."

199. Amy Barrett, John Carey, and Michael Arndt, "Feeding the Pipeline," Business Week (May 5, 2003): 78-83.

200. Frits Pil and Matthias Holweg, "Exploring Scale: The Advantages of Thinking Small." Sloan Management Review (Winter 2003): 33-39.

201. Thomas Gartenmann and Philippe Guy, "Rx Industry Post M\&A Integration, Parr I: Marketing and Sales," In Vivo (Dec, 1997): 20-25.

202. Deborah Erickson, "Novartis Bucks the Trend," In Vivo (Feb. 2004): 43-52; Pil and Holweg, "Exploring Scale"; Lawrence Fisher, "The New Architecture of Biomedieal Research," Strategy + Business, 33 (2003): 58-69.

203. Thomas Burton, "By Learning from Failures, Lilly Keeps Drug Pipeline Full," Wall Stret Journal (Apr. 21, 2004): A1, A12.

204. Mark Ratner, "How Experimental Medicine is Affecting Big Pharma," In Vivo (App. 2004): 59-64; Erickson, "Novartis Bucks the 'Trend."

205. Peter Landers, "With Dry Pipelines, Big Drug Makers Stock up in Japan," Wall Streel Journal (Nov, 24, 2003): A1, A7; Peler Landers, "Drug Industry's Big Push into Technology Falls Short," Wall Street journal (Feb. 24, 2004): Al, A8.

206. Roger Longman, "Lilly's Chorus Experiment," In Vivo (May 2007): 35-39; Ed Silverman "Lilly Tries to Buy Time," In Vivo (Dec. 2009): 26-32; Accenture, Achieving Hight Performance in Pharmaceuticals (New York: Accenture, 2007).

207. Anna Peterson and August Vlak, "The Missing Link in Innovative Research," Stratggy Business (May 30,2011). Available at wwwstrategy-business.com/media/file/00077.pdl Accessed Sept. 12, 2011.

208. Christopher Tkaczyk, "Encouraging Innovation," Fortune (Oct. 12, 2009): 22.
209. Henderson and Cockburn, "Measuring Competence?"

210. Rockoff and Winslow, "Drug Firms Up Ante in Japan."

211. William Riley, Douglas Wholey, Amy Wilson, and David Knoke, "Informal Consultation in Medical Clinics: Intra- and Inter-Personal Talk," paper presented at Sixth Annual Health Care Organizations Conference, Boston University, June 2004.

212. Tanya Menon, Hoon-Seok Choi, and Leigh Thompson, "Tainted Knowledge versus Tempting Knowledge: Why People Avoid Knowledge from Internal Rivals and Seek Krowledge from External Rivals," unpub. manuscript, Graduate School of Business, University of Chicago, 2004.

3. Jannarone, "Merck Tests an R\&D Remedy."

214. Licking, "Sanofi/Genzyme."

215. Rikand Larsson and Sydney Finkelstein, "Integrating Strategic, Organizational, and Human Resource Perspectives on Mergers and Acquisitions: A Case Survey of Synergy Realization, "Organization Science, 10(1) (1999): 1-26.

216. Ravenscraft and Long, "Paths to Creating Value"; Iain Clark, "Drug Discovery - Resolving the Bottlenecks;" Horizons, Pharmaceutical issue 1 (Dec. 2001); Wood MacKenzie. Available at www.woodMac.com. Accessed June 21, 2011.

217. Analysts are skeptical about whether "democratic" processes of cooperation promote the success of integration in M\&A.

218. Hitt Ireland, and Harrison "Mergers and Acquisitions.

219. Phillippe Haspeslagh and David Jemison, Managing Acquisitions: Creating Value Through Corporate Renewal (New York: Free Press, 1991); Lars Schweizer, "The Key Drivers and Success Factors for M\&A Strategies in the Biotechnological and Pharmaceutical Industry," Pharmaceuticals Policy and Law, 5 (2002); 41-62. Lars Schweizer, "Organizational Integration of Acquired Biolechnology Companies into Pharmaceutical Companies: The Need for a Hybrid Approach," Academy of Management Journal, 48(6) (2005): 1051-1074, 20. Deloitte Research, Collaborative Knowledge Networks.

221. Landers, "Drug Industry's Big Push."

222. Deborah Erickson, "Wanted: Drug Hunters," In Vivo (Sept. 2003): 45-52; Gary Hamel and Gary Getz, "Funding Growth in an Age of Austerity," Harvard Business Review, 82(7/8) (2004): 76-84; Landers, "Dry Pipelines."

223. Daniel Tzabbar, "What Helps and Hinders Innovation?" Sloan Management Review (2009): 17; Daniel Tzabbar, Barak Aharonson, Terry Amburgey, and Andreas Al Laham, "When is the Whole Bigger Than the Sum of its Parts? Bundling Knowledge Stocks for Innovative Success," Strategic Organization, 6(4) (2008): 375-406.

224. Geoff Colvin, "Disease Hunter: Gilead CEO John Martin Hit it Big with HIV Drugs - Now He's Planning an Encore," Fortune (May 23, 2011): 80-87.

225. Steven Paul, Daniel Mytelka, Christopher Dunwiddie, et al., "How to Improve R\&D Productivity: The Pharmaceutical Industry's Grand Challenge," Nature Reviews Drug Discovery, 9 (Mar. 2010): 203-214.

26. Ratner, "Experimental Medicine"; Erickson, "Novartis Bucks the Trend."

227. John Simons, "Lilly goes off Prozac," Fortune (June 28, 2004): 179-184; Burton, "Learning from Failures."

228. The Chorus Story, http://choruspremier.com/Chorus.Brochure.02/une2009.pdf.

229. Kandybin and Kihn, "Raising Your Return on Innovation Investment." 
230. Matthew Herper, "Rallying Pharma's Rebels," Forbes (Aug. 22, 2011): 95-97. 231. Roger Longman, "Jumpstart to Products," in Vivo (Feb. 2004): 17-30.

232. Cf. Nelson Sims and Anton Gueth, "Managing Alliances at Lilly," in Vivo, 19(6) (200) 71-77. The topic of strategic alliances (e.g., in-licensing) is too big for this chapter, and really warrants separate treatment. The topic is only briefly considered below.

233. Roger Longman, "Why Doesn't Pharma Get Smaller?" In Vivo (June 2009): 26-32. Roger Longman, "Pfizer/Wyeth: Industrializing Pharma?" In Vivo (Feb. 2009): 36-41

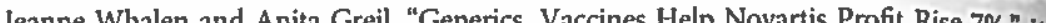

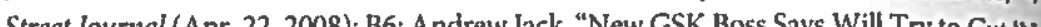
Strect Journal (Apr. 22, 2008). B6, Andrew Jack, "New GSK Boss Says Wil Try to Cut 'Nass Surprises," Financial Times (June 13, 2008). Available at www.ft.com/cms/s/0/2124906038e2-11 dd-8aed-0000779fd2ac.html\#axzzl lhrZBfyY. Accessed June 20, 2011. Shirley Wang and Peter Loftus, "I\&] Thrives Due to Diverse Exposure," Wall Stret Journal (Apr. 17, 2008). Available at: http://online.wsj.com/article/SB1 208242744331 15709.html. Accessed June 20 2011. Kathleen Kingsbury, "Roche's Rush," Time (Oct. 13, 2008): Global 1, 2, 5; Peter Loftuss "Drug Makers Move to Diversify," Wall Street Journal (July 30, 2008): B4.

234. William Launder and Eyk Henning, "Batte Heats Up for Drug Firm," Wall Street foumal (Mar. 4, 2010): B2

235. Andrew Gary, "Rx: Bust Up Big Pharma," Barrons (Feb, 12, 2011). Available at httpol online.barrons.com/article/SB50001 424052970204098404576130374232056878 . html\#printMode. Accessed June 24, 2011.

236. C. Anthony Butler and Mark Purcell, Major Pharmaceuticals: Divergent Business Modeis 2010-2015 (London: Barclays Capital, Jan. 26, 2010).

237. Peter Loftus, "Amid Challenges, Drug Makers Add 'Strategy Masters' To Ranks," Dow Jones Newswires (Apr. 11, 2008); Dow Jones News Service, New York,

238. Jessica Merrill, "Bristol Spins Off Mead Johnson in Stock Swap: Finally Pure Pharma," in Vivo (Dec. 2009): 19-20; Wendy Diller, "Can BMS - With the Help of Medarex and Others - Deliver on Innovation?" In Vivo (Sept. 2009): 16, 18; Longman, "Why Doesn't Pharma Get Smaller?"

239. Pfizer, Inc., "Pfizer to Explore Strategic Alternatives for its Animal Health and Nutrition Businesses," company press release (July 7, 2011).

240. Frank Lichtenberg, "Industrial De-Diversification and its Consequences for Productivity;" Joumal of Economic Behavior and Organization, 18(3) (1992): 427-438.

241. Robert Guth, Wall Street Journal (May 26, 2010).

242. Ad Rawcliffe. Personal communication.

243. Danzon, Nicholson, and Pereira, "Productivity in Pharmaceutical Biotechnology R\&D."

244. Ashish Arora, Alfonso Gambardella, Fabio Pammolli, and Massimo Riccaboni, "The Nature and the Extent of the Market for Technology in Biopharmaceuticals," unpublished manuscript, H. John Heinz, School, Carnegie Mellon University, 2000; Joseph Dimasi, "Risks in New Drug Deweptops Clinical Pharmacology and Therapeutics, 69(8) (2001): 297-307; Arora, Gambardetlan Magazzini, and Pammolli, "A Breath of Fresh Air? Firm Type, Scale, Scope and Selection Effects in Drug Development," MPRA Paper 16042, University Library of Munich, 2007.

245. Scott Hensley, "Biggest Drug Firm Faces Generics but has an Edge: its Very Bigness," Wall Street Journal (Aug, 23, 2004): A1, A6.
246. Andrew Jack, "Supply Running Low," Financial Times (Feb. 10, 2011): 9

247. Paul, Mytelkn, Dunwiddie, et al., "How to Improve R\&D Productivity."

248. Cacciotti, Hewitt, and Shew, Shadow of a Drought.

249. Behnke and Hueltenschmidt, "Changing Pharma's Innovation DNA."

250. Baron Jaruzelski and Richard Holman, "The Three Paths to Open Innovation," Strategy + Business (May 2010). Available at /www.strategy-business.com/article/00075? $\mathrm{pg}=2$ Accessed June 30, 2011.

25I. Tanouye, "Mergers will Keep Shufling Rankings."

252. PricewaterhouseCoopers, Pharme 2020: Challenging Business Models - Which Path Will You Take? (2000). Accessed July 14, 2011 at: www.pwc.com/en_GX/gx/pharma-lifesciences/pdf/Challenge.pdf

253. IMS Health.

254. Jeanne Whalen, "Hurdles Multiply for Latest Drugs," Wall Street Journal (Aug. 1, 2011): $B 1-B 2$

255. Vanessa Fuhrmans, "Insurers, FDA Team Up to Find Problem Drugs," Wall Street lournal (Apr. 15, 2008): available at: http://online.wsj.com/article/SB120822459568214991.html. Accessed lune 30, 2011.

256. Janet Carruthers, Michel Rod, and Nicholas Ashill, "Purchaser-Provider Interaction in UK Public Health: Improving Stakeholder Cooperation," International fourtial of Pharmaceutical and Healthcare Marketing, 1(1) (2007): 12-26.

257. Olivier LeClerc, Mandy Leung, and Heather Sumner, "Exploring the Full Potential of Risk-Sharing Agreements between Pharmaceutical Companies and Payors," In Vivo (May 2010): 56-61.

258. Deloitte, Pharma's New US Commercial Model: Promoting the Sciente Not the Swag (Deloitte, 2009); Jeanne Whalen, "Glaxo Becomes Master of Reinventing its Drugs," Wall Strcet Journal (Apr, 17, 2008). Available at http://online.wsj.com/article/SB120833908419819167.html? mod=todays_us_marketplace. Accessed June 30, 2011, IMS, "21st Century Pharma: Managing Current Challenges to Ensure Future Growth," IMS Intelligence Webinar (June 12, 2008); Zhenya Lindgardt, Martin Reeves, and Judith Wallenstein, "Waking the Giant: 12, 2008); Zhenya Lindgardt, Martin Reeves, and Judith Wallenstein, "Waking the
Business Model Innovation in the Drug Industry," In Vivo (June 2008): 54-59.

259. Jeanne Whalen, "UK Pushback on Glaxo Drug Price," Wall Street Journal (Oct. 1-2, 2011): B3.

260. Sean Tunis, David Stryer, and Carolyn Clancy, "Practical Clinical Trials: Increasing the Value of Clinical Research for Decision Making in Clinical and Health Policy," Journal of American Medical Association, 290(12) (2003): 1624-1632.

261. Jeanne Whalen, "Glaxo Seeks Guidance From Health Systems," Wall Street Journal (July 7, 2008). Available at http://online.wsj.com/article/SB121538798154831045.html. Accessed June 30, 2011. Jeanne Whalen, "New Sanofi CEO Expected to Map Fresh Course on Developing Drugs," Wall Street Joumal (Dec. 1, 2008). Available at Juttp://online,wsj.com/ article/SB122807657188167211. html?mod=googlenews wsj. Accessed June 30, 2011.

262. Eli Lilly and Co., "New Analysis Showed Effient(R) Cost-Effective Compared with Clopidogrel for Patients with Acute Coronary Syndromes Undergoing PCl," company press release (Jan. 5, 2010). http://newsroom.lilly,com/releasedetail.cfm?releaseid $=434208$.

263. Christopher Truffer, Sean Keehan, Sheila Smith, et al., "Health Spending Projections Through 2019: The Recession's Impact Continues," Health Affairs, 29(3) (2011):522-529. 
264. Robert Seidman, "Protecting Affordable Access to Next Generation Medical Solutions" presentation to the Pharma, Biotech, and Device Colloquium, Princeton, NJ, June 7, 2004. 265. Andrew Pollack, "Coupons for Patients, but Higher Bills for Insurers," New York Times (latr. 2011). Available at www.nytimes.com/2011/01/02/business/02coupon.html. Accessed June 30, 2011.

266. Wendy Diller, "Managed Care Tackles Biotech Budget Busters," In Vivo (Jan. 2004): 31-41 267. Booz and Company, personal communication with the author.

268. Wendy Diller, "As Specialty Pharmacy Evolves, Biotech Companies Stay Tuned," In Vivo (Mar. 2004): 53-61.

269. John Holahan, Lisa Clemans-Cope, Emily Lawton, and David Rousseau, Medicaid Spending Growth Over the Last Decade and the Great Recession, 2000-2009, Issue Paper (Feb. 2011). Kaiser Commission on Medicaid and the Uninsured.

270. A. T. Kearney, The State as a Customer (Chicago, IL: A. T. Kearney, 2003).

271. Jim Gilbert and Paul Rosenberg, "Imbalanced Innovation: The High Cost of Europe's 'Free Ride," In Vivo (Mar. 2004): 62-69.

272. Cap Gemini Ernst and Young, Prescriptions for the Smart and Lean Pharmaceutical Company: Vision and Reality Survey 2003. Available at www.capgemini.com/services. and-solutions/by-industry/life-sciences/publications/.

273. Ibid.

74. Robert Galvin, "Employer's Perspective on the Role of Pharma, Biotech, and Device Sectors," presentation to the Pharma, Biotech, and Device Colloquium, Princeton, $\mathrm{N}_{\text {, }}$ June $7,2004$.

275. Cap Gemini Ernst and Young, Prescriptions for the Smart and Lean Pharmaceutical Company.

276. Brian Buxton and Robert Enston, "Blockbusters to New-Engine Drugs: The Key Industry Shift," In Vivo (July-Aug. 2003): 63-70.

277. Shirley Wang, "I\&J, Vanderbilt Team Up on Schizophrenia Drugs," Wall Street Joumal (Jan. 8, 2009). Available at www.reuters.com/article/2009/01/09/johnsonandjohnson. vanderbilt-idUSBNG12204220090109. Accessed June 30, 2011. Shirley Haley, "Pharma and Academia: Finding New Ways to Join Hands for Mutual Benefit," Start-Up, 14(10) (Nov 2009) (Bridgewater, NI: Elsevier Business Intelligence). Available at Www.elservecti

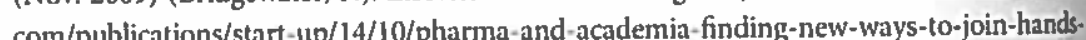

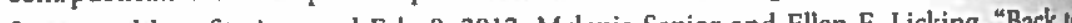
for-mutual-benefit. Accessed Feb. 8, 2012. Melanie Senior and Ellen F. Licking, "Back to
School: Big Pharmas Test New Models for Tapping Academia," In Viro (Feb. 2011): 22-28.

278. Leon Rosenberg, "Physician-Scientists - Endangered and Essential," Science, 283 (1993). 331-332; Elliot Gershon, "Making Progress: Does Clinical Research Lead to Breakthroughs in Basic Biomedical Sciences?" Academic Medicine, 42 (1998): 95-102 Moreover, recent evidence sugests that proximity to a university promotes employment growth from both start-ups and incumbent firms. Naomi Hausman, "Effects of Universith Innovation on Local Economic Growth and Entrepreneurship," unpub, manuscriph Harvard University, Jan. 2011.

279. "The New Role of Acadentia in Drug Development: New Thinking, New Competencics New Results," Driving New Paradignts in Clinical Research (Kansas City, MO: Ewing

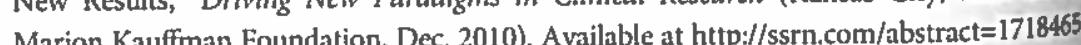
Accessed Oct. 3, 2011
280. Senior and Licking, "Back to School."

281. Pfizer, Inc., "Pfizer Becomes the First Pharmaceutical Company to be Accredited for Protection of Human Rights in Clinical Research," company press release (Apr. 3, 2009).

282. Carol Hymowitz, "The Best Innovations Come from Smart Questions," Wall Street Journal (Apr. 13, 2004): B1.

283. Sharon Begley, "Researchers Try to Cut New Path to the Pharmacy," Wall Street fournal (Jan. 12, 2004): A1.

284. Eric G. Campbell, Russell L. Gruen, James Mountford, et al., "A National Survey of Physician-Industry Relationships," New England Journal of Medicine, 356(17) (2007): $1742-1750$.

285. "Big Trouble for Big Pharma," The Economist (Dec. 6, 2003): 67. 
CAMMRIDGE UNIVERSITt PRESS

Cambridge, New York, Melbourne, Madrid, Cape Town

Singapore, São Paulo, Delhi, Mexico City

Cambridge University Press

The Edinburgh Building, Cambridge CB2 8RU, UK

Published in the United States of America by Cambridge University Press, New York

Www.cambridge. org

Information on this title: www.cambridge.org/9781 107607774

(6) Cambridge University Press 2012

This publication is in copyright. Subject to statutory exception

and to the provisions of relevant collective licensing agreements.

no reproduction of any part may take phace withoul ine wille

permission of Cambridge University Press.

First published 2005

Second edition 2012

Printed in the United Kingdom by the MPG Books Grou

A catslogue record for this publication is available from the British Library

Library of Congress Cataloguing in Pullication data

The business of healthcare innovation / [edited by] Lawton Robert Burns. - 2nd ed.

p. ; $\mathrm{cm}$.

Includes bibliographical references and index

ISBN 978-1-107-02497-7 (hardback) - ISBN 978-1-107-60777-4 (pbk.)

J. Burns, Lawton Robert

IDNLM: 1. Diffusion of innovation. 2. Health Care Sector. 3. Biotechnology-economics.

4. Equipment and Supplies-economics. 5. Technology, Pharmaceutical-economics. W 74.1]

4. Equipment

2012013418

ISBN 978-1-107-02497-7 Hardback

ISBN 978-1-107-60777-4 Paperback

Cambridge University Press has no responsibility for the persistence or

accuracy of URLs for external or third-party internet websites referred to

in this publication, and does not guarantee that any content on such

websites is, or will remain, accurate or appropriate

\section{Contents}

List of figures

page viii

List of contributors

xiv

List of abbreviations

The business of healthcare innovation in the Wharton School curriculum

Lawton Robert Burns

The pharmaceutical sector: rebooted and reinvigorated Jonathan P. Northrup, Marina Tarasova, and Lee Kalowski

Pharmaceutical strategy and the evolving role of merger and acquisition 116 Lawton Robert Burns, Sean Nicholson, and Joanna P. Wolkowski

Thiotechnology sector: therapeutics Cary G. Pfeffer

Biotechnology business and revenue models: implications for strategic alliances and capitalization Stephen M. Sammut

The medical device sector Kurt H. Kruger and Max A. Kruger

The healthcare information technology sector Adam C. Powell and Jeff C. Goldsmith

Healthcare innovation across sectors: convergences and divergences Lawton Robert Burns, David M. Lawrence, and Stephen M. Sammut 